\title{
Análise de Planos de Corte de Carga Através de Métodos Diretos
}

\author{
Leandro Castilho Brolin
}

Dissertação apresentada à Escola de Engenharia de São Carlos, da Universidade de São Paulo, como parte dos requisitos para obtenção do Título de Mestre em Engenharia Elétrica.

Orientador: Prof. Dr. Rodrigo Andrade Ramos 

AUTORIZO A REPRODUÇÃO E DIVULGAÇÃO TOTAL OU PARCIAL DESTE TRABALHO, POR QUALQUER MEIO CONVENCIONAL OU ELETRÔNICO, PARA FINS DE ESTUDO E PESQUISA, DESDE QUE CITADA A FONTE.

Ficha catalográfica preparada pela Seção de Tratamento da Informação do Serviço de Biblioteca - EESC/USP

B867a

Brolin, Leandro Castilho

Análise de planos de corte de carga através de métodos diretos / Leandro Castilho Brolin ; orientador Rodrigo Andrade Ramos. -- São Carlos, 2010.

Dissertação (Mestrado - Programa de Pós-Graduação em Engenharia Elétrica e Área de Concentração em Sistemas Elétricos de potência) -- Escola de Engenharia de são Carlos da Universidade de são Paulo, 2010.

1. Proteção de sistemas elétricos. 2. Sistemas elétricos de potência - subfrequência. 3. Corte de carga - planos. 4. Função energia. I. Título. 


\section{FOLHA DE JULGAMENTO}

Candidato(a): Engenheiro Eletricista LEANDRO CASTILHO BROLIN.

Dissertação defendida e julgada em 03/12/2010 perante a Comissão Julgadora:

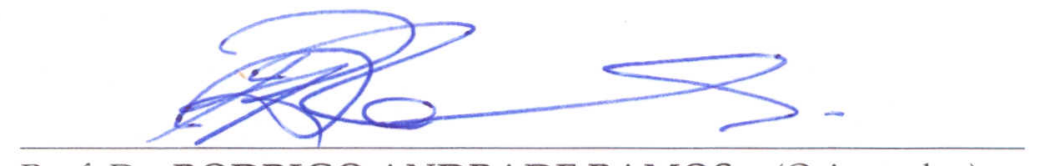

APROVADO

Prof. Dr. RODRIGO ANDRADE RAMOS - (Orientador)

(Escola de Engenharia de São Carlos/USP)

Romankuiara

Aprovado

Dr. RÔMAN KUIAVA

(Pós-Doutorado/FAPESP)

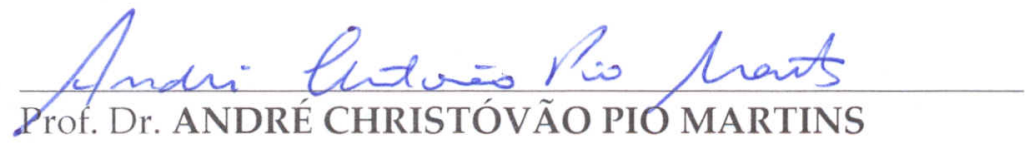

ARROUADO

(Universidade Estadual Paulista "Júlio de Mesquita Filho"/UNESP/campus de Bauru)

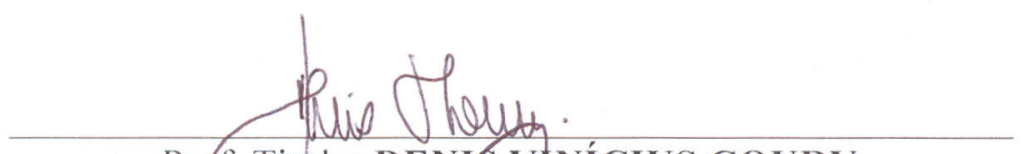

Prof. Titular DENIS VINÍCIUS COURY

Coordenador do Programa de Pós-Graduação em Engenharia Elétrica

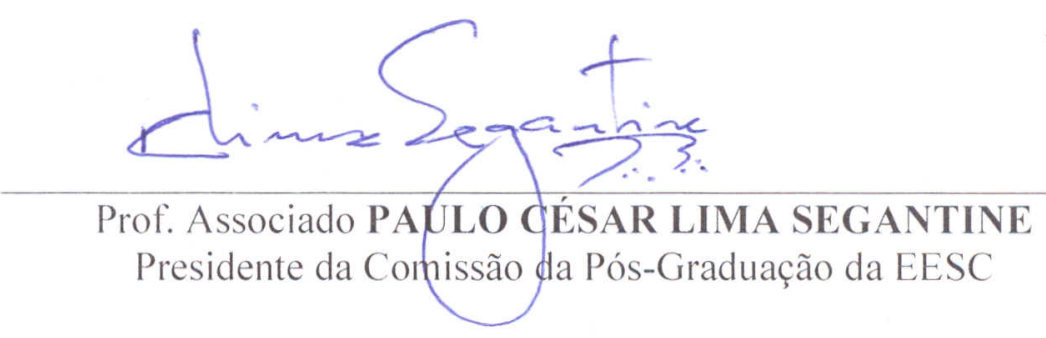


"Dedico este trabalho à minha família." 
"Tudo posso Naquele que me fortalece." (Apóstolo Paulo) 

Aos meus pais, David e Deli, e irmã, Denise pelo amor e pela confiança que me deram.

À minha namorada, Thaisa pelo apoio, amor e paciência. Ao professor Dr. Rodrigo Andrade Ramos pela orientação, dedicação e confiança para o sucesso do projeto de pesquisa.

Ao professor Dr. Luís Fernando Costa alberto, pela co-orientação e apoio neste projeto de pesquisa. Aos professores do LACo-SEP (Laboratório de Análise Computacional em Sistemas Elétricos de Potência), Newton Geraldo Bretas e João Bosco A. London Jr.. Aos meus amigos e colegas Nanni (Marcelo Nanni), Escama (Marcelo Castoldi), Arre (Moussa), Perninha (Raphael Benedito), Aderbal (Carlisson), A lenda (Elmer), Pedrão Fenômeno (Pedro), Perdigão (Rodrigo Salim), Banqueiro (Rafael Borges), Zero 2 (Fabiolo), Krow (Carol), Augustus (Augusto), Jaja (Saulo), Madlein (Madaleine), Marceleza (Marcelo), Cabelera (Marcel), Prodígio (Edson), Japoneis Doido (Marcelo Suetake), Gordin (Gabriel), Mulher Maravilha (Karen), Maranhão (Antonio) e Fabin (Fabinho). A todos meus amigos e colegas cujo nome não foi citado acima. E à CAPES, pelo apoio financeiro. 



\section{Resumo}

BROLin, L. C., Análise de planos de corte de carga através de métodos diretos. São Carlos, 2010, 73p. Escola de Engenharia de São Carlos, Universidade de São Paulo.

Sistemas Elétricos de Potência (SEPs) muitas vezes não são capazes de retornarem a uma nova condição de equilíbrio após grandes perdas de geração ou mesmo pela retirada de importantes linhas de transmissão. O déficit de potência causado por alguns desses distúrbios pode acarretar no declínio gradual da frequência do sistema. Caso a reserva girante ou o próprio sistema de transmissão não sejam capazes de recompor o SEP, medidas corretivas devem ser tomadas para evitar o colapso do mesmo. Nesta condição de emergência, um montante de carga deve ser desconectado de forma a restaurar uma nova condição de equilíbrio através de um esquema emergencial conhecido como plano de corte de carga por subfrequência. Muitos trabalhos vem sendo desenvolvidos ao longo dos anos, nos quais são propostas diferentes técnicas para a determinação de planos de corte de carga. Na maioria delas utiliza-se uma modelagem equivalente e linearizada do sistema. Tais simplificações trazem grandes facilidades para a representação do sistema. Porém, para que a integridade do mesmo seja garantida, muitas vezes os planos de corte de carga envolvem montantes de carga maiores que o necessário. A metodologia apresentada neste trabalho utiliza uma representação não linear para o SEP, o que permite um estudo do comportamento dinâmico de suas unidades geradoras para que os limites de frequência sejam determinados. Assim, os planos podem ser determinados com eficiência, reduzindo o número de consumidores desprovidos de energia elétrica durante o processo de alívio de carga. Entretanto, a escolha de um modelo mais completo para a representação do sistema pode acarretar num grande esforço na análise e determinação dos esquemas de alívio de carga, quando aplicados em sistemas de grande porte. Sendo 
assim, é proposta neste trabalho uma metodologia capaz de auxiliar tais estudos, o que diminui os esforços tanto da parte computacional quanto da parte empregada pelo projetista. Uma abordagem energética é aplicada ao problema e, dessa forma, dada uma perda de geração é possível determinar o valor mínimo de frequência atingido pelo sistema sem que haja a necessidade de se conhecer a trajetória do ponto de operação do sistema. Portanto, é proposta uma metodologia baseada em funções energia para a determinação de planos de corte de carga e, posteriormente, são realizadas simulações em uma representação simplificada de um sistema elétrico de potência para a validação da mesma. Também é mostrado o comportamento da frequência do sistema durante uma condição de subfrequência sobre duas perspectivas. Uma delas utiliza-se de uma modelagem não linear para a representação do sistema e a outra utiliza-se do modelo linearizado para a representação deste mesmo sistema. Este trabalho tem por finalidade o estudo e modelagem matemática do problema emergencial de alívio de carga de uma forma introdutória, para que posteriormente, possa ser desenvolvida de uma ferramenta capaz de auxiliar tais estudos. O método proposto demonstrou-se muito promissor, apesar das simplificações utilizadas para a construção do modelo.

Palavras-chave: Subfrequência, planos de corte de carga e função energia. 


\section{Abstract}

BROLIN, M. R., Algorithm for elaboration of plans for service restoration to largescale distribution systems. Sao Carlos, 2010. 73p. Dissertation (Master study), Engineer School of Sao Carlos, University of Sao Paulo.

Electric power systems (EPS) are not always capable of achieving a new stable equilibrium point after a severe generation loss or even after the loss of important transmission lines. The lack of active power generation caused by some of these disturbances can lead to a gradual decay of the system frequency. If the spinning reserve or even the bulk transmission system are not capable of restoring the system, then, corrective actions should be taken to avoid a system collapse. Under this emergency condition, a portion of the load should be disconnected, as a way to restore a new stable equilibrium condition, through an emergency scheme known as underfrequency load shedding (UFLS). Several works have been developed in this field throughout the years, in which different techniques are proposed to determine the load shedding schemes. The majority of these works use an equivalent linearized model of the system, which facilitates the system representation. However, in order to keep the integrity of the system, it is common to overestimate the shedding of loads. The validation of load shedding schemes that use a linear methodology is generally performed through simulations based on nonlinear models of the whole system. The methodology presented in this work uses a nonlinear representation for the EPS for developing an UFLS scheme, which permits a study of the dynamic behavior of its generators in order to find the frequency limits. In this way, the schemes can be efficiently determined, aiming a reduction on the number of consumers affected by the load shedding scheme, and avoiding additional simulations to validate the designed scheme. An energetic approach is applied to the problem and, in this way, given a generation loss it is possible to determine the minimum frequency 
value achieved by the system without the need for the knowledge of the trajectory of the system's operating point. Voltage regulators and speed governors are neglected, and the loads and network equipments are represented through a constant impedance model, whereas the generators are modeled through its classical model.

Key-words: Underfrequency, Load Shedding Plans, Energy Function. 


\section{Sumário}

Resumo

Abstract $\quad$ xiii

Lista de Figuras $\quad$ xvii

$\begin{array}{lc}\text { Lista de Tabelas } & \text { xix }\end{array}$

Lista de Abreviaturas e Siglas $\quad$ xxi

1 Introdução 1

2 Modelagem Simplificada para Estudo do Corte de Carga $\quad 7$

2.1 Geradores Síncronos . . . . . . . . . . . . . . . . . . 7

2.1.1 Equações Mecânicas do Gerador . . . . . . . . . . . . . . . . . . 9

2.1.2 Equações Elétricas do Gerador . . . . . . . . . . . . . . . . 13

2.2 Rede Elétrica e Cargas . . . . . . . . . . . . . . . . . . 15

2.3 Corte de carga . . . . . . . . . . . . . . . . . . . 20

2.3.1 Modelagem do corte de carga monoestágio . . . . . . . . . . 22

2.3.2 Modelagem do corte de carga multiestágio . . . . . . . . . . . 24

2.3.3 Linearização do modelo para estudo do corte de carga . . . . . . 25

3 Revisão Bibliográfica $\quad 27$

4 Metodologia Proposta para Determinação de Planos de Corte de Carga $\quad 35$

4.1 Modelagem da Função Energia para corte de carga monoestágio . . . . 36

4.2 Critério das Áreas . . . . . . . . . . . . . . . . . . . . . . . . . 38

4.3 Proposta do Trabalho . . . . . . . . . . . . . . . . . . . . . 41

4.3.1 Corte de carga monoestágio . . . . . . . . . . . . . . 41 
5 Resultados $\quad 45$

5.1 Descrição do sistema em estudo . . . . . . . . . . . . . . . 45

5.1 .1 Comportamento da frequência . . . . . . . . . . . . . . 52

5.1 .2 Comportamento da potência elétrica . . . . . . . . . . 53

5.2 Corte de carga monoestágio . . . . . . . . . . . . . . . . 55

5.2 .1 Tamanho do Corte Insuficiente . . . . . . . . . . . . . . 56

5.2 .2 Tempo de corte atrasado . . . . . . . . . . . . . . . 59

5.2 .3 Tempo de corte exato . . . . . . . . . . . . . . . . . . 64

5.3 Modelo linearizado . . . . . . . . . . . . . . . . . . . . 65

6 Conclusões e Perspectivas Futuras $\quad 69$

$\begin{array}{ll}\text { Referências Bibliográficas } & 71\end{array}$ 


\section{Lista de Figuras}

FIGURA 1.1 Incremento na amplitude de vibração com a frequência de ope-

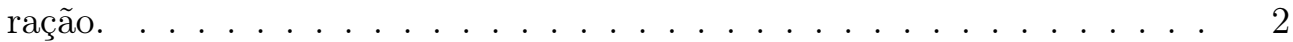

FIGURA 2.1 Máquina Síncrona de dois polos. . . . . . . . . . . . . . . . 9

FIGURA 2.2 Modelo Clássico do Gerador. . . . . . . . . . . . . . . . . 15

FIGURA 2.3 Rede Elétrica. . . . . . . . . . . . . . . . . . . . . . . 17

FIGURA 2.4 Corte de carga multiestágios. . . . . . . . . . . . . . . 21

FIGURA $3.1 \quad$ Modelo SFR. . . . . . . . . . . . . . . . . . . . . . 28

FIGURA 3.2 Plano de fase. . . . . . . . . . . . . . . . . . . 31

FIGURA 4.1 Critério das áreas iguais adaptado ao corte de carga. . . . . . 39

FIGURA 4.2 Funções energia. . . . . . . . . . . . . . . . . . . . . . . 43

FIGURA $5.1 \quad$ SEP simplificado. . . . . . . . . . . . . . . . . 46

FIGURA 5.2 SEP simplificado equivalente. . . . . . . . . . . . . 46

FIGURA 5.3 SEP no período pré-perda de geração. . . . . . . . . . . . . . . 49

FIGURA 5.4 SEP no período pré-corte de carga. . . . . . . . . . . . 50

FIGURA 5.5 SEP no período pós-corte de carga. . . . . . . . . . . . 50

FIGURA 5.6 Variação da frequência durante o corte de carga. . . . . . . . . 52

FIGURA 5.7 Curva $P \times \delta$ SEP simplificado equivalente. . . . . . . . . . . 53 
FIGURA 5.8 Curva $P x \delta$ SEP simplificado equivalente durante o corte de carga. . . . . . . . . . . . . . . . . . . . . 54

FIGURA 5.9 Energia potencial para o corte de carga insuficiente. . . . . . . 57

FIGURA 5.10 Energia total para o corte de carga insuficiente. . . . . . . . 58

FIGURA 5.11 Comportamento da frequência para o corte de carga insuficiente. 59

FIGURA 5.12 Energia potencial para o corte de carga atrasado. . . . . . . . 61

FIGURA 5.14 Energia cinética para o corte de carga atrasado. . . . . . . . . 61

FIGURA 5.13 Energia total para o corte de carga atrasado. . . . . . . . . . . 62

FIGURA 5.15 Comportamento da frequência para o corte de carga atrasado. 63

FIGURA 5.16 Comportamento da frequência para o corte de carga no instante exato. . . . . . . . . . . . . . . . . . . . . 64

FIGURA 5.17 Comparação do comportamento da frequência entre o sistema linearizado e o não linear. . . . . . . . . . . . . . . . . . . . . 67 


\section{Lista de Tabelas}

TABELA 5.1 Dados SEP equivalente. . . . . . . . . . . 47

TABELA 5.2 Resultado para os ajustes propostos. . . . . . . . . . 65 



\section{Lista de Abreviaturas e Siglas}

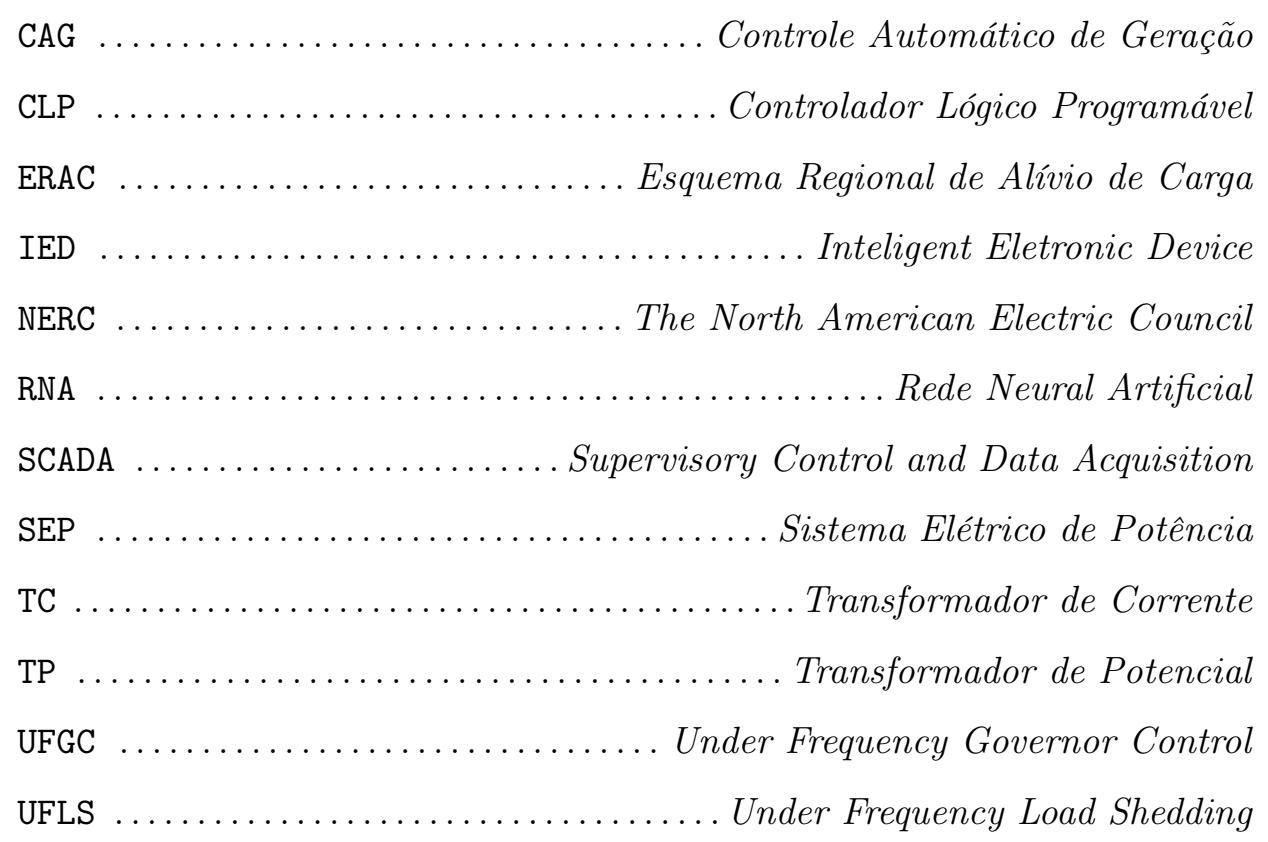





\section{Capítulo 1}

\section{Introdução}

Durante certas condições de emergência, um desbalanço significativo entre carga e geração pode acarretar em um declínio ou crescimento gradual da frequência do Sistema Elétrico de Potência (SEP). A dinâmica do sistema (relacionada ao déficit entre geração e carga) depende de vários fatores como, por exemplo, a gravidade do distúrbio, a resposta dos esquemas de emergência e dos reguladores de velocidade. Para um incremento gradual de carga os reguladores de velocidade aumentam a entrada de potência das unidades, visando sempre manter o equilíbrio entre a potência elétrica gerada e a consumida. Muitas vezes, distúrbios severos podem acarretar no rápido declínio da frequência, de modo que os controles primário e secundário de frequência não sejam capazes de responder tão rápido quanto necessário. Afim de ajudar na recuperação da frequência do sistema, esquemas automáticos de alívio de carga são utilizados juntamente com reguladores de velocidade, evitando assim o colapso do sistema (Chuvychin et al., 2005).

A integridade do sistema frente à variação de frequência vem sendo estudada em detalhes nos últimos anos, pois cada vez mais os SEPs vão sendo forçados a trabalharem próximos de seus limites de transmissão e geração. Portanto, condições de emergência são frequentimente alcançadas para grandes perdas de geração do sistema.

Os SEPs são constituídos por equipamentos que, por muitas vezes, são projetados para operarem numa faixa estreita de frequência. Portanto, condições de subfrequência ou, sobrefrequência podem levar ao mal funcionamento ou em casos extremos, acarretar em sérios danos aos equipamentos. Os vários tipos de turbinas existentes, independente 
de suas fontes primárias de energia, possuem diferentes tamanhos e configurações, o que caracteriza diferentes frequências naturais de ressonância para cada uma delas. As turbinas são cuidadosamente projetadas para operarem à uma frequência suficientemente distante de suas frequências naturais. Tal restrição procura evitar um excesso de vibrações nas turbinas, o que leva a mesma a sofrer um desgaste mecânico. O diagrama representado pela Figura 1.1 mostra a amplitude da vibração mecânica ocasionada à turbina em função de sua frequência de operação classificadas em três níveis, A,B e C. Note que o gráfico tem o formato de uma bacia, assim, valores de frequência localizados fora da bacia ocasionam fadiga mecânica, o que diminui a vida útil da turbina. Os fenômenos de ressonância causados a estas turbinas permitem vibrações mecânicas excessivas, mesmo durante curtos períodos de tempo, pois os desgastes mecânicos vão se acumulando ao longo do tempo (Berdy et al., 1974).

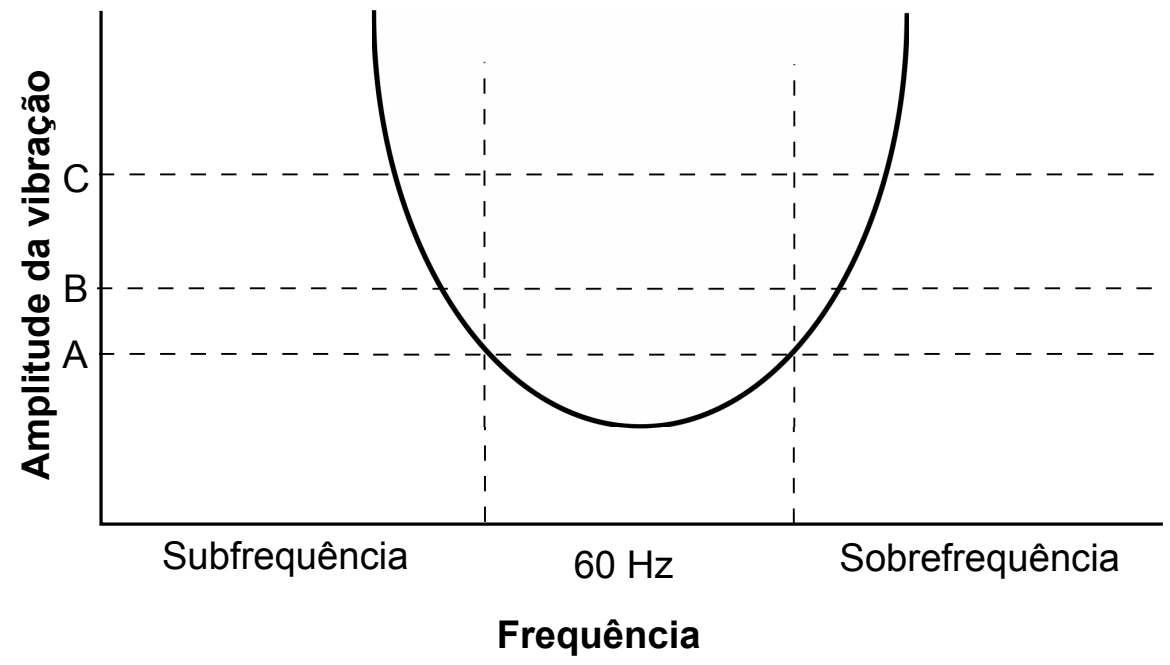

Figura 1.1: Incremento na amplitude de vibração com a frequência de operação.

Muitas vezes os relés são os equipamentos responsáveis pela proteção dos geradores e, sendo assim, quando determinados níveis de frequência são atingidos, um sinal denominado de trip é enviado aos disjuntores para que as unidades geradoras sejam isoladas do restante do sistema (evitando assim maiores danos aos equipamentos). Observe que, se nenhuma medida de emergência for tomada durante certas condições de subfrequência, o sistema pode chegar facilmente ao colapso, desconectando por completo todas as unidades geradoras do mesmo (IEEE Power Engineering Society, 2007).

Esquemas de alívio de carga são utilizados para que o equilíbrio entre carga e geração seja reconstituído durante condições de emergência. Os planos de corte de carga 
são construídos com base em estudos sobre a dinâmica das unidades geradoras do sistema, considerando as possibilidades de desbalanço de potência. Os planos podem ser coordenados em sistemas interconectados juntamente com esquemas de subfrequência para o isolamento de geradores, desligamento de bancos de capacitores, e outras ações automáticas de controle, visando evitar problemas de sobretensão, sobrecarga nos equipamentos, dentre outros (IEEE Power Engineering Society, 2007). Infelizmente, os tipos de proteções empregadas nos esquemas de emergência muitas vezes não são coordenados com outros aspectos operacionais do sistema, o que leva muitas vezes ao blecaute do mesmo (Bialek, 2007; Andersson et al., 2005).

Sistemas isolados ou industriais, constituídos por sistemas próprios de geração, também podem ser dotados de planos de corte de carga, eliminando assim as cargas menos prioritárias do sistema. Após uma condição de subfrequência estas cargas podem ser novamente reconectadas ao sistema (IEEE Power Engineering Society, 2007).

A construção de tais planos não é uma tarefa trivial, pois as medidas tomadas para mitigar um problema de subfrequência podem levar a um problema de sobrefrequência, tendo em vista que o comportamento da frequência do sistema está diretamente relacionado com o equilíbrio entre os torques mecânico e elétrico de cada unidade de geração. Quando ocorre uma perda de geração, o torque elétrico solicitado pelas cargas conectadas ao sistema é maior que o torque mecânico produzido nos geradores pelas fontes primárias de energia (água, vento e vapor, por exemplo). Assim, a frequência do sistema sofre um declínio em seu valor. Após a atuação dos esquemas automáticos de alívio de carga, montantes de carga são retirados, de forma que um nova condição de equilíbrio possa ser atingida. Caso o montante de carga retirado seja muito grande, o torque mecânico se torna maior que o torque elétrico, podendo levar as máquinas do sistema a uma condição de velocidade superior à velocidade síncrona antes que o equilíbrio possa ser novamente atingido. Condições de sobrefrequência e sobretensão podem ser facilmente atingidas após a atuação dos esquemas emergenciais. Em (Gomes e Sardinha, 2001) são apresentados alguns dos impactos no sistema interligado brasileiro observados durante o dimensionamento dos esquemas de alívio de carga do mesmo e, dentre tais impactos, encontram-se tanto condições de subfrequência e sobrefrequência.

A frequência do gerador é mantida pelos reguladores de velocidade. O ajuste da referência de carga é fornecido pelo controle automático de geração (CAG), que baseia-se 
no despacho econômico. Em condições severas de subfrequência a reserva girante pode ser acionada, tão rápido quanto o possível, para que a frequência seja restaurada. O trabalho realizado em (Anderson e Mirheydar, 1992) propõe uma coordenação entre os montantes de carga retirados durante o processo de alívio de carga e a ação dos reguladores de velocidade atuando simultaneamente. Desta forma, resultados mais eficientes podem ser alcançados.

A metodologia mais utilizada para aplicação dos planos de cortes de carga é baseada no valor do desvio da frequência. O relé consegue não somente identificar o valor absoluto de frequência, mas também a tendência que o sistema possui para que um novo ponto de equilíbrio seja atingido (Anderson e Mirheydar, 1992). A partir daí, novas vertentes são desenvolvidas utilizando o desvio da frequência juntamente com inteligência artificial, sistemas de telecomunicação, sistemas SCADA (do inglês, Supervisory Control And Data Acquisition), otimização, dentre outros (Shokooh et al., 2005; Parniani e Nasri, 2006; Halevi e Kottick, 1993).

A maioria dos métodos empregados nos trabalhos citados utilizam-se de uma modelagem equivalente e linearizada do sistema, o que impossibilita a determinação do comportamento da frequência de forma precisa para que os limites atingidos por ela sejam determinados. Portanto, os resultados obtidos durante o processo de construção dos planos de corte de carga podem ser um tanto quanto conservadores, interrompendo o fornecimento de energia durante condições de subfrequência para mais clientes do que o necessário. Tal conservadorismo visa garantir uma condição de estabilidade após o período emergencial, sendo que um dos motivos é a imprecisão dos modelos utilizados.

A metodologia apresentada neste trabalho utiliza uma representação não linear para o SEP, o que permite um estudo do comportamento dinâmico de suas unidades geradoras de forma precisa. Assim, os planos podem ser determinados com eficiência, visando reduzir ainda mais o número de consumidores desprovidos de energia elétrica durante o processo de alívio de carga e, ainda assim, garantindo a estabilidade do sistema.

Para uma primeira abordagem relativa ao problema do corte de carga, neste trabalho são desconsideradas as atuações dos reguladores de velocidade e tensão e é adotado o modelo clássico para a representação das unidades geradoras. Somente o comportamento da frequência do sistema será observado, desprezando o efeito que o corte exerce sob as tensões nos barramentos, dentre outras hipóteses. 
Nesta parte introdutória do trabalho não foi apresentada uma revisão bibliográfica detalhada sobre os métodos empregados para determinação dos planos de corte de carga. Optou-se por apresentar a mesma em uma seção posterior a esta, após terem sido apresentados alguns conceitos fundamentais para o entendimento do problema em estudo.

O texto está estruturado da seguinte forma: o capítulo 2 apresenta a modelagem de sistemas elétricos de potência utilizada neste trabalho; no capítulo 3 é apresentada uma revisão bibliográfica sobre as metodologias empregadas para a determinação dos planos emergenciais de corte de carga; no capítulo 4 é apresentada a modelagem matemática para a formulação do problema de corte de carga monoestágio e multiestágios aplicada a um simples sistema elétrico de potência; o capítulo 5 apresenta os resultados obtidos. Por fim, as conclusões e perspectivas futuras são apresentadas no capítulo 6 . 



\section{Capítulo 2}

\section{Modelagem Simplificada para}

\section{Estudo do Corte de Carga}

Para o estudo da dinâmica rotacional inerente às máquinas dos SEPs se faz necessária uma modelagem matemática do mesmo. A modelagem dos diversos componentes que constituem um SEP (tais como geradores, redes de transmissão, transformadores e cargas) é apresentada de forma sucinta neste capítulo. Assim, um modelo simplificado será construído para que a metodologia de corte de carga proposta seja aplicada.

\section{$2.1 \quad$ Geradores Síncronos}

As máquinas síncronas trifásicas são constituídas basicamente por um componente rotacional, o rotor, e outro estacionário denominado estator. Com raras exceções, o enrolamento de armadura localiza-se no estator, sendo composto por um conjunto trifásico de enrolamentos defasados de $120^{\circ}$ entre si, localizados em ranhuras (diametralmente opostas) distribuídas ao longo da periferia interna do estator. No rotor é onde estão localizadas as bobinas do enrolamento de campo. As máquinas podem ser classificadas em dois grupos quanto ao tipo de excitação: auto-excitadas e de excitação independente. Ambas produzem um campo magnético que é difundido pelo entreferro da máquina. Para a máquina síncrona operando como gerador, o movimento rotacional do rotor, associado ao campo magnético gerado pelo enrolamento de campo, induz uma tensão aproximadamente senoidal nos terminais de saída do estator. Quando a carga é conec- 
tada ao estator, uma potência elétrica é fornecida ao mesmo pela máquina. Assim, a corrente de armadura cria uma onda de fluxo eletromagnético no entreferro que gira à velocidade síncrona. Devido à tendência de alinhamento entre os fluxos há o surgimento de um conjugado eletromecânico, que advêm da interação entre o fluxo criado pela corrente de campo e o fluxo no entreferro. No gerador, este conjugado opõe-se ao movimento rotacional. Portanto, é necessária a injeção de um conjugado mecânico externo (produzido por água ou vapor, por exemplo) sobre o eixo que liga a turbina ao gerador capaz de manter a velocidade do mesmo (Fitzgerald et al., 2006; Kuiava, 2007).

Pode-se classificar a máquina síncrona de acordo com o tipo de rotor encontrado. A seguir serão definidos os dois tipos básicos.

As máquinas de polos lisos possuem seus enrolamentos de campo situados em ranhuras ao longo do rotor, e também são chamadas de turbogeradores. Estas máquinas possuem rotores cilíndricos com pequeno número de polos e, sendo assim, operam em altas velocidades para que se possa atender às especificações de frequência do sistema (60 Hz no caso do Brasil). Basicamente, os turbogeradores têm como fonte primária de energia o vapor (Kuiava, 2007).

As máquinas de polos salientes geralmente são acionadas por turbinas hidráulicas. As bobinas de campo se encontram ao longo do eixo do rotor e, devido a esta característica construtiva, seu entreferro é altamente não-uniforme. Seu rotor é constituído por vários pares de polos e, portanto, estes operam com baixa velocidade de rotação (Kuiava, 2007).

Por simplicidade, uma máquina síncrona que contém somente dois polos salientes é apresentada na Figura 2.1. Porém, qualquer máquina que contenha um número maior de polos salientes pode ser representada de forma equivalente por uma máquina com apenas dois polos (Kimbark, 1995). Também podem ser vistos os enrolamentos do estator (representados pelas fases a, b e c) e um enrolamento de campo designado por $F$. O eixo na direção do rotor é chamado de eixo direto (d). Defasado de $90^{\circ}$ graus em relação a este, no sentido contrário a velocidade rotacional $\omega$, é definido o eixo em quadratura (q). Com a finalidade de amortecer eventuais oscilações provocadas por perturbações no balanço de potência da máquina, existem os enrolamentos amortecedores. Estes enrolamentos podem ser representados de maneira equivalente pelos enrolamentos $Q$ e $D$. É definido também $\theta_{m}$ como o ângulo entre o eixo d e uma referência fixa ao estator. 
O modelo de máquina utilizado para estudos envolvendo SEPs depende de fenômenos que se deseja observar. Sendo assim, modelos mais simples podem ser encontrados. Para maiores detalhes sobre a modelagem de geradores podem ser consultadas as seguintes referências: (Sauer e Pai, 1998) e (Ramos et al., 2000).

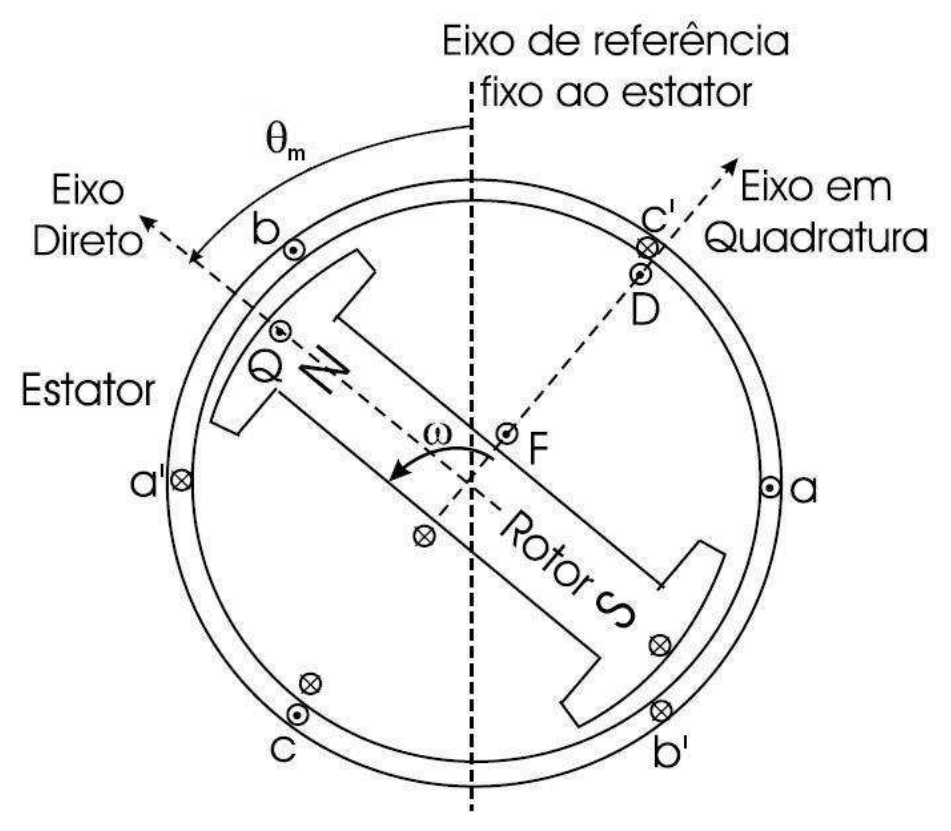

Figura 2.1: Máquina Síncrona de dois polos.

\subsubsection{Equações Mecânicas do Gerador}

O objetivo aqui é encontrar uma expressão que relaciona os desbalanços de potência ocorridos ao longo tempo (de natureza elétrica e mecânica) com as respectivas variações nas velocidades das máquinas. As equações diferenciais são obtidas através de um balanço de potência em cada máquina do sistema. O gerador elétrico tem como princípio básico de funcionamento efetuar a transformação de energia mecânica (fornecida por uma fonte energética primária) em energia elétrica. Todavia, a parte que não é convertida em energia elétrica se transforma em potência de aceleração do rotor da máquina, desconsiderando as perdas envolvidas no processo (Bretas e Alberto, 2000).

Considere a máquina ilustrada na Figura 2.1. Seu movimento é descrito pela Equação (2.1).

$$
J \cdot \ddot{\theta}_{m}=T_{a}
$$

$J$ é o momento de inércia do rotor, $T_{a}$ é o torque de aceleração do rotor e $\theta_{m}$ é o 
ângulo mecânico do eixo direto do rotor com relação a um eixo de referência estacionário.

O torque $T_{a}$ resulta da diferença entre os torques mecânico e elétrico aplicados ao rotor. Para a máquina funcionando como gerador o torque mecânico $T_{m}$ (grandeza positiva) atua no sentido de acelerar o rotor. Em oposição ao torque mecânico há o surgimento de um agente contrabalanceador, o torque elétrico $T_{e}$ (grandeza positiva), que atua no sentido contrário desacelerando o rotor. Portanto, através da Equação (2.2) é estipulada a convenção do sinal para o torque resultante, ou seja, a relação entre o agente mecânico (turbina movida por água ou vapor, por exemplo) e o torque elétrico. Este torque é gerado pelas correntes das cargas conectadas ao sistema, desprezando-se as perdas rotacionais (Ramos et al., 2000).

$$
T_{a}=T_{m}-T_{e}
$$

Devido à referência estacionária para a variável $\theta_{m}$, sua expressão em regime permanente depende da frequência do sistema (em outras palavras, a mesma varia com o tempo). Isto gera certos inconvenientes nas expressões elétricas e mecânicas, pois dificulta a modelagem e o estudo do gerador. Portanto, é importante que uma referência girante seja adotada para os estudos de planos de corte de carga, assim como tem sido feito para estudos de estabilidade (Ramos et al., 2000). Na Equação (2.3) é redefinido o ângulo do rotor em termos de uma nova referência.

$$
\delta_{m}(t)=\theta_{m}(t)-\left(\omega_{0 m} \cdot t+\frac{\pi}{2}+\alpha\right)
$$

Tal artifício matemático permite que, em regime permanente, a máquina atinja um ângulo constante em relação à referência girante. Assim, um problema de busca por soluções de equilíbrio transforma-se em um problema de busca por pontos de equilíbrio. Sendo assim, $\omega_{0 m}$ é a velocidade síncrona e $\left(\omega_{0 m} \cdot t+\frac{\pi}{2}+\alpha\right)$ define a referência girante. Para $t=0$ tem-se $\alpha$ como o ângulo de defasagem entre a referência fixa e a girante neste instante de tempo. Portanto, o ângulo do rotor $\left(\delta_{m}(t)\right)$ é o ângulo entre o eixo em quadratura e a referência girante, sendo uma constante em regime permanente.

Obtida a nova expressão para o ângulo do rotor, no referencial girante, é necessário redefinirmos a Equação (2.1) em função de $\delta_{m}(t)$. Derivando-se a Equação (2.3) obtém- 
se a Equação (2.4), conforme a expressão abaixo:

$$
\dot{\theta}_{m}(t)=\dot{\delta}_{m}(t)+\omega_{0 m}
$$

Agora, derivando-se a Equação (2.4) obtém-se a Equação (2.5).

$$
\ddot{\theta}_{m}(t)=\ddot{\delta}_{m}(t)
$$

Visto que a aceleração mantém-se inalterada em ambos os referenciais, o que caracteriza o sistema com referência inercial, pode-se então escrever a Equação (2.6).

$$
J \cdot \ddot{\delta}_{m}=T_{m}-T_{e}
$$

Para estudos envolvendo SEPs não é conveniente trabalhar-se com a grandeza de torque, visto que sua medição é extremamente complica comparada à medição de potência elétrica. Multiplicando a Equação (2.6) em ambos os lados pela velocidade mecânica tem-se a Equação (2.7).

$$
J \cdot \omega_{m} \cdot \ddot{\delta}_{m}=P_{m}-P_{e}
$$

A expressão acima está em função da potência elétrica e mecânica, porém no lado esquerdo foi introduzida uma não linearidade na equação. Pode-se eliminar esta não linearidade através de uma simplificação que advém de duas hipóteses. A primeira delas considera que não ocorre a perda de sincronismo entre as unidades geradoras, o que poderia levar o sistema a uma condição de instabilidade. A outra hipótese considera que não ocorre nenhuma violação dos limites operacionais do sistema, quando o mesmo é submetido a condições de subfrequência. Sendo assim, a velocidade $\omega_{m}$ não se afasta significativamente de $\omega_{0 m}$.

Portanto, a seguinte simplificação é efetuada:

$$
J \cdot \omega_{m} \approx J \cdot \omega_{0 m}=M_{m}
$$

onde $M_{m}$ é chamada de constante de inércia da máquina. Substituindo (2.8) em (2.7) tem-se:

$$
M_{m} \cdot \ddot{\delta}_{m}=P_{m}-P_{e}
$$


A Equação (2.9) possui um erro introduzido pela aproximação feita em (2.8). Para minimizar este efeito é então inserido um termo $\left(D_{d} \cdot \omega_{m}\right)$ à expressão, onde $D_{d}$ é uma constante de amortecimento. Este termo amortecedor também pode representar o efeito dos enrolamentos amortecedores do gerador ou da variação das cargas com a frequência. Sendo assim, obtém-se a Equação (2.10).

$$
M_{m} \cdot \ddot{\delta}_{m}+D_{d} \cdot \omega_{m}=P_{m}-P_{e}
$$

Entretanto, as potências elétricas da rede são dadas em função dos ângulos elétricos. Desta forma, é utilizada uma relação entre as grandezas elétricas e mecânicas, onde $p$ é o número de polos da máquina conforme a Equação (2.11).

$$
\delta_{e}=\frac{p}{2} \cdot \delta_{m}
$$

Pode-se, da mesma maneira, definir a velocidade elétrica da seguinte forma:

$$
\omega_{e}=\frac{p}{2} \cdot \omega_{m}
$$

Derivando-se a Equação (2.12) com relação ao tempo obtém-se:

$$
\ddot{\delta}_{e}=\frac{p}{2} \cdot \ddot{\delta}_{m}
$$

A substituição de (2.12) e (2.13) em (2.10) resulta na Equação (2.14).

$$
\frac{2}{p} \cdot M_{m} \cdot \ddot{\delta}_{e}+\frac{2}{p} \cdot D_{d} \cdot \omega_{e}=\frac{2}{p} \cdot M_{m} \cdot \dot{\omega}_{e}+\frac{2}{p} \cdot D_{d} \cdot \omega_{e}=P_{m}-P_{e}
$$

Para que se possa representar a equação da dinâmica da máquina com grandezas por unidade (p.u.), a Equação (2.14) será dividida pela potência base $S_{B}$, resultando assim na Equação (2.15).

$$
\frac{2 \cdot M_{m}}{p \cdot S_{B}} \cdot \dot{\omega}_{e}+\frac{2 \cdot D_{d}}{p \cdot S_{B}} \cdot \omega_{e}=\frac{P_{m}}{S_{B}}-\frac{P_{e}}{S_{B}}
$$

É conveniente definir uma nova constante de inércia $M=\frac{2 \cdot M_{m}}{p \cdot S_{B}}$ e uma nova cons- 
tante de amortecimento $D=\frac{2 \cdot D_{d}}{p \cdot S_{B}}$ para simplificação da Equação (2.15). Tomando $\omega_{e}=\dot{\delta}_{e}=\dot{\delta}$, finalmente encontra-se a expressão final que descreve o comportamento dinâmico da máquina em p.u., denominada equação de balanço ou de swing, que é a Equação (2.16).

$$
M \cdot \dot{\omega}+D \cdot \omega=P_{m u}-P_{e u}
$$

Entretanto, os fabricantes usualmente não fornecem a constante M e sim um parâmetro $H$, também chamado de constante de inércia. Este é definido como a razão entre a energia cinética da máquina em velocidade síncrona e a potência base do sistema, dada pela Equação (2.17).

$$
H=\frac{J \cdot \omega_{0 m}^{2}}{2 \cdot S_{B}}
$$

Inserindo a constante de inércia $M$ em (2.17), tem-se a relação entre $M$ e o parâmetro fornecido pelo fabricante, conversão esta realizada através da Equação (2.18).

$$
M=\frac{H}{\pi \cdot f_{0}},
$$

onde $f_{0}$ é a frequência elétrica síncrona do sistema em $\mathrm{Hz}$.

A modelagem mecânica da máquina apresentada nesta seção segue a referência (Bretas e Alberto, 2000). Portanto, para mais informações a mesma deve ser consultada.

\subsubsection{Equações Elétricas do Gerador}

Caso fosse adotada uma referência fixa para a representação das variáveis do enrolamento de armadura, grandezas como tensão, corrente e fluxo teriam grandes dificuldades para serem representadas, pois as mesmas sofreriam variações no espaço e no tempo de acordo com a posição angular do rotor $\theta_{m}$. Para resolver este problema utiliza-se uma ferramenta matemática chamada Transformação de Park.

Através da Transformação de Park é possível definir uma nova referência para o sistema. Tal artifício matemático permite que as variáveis da máquina sejam representadas sob uma referência rotacional de acordo com o movimento do rotor. Desta forma, tais variáveis são expressas em relação aos dois eixos $d$ e $q$, conforme visto pela Figura 2.1, sendo que um terceiro eixo estacionário, associado à componente de sequência zero, não 
será inserido ao modelo, pois considera-se a máquina operando de forma balanceada.

Para a obtenção do modelo de máquina utilizada para estudos transitórios envolvidos no processo de alívio de carga, algumas hipóteses simplificadoras serão adotadas:

- Os efeitos dos enrolamentos amortecedores podem ser desprezados;

- Correntes de Foucault no rotor podem ser desprezadas;

- As tensões transformatórias são pequenas em comparação com as tensões rotacionais e podem ser desprezadas;

- As quedas de tensão nas resistências do estator são desprezíveis;

- A velocidade angular absoluta não varia de forma tão significativa do ponto de vista das grandezas elétricas do estator que dependem da mesma, podendo ser considerada igual a $\omega_{0}$ (ou 1 p.u.) nas equações do estator;

- As indutâncias transitórias $L_{q}^{\prime}$ e $L_{d}^{\prime}$ são aproximadamente iguais;

- Durante o período transitório o fluxo no eixo direto $E_{F D}$ é aproximadamente constante;

- O ângulo $\delta$ da força eletromotriz coincide com o ângulo do rotor;

- Após a perda de geração a potência mecânica permanece constante durante todo o intervalo de tempo de interesse do estudo (período transitório), ou seja, desconsiderase a atuação dos reguladores de velocidade.

As simplificações citadas acima resultam num modelo equivalente para a máquina denominado de modelo clássico. Este modelo é amplamente utilizado em estudos transitórios, desde a época em que surgiram os primeiros trabalhos na área. O circuito equivalente associado a este modelo é visto pela Figura 2.2. Neste circuito, a força eletromotriz $\left(E^{\prime}\right)$ encontrada atrás da reatância transitória de eixo direto $\left(x_{d}^{\prime}\right)$ é uma constante. No estator a força eletromotriz $E_{q}^{\prime}$, correspondente a uma corrente de campo, é aproximadamente constante e igual à tensão $E^{\prime}$. As únicas variáveis de estado resultantes de tal modelo são o ângulo $\delta$ e a velocidade $\omega$. Para mais informações a respeito do modelo aqui descrito, podem ser consultadas as referências: (Anderson et al., 1979), (Kundur, 1994) e (Ramos et al., 2000). 


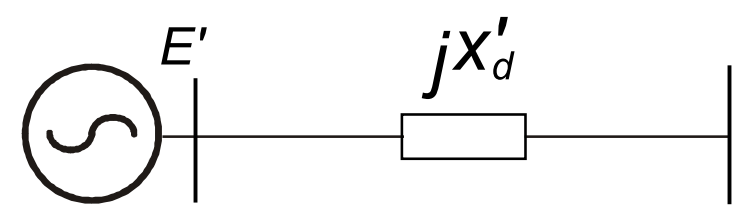

Figura 2.2: Modelo Clássico do Gerador.

\section{$2.2 \quad$ Rede Elétrica e Cargas}

Um dos importantes fatores considerados na construção de um modelo final capaz de representar o sistema está na determinação do modelo de carga utilizado. Neste trabalho as cargas são representadas por impedâncias constantes. Tal artifício, além de simplificar o modelo final do sistema, possibilita a aplicação de um processo de redução da rede, eliminando assim o conjunto de equações algébricas que representa a rede e as cargas no modelo do SEP. Consequentemente, uma expressão analítica para a potência elétrica é obtida, o que possibilita a determinação de uma função energia para o sistema. Desta forma, o resultado final é um conjunto de equações diferenciais na forma de espaço de estados.

As cargas muitas vezes podem variar de acordo com a frequência à qual estão submetidas. Este efeito pode ser inserido no modelo multimáquinas através do ajuste da constante de amortecimento $D$, conforme consta na Equação (2.10). Assim, além da compensação efetuada pela aproximação em (2.10), o amortecimento pode representar uma parcela relativa ao comportamento dinâmico da carga. Outros efeitos também podem ser representados através da constante de amortecimento (enrolamentos amortecedores e atrito) (IEEE Task Force, 1999).

Pode-se admitir que a rede esteja em regime permanente senoidal na frequência síncrona. Considerando que as constantes de tempo da rede de transmissão são desprezíveis quando comparadas à frequência eletromecânica de oscilação, considere um SEP que possui $n$ geradores, sendo que a matriz de admitância $Y_{\text {bus }}$ representa a rede deste sistema, pois contém somente as reatâncias das linhas de transmissão e dos transformadores. Na matriz $Y_{\text {bus }}$ os $n$ primeiros nós estão relacionados aos $n$ geradores do sistema e $m$ representa os nós onde estão conectadas as cargas e demais barras da rede. Portanto, a ordem da matriz de admitância da rede é $(m+n) \times(n+m)$, como pode ser visto a seguir: 


$$
Y_{\text {bus }}=\left[\begin{array}{cc}
n & m \\
Y_{1} & Y_{2} \\
Y_{3} & Y_{4}
\end{array}\right]_{m}^{n}
$$

Pretende-se construir uma matriz de admitância que também inclua as cargas (modelo de admitância constante) e as admitâncias transitórias dos $n$ geradores. Sendo assim, define-se a matriz diagonal $Y_{x d}$ de ordem $n \times n$, onde os elementos da diagonal são as admitâncias transitórias dos geradores.

$$
Y_{x d}=\left[\begin{array}{cccc}
Y_{1}^{\prime} & 0 & 0 & 0 \\
0 & Y_{2}^{\prime} & 0 & 0 \\
0 & 0 & \ddots & \vdots \\
0 & 0 & \cdots & Y_{n}^{\prime}
\end{array}\right]
$$

As cargas são normalmente fornecidas com um valor de potência constante (valor utilizado no cálculo do fluxo de carga). Portanto, é necessária a transformação destas grandezas em um modelo de carga com admitância constante. De fato, tal artifício possibilita a representação algébrica do problema através da inserção das cargas na matriz de admitância do sistema. Através da aplicação da fórmula da potência complexa, Equação (2.21), podem ser obtidos os valores das admitâncias das cargas.

$$
y_{l i}=\frac{P_{l i}-j Q_{l i}}{\left|V_{l i}\right|^{2}}, \quad i=n+1, \ldots, 2 n+m
$$

onde $\left(P_{l i}+j Q_{l i}\right)$ é a potência no barramento de carga $i$ e $V_{l i}$ a tensão no barramento de carga $i$.

É definida então a matriz diagonal de admitância para as cargas do sistema, de ordem $(n+m) \times(n+m)$, como:

$$
Y_{l}=\left[\begin{array}{cc}
Y_{l g} & 0 \\
0 & Y_{l l}
\end{array}\right]=\left[\begin{array}{cccc}
Y_{l 1}^{\prime} & 0 & 0 & 0 \\
0 & Y_{l 2}^{\prime} & 0 & 0 \\
0 & 0 & \ddots & \vdots \\
0 & 0 & \cdots & Y_{(n+m)}^{\prime}
\end{array}\right]
$$


A submatriz interna $Y_{l g}$, de dimensão $n \times n$, contém as cargas conectadas aos $n$ barramentos de geração. Já a submatriz $Y_{l l}$, de ordem $m \times m$, representa as cargas conectadas aos $m$ últimos barramentos, onde são encontradas somente cargas. Portanto, através das matrizes (2.19), (2.20) e (2.22) pode-se construir a matriz completa do sistema, de ordem $(2 n+m) \times(2 n+m)$, como sendo:

$$
\tilde{Y}_{B U S}=\left[\begin{array}{ccc}
Y_{x d} & -Y_{x d} & 0 \\
-Y_{x d} & Y_{1}+Y_{x d}+Y_{l g} & Y_{2} \\
0 & Y_{3} & Y_{4}+Y_{l l}
\end{array}\right]
$$

Para uma primeira análise e estudo na determinação de planos de corte de carga, o primeiro interesse está nas variações das velocidades das máquinas e não nas variações das tensões nos barramentos do sistema. Tendo isso em mente, de modo a simplificar o equacionamento do problema, faz-se necessário a redução da matriz $\widetilde{Y}_{B U S}$ aos $n$ primeiros nós, obtendo-se a matriz reduzida $Y_{R E D}$. O SEP tem suas equações de potência elétrica em termos dos ângulos internos às máquinas, conforme visto pela Figura 2.3.

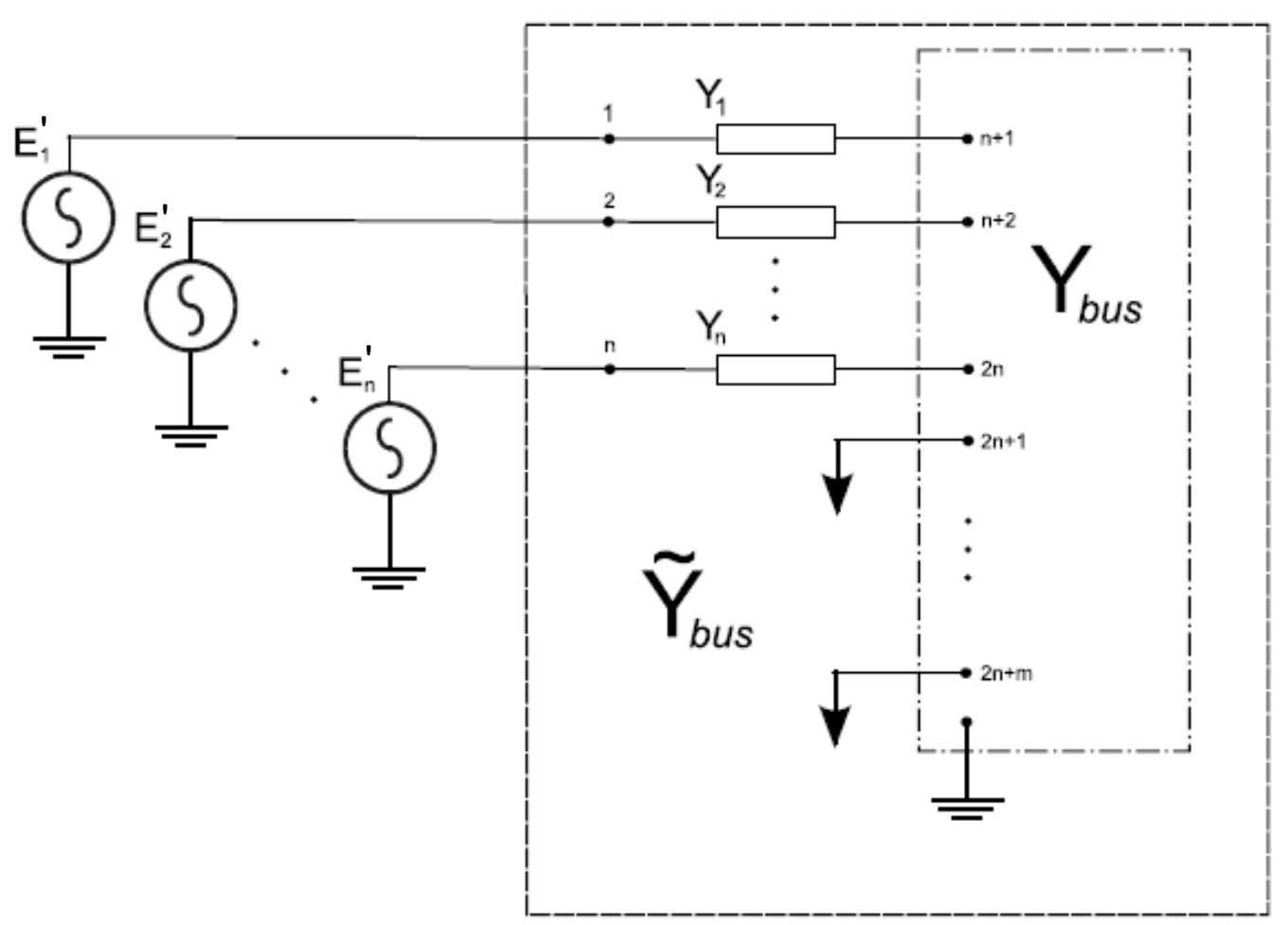

Figura 2.3: Rede Elétrica. 
Para o processo de redução do sistema aos nós internos dos geradores, com as cargas inseridas na matriz de admitância, a injeção de corrente em todas as barras é igual a zero, exceto nas barras internas dos geradores.

Desta forma tem-se a seguinte equação matricial:

$$
\left[\begin{array}{c}
I_{G} \\
0
\end{array}\right]=\left[\begin{array}{cc}
n & n+m \\
Y_{A} & Y_{B} \\
Y_{C} & Y_{D}
\end{array}\right] \cdot\left[\begin{array}{c}
E^{\prime} \\
E
\end{array}\right],
$$

sendo que:

$$
\begin{gathered}
Y_{A}=Y_{x d} \\
Y_{B}=Y_{C}^{T}=\left[\begin{array}{cc}
-Y_{x d} & 0
\end{array}\right] \\
Y_{D}=\left[\begin{array}{cc}
Y_{1}+Y_{x d}+Y_{l g} & Y_{2} \\
Y_{3} & Y_{4}+Y_{l l}
\end{array}\right]
\end{gathered}
$$

Como é visto pela Equação (2.24) pode-se eliminar os $(n+m)$ nós, já que não existe injeção de corrente nos mesmos, lembrando que $E^{\prime}$ é a f.e.m interna dos geradores. Portanto, podem ser obtidas as seguintes equações:

$$
\begin{gathered}
I_{G}=Y_{A} \cdot E^{\prime}+Y_{B} \cdot E \\
0=Y_{C} \cdot E^{\prime}+Y_{D} \cdot E
\end{gathered}
$$

Da Equação (2.29) pode-se isolar $E$ :

$$
E=-Y_{D}^{-1} \cdot Y_{C} \cdot E^{\prime}
$$

Substituindo-se (2.30) em (2.28), obtém-se:

$$
I_{G}=\left(Y_{A}-Y_{B} \cdot Y_{D}^{-1} \cdot Y_{C}\right) \cdot E^{\prime}=Y_{R E D} \cdot E^{\prime}
$$

Representando a matriz reduzida em termos das partes real $(\mathrm{G})$ e imaginária (B) obtém-se:

$$
Y_{R E D}=G+j B
$$


, sendo que $Y_{R E D}$ possui ordem $n$.

Baseada na matriz reduzida será determinada uma expressão que representará as equações diferenciais do sistema na forma de variáveis de estado.

A expressão para a potência real injetada no nó $i$ pelo respectivo gerador em termos da voltagem interna do mesmo é:

$$
P_{e i}=\Re e\left[E_{i}^{\prime} \cdot I_{i}^{*}\right]
$$

onde

$$
I_{i}=\sum_{j=1}^{n} E_{j}^{\prime} \cdot Y_{i j}
$$

sendo $Y_{i j}$ um elemento da matriz reduzida.

Expressando as tensões internas dos geradores e as admitâncias da matriz reduzida do sistema na forma polar, obtém-se:

$$
\begin{gathered}
E_{j}^{\prime}=\left|E_{j}^{\prime}\right| \angle \delta_{j} \\
Y_{i j}=G_{i j}+j \cdot B_{i j}=\left|Y_{i j}\right| \angle \phi_{i j}
\end{gathered}
$$

Obtendo as tensões e admitâncias na forma polar, e substituindo (2.34) em (2.33), obtém-se:

$$
P_{e i}=\left|E_{i}^{\prime}\right|^{2} \cdot G_{i i}+\sum_{\substack{j=1 \\ j \neq i}}^{n}\left|E_{i}^{\prime}\right| \cdot\left|E_{j}^{\prime}\right| \cdot\left|Y_{i j}\right| \cdot \cos \left(\phi_{i j}-\left(\delta_{i}-\delta_{j}\right)\right)
$$

A função cosseno pode ser decomposta utilizando-se a identidade trigonométrica $\cos (a-b)=\cos (a) \cdot \cos (b)+\operatorname{sen}(a) \cdot \operatorname{sen}(b)$. Portanto, aplicando-se tal identidade em (2.37), têm-se:

$$
P_{e i}=\left|E_{i}^{\prime}\right|^{2} \cdot G_{i i}+\sum_{\substack{j=1 \\ j \neq i}}^{n}\left|E_{i}^{\prime}\right| \cdot\left|E_{j}^{\prime}\right| \cdot\left|Y_{i j}\right| \cdot\left[\cos \left(\phi_{i j}\right) \cdot \cos \left(\delta_{i}-\delta_{j}\right)+\operatorname{sen}\left(\phi_{i j}\right) \cdot \operatorname{sen}\left(\delta_{i}-\delta_{j}\right)\right]
$$

Substituindo-se $P_{e i}$ na Equação (2.16), obtém-se finalmente a equação dinâmica do sistema: 


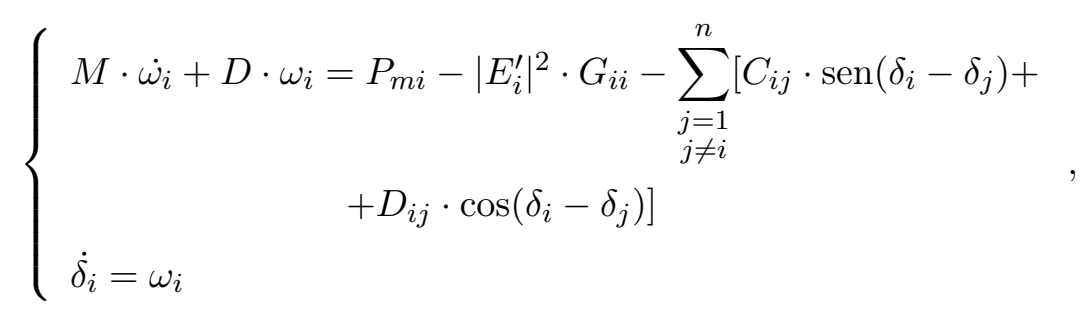

sendo que:

$$
\begin{aligned}
& C_{i j} \triangleq\left|E_{i}^{\prime}\right| \cdot\left|E_{j}^{\prime}\right| \cdot G_{i j} \\
& D_{i j} \triangleq\left|E_{i}^{\prime}\right| \cdot\left|E_{j}^{\prime}\right| \cdot B_{i j}
\end{aligned}
$$

A solução das equações diferenciais acima fornece os valores de desvio de velocidade e de ângulo para cada unidade geradora, representada pelo índice $i$, sendo que $G_{i j}$ e $B_{i j}$ são elementos de $\mathrm{G}$ e $\mathrm{B}$, respectivamente.

Após terem sido modelados os diversos componentes que constituem o SEP, será apresentada a modelagem do problema de corte de carga logo a seguir.

\subsection{Corte de carga}

Em certos casos, grandes perdas de geração podem acarretar em uma queda repentina de velocidade nas demais máquinas do sistema, visto que, muitas vezes, os reguladores de velocidade não são rápidos o suficiente para o restabelecimento do balanço entre os torques elétrico e mecânico. Assim, a frequência do sistema pode alcançar valores insustentáveis do ponto de vista operacional. Por esta razão, medidas corretivas devem ser tomadas para evitar o colapso do sistema.

Para que o equilíbrio entre a potência elétrica gerada e a demanda do sistema seja mantido, sob determinadas condições de subfrequência, cargas devem ser desconectadas do sistema. O corte de carga é a última opção para a recomposição do sistema, visto que grandes prejuízos financeiros podem ser causados tanto aos consumidores quanto às concessionárias de energia elétrica. Portanto, o corte deve ser realizado de forma que a menor parcela de consumidores seja desconectada, sem que limites operacionais de frequência e tensão, dentre outros, sejam ultrapassados.

As cargas podem ser classificadas conforme um índice de prioridade. Assim, para cargas como hospitais, indústrias de processo contínuo, dentre outras, deve-se evitar 
ao máximo a interrupção de seus respectivos fornecimentos de energia. Em alguns países a medida de corte de carga pode ser contratada como serviço ancilar, ou seja, o consumidor recebe alguns benefícios (diminuição da tarifa de energia, por exemplo) para que o seu fornecimento de energia seja interrompido caso alguma medida de alívio de carga seja necessária para recomposição do sistema.

São definidos então planos de corte de carga baseados em estudos relativos a dinâmica do sistema, dada uma probabilidade de desbalanço entre carga e geração. Basicamente, os planos são divididos em estágios, sendo que cada estágio possui um valor de ajuste de frequência que se relaciona a um montante de carga. Caso o sistema atinja o valor de frequência ajustado tal montante terá seu fornecimento de energia interrompido.

Muitas vezes relés de subfrequência, IEDs (do inglês, Inteligent Eletronic Devices) ou CLPs são os equipamentos responsáveis pelo envio do sinal de trip. Este sinal é transmitidos aos disjuntores para que as parcelas de carga (definidas sob cada estágio) sejam desconectadas. Tais equipamentos localizam-se em pontos específicos, de onde são coletadas as medidas de frequência. Assim, conforme a frequência do sistema vai atingindo os valores de frequência computados em cada estágio, as cargas vão sendo retiradas do mesmo, de forma a manter a integridade do sistema.

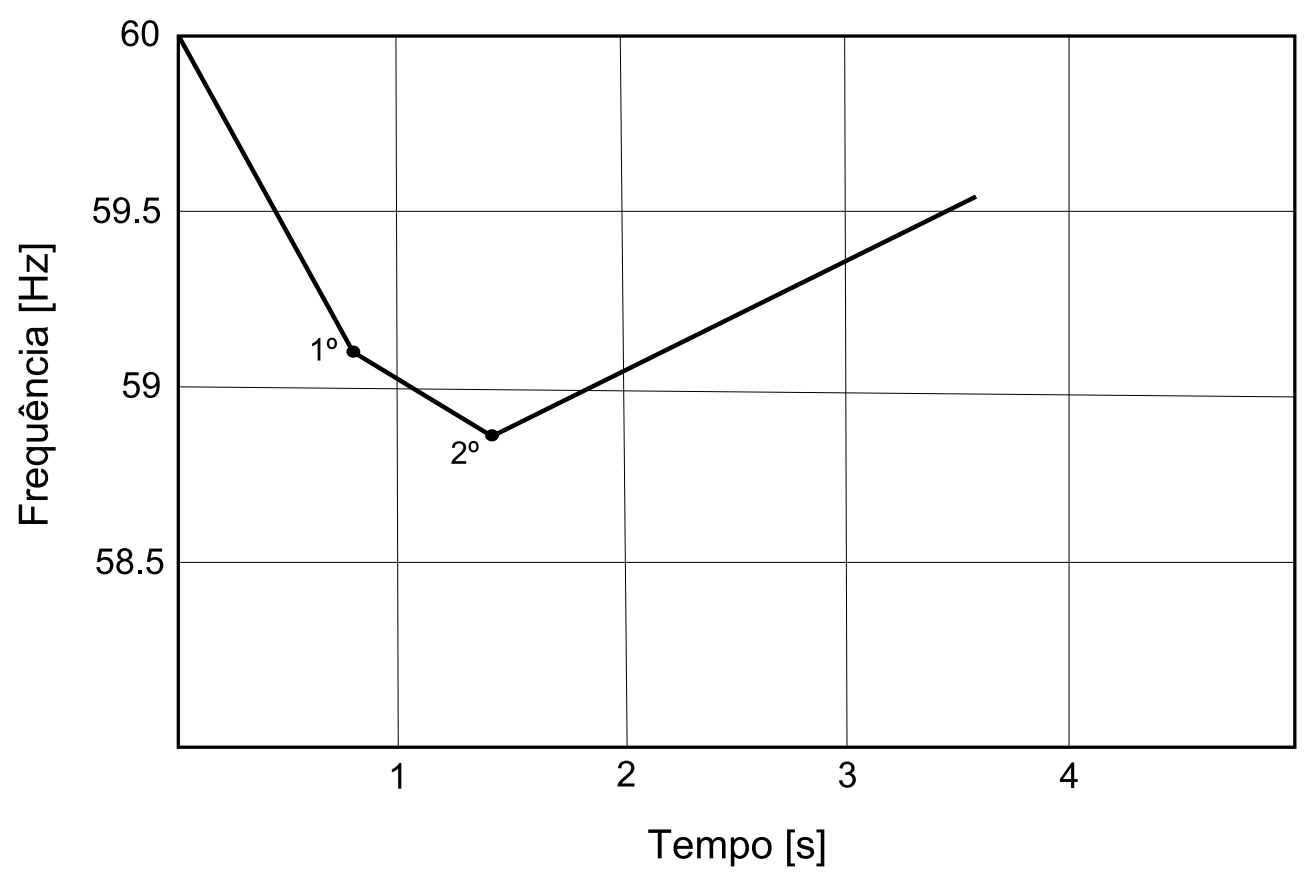

Figura 2.4: Corte de carga multiestágios. 
Para ilustrar um esquema de corte de caga multiestágios, a Figura 2.4 mostra (de forma quantitativa) o típico comportamento da frequência de um SEP durante uma condição de subfrequência onde um esquema com dois estágios foi empregado (IEEE Power Engineering Society, 2007).

\subsubsection{Modelagem do corte de carga monoestágio}

Para uma primeira abordagem relativa ao problema do corte de carga, serão desconsideradas as atuações dos reguladores de velocidade e tensão, e o modelo clássico para as unidades geradoras será adotado, considerando todas as hipóteses descritas neste capítulo. Somente o comportamento da frequência do sistema será observado, desprezando-se o efeito que o corte exerce sobre as tensões nos barramentos.

Nesta seção deseja-se formular um conjunto de equações matemáticas que descrevam o comportamento do SEP, quando o mesmo é submetido a condições de emergência envolvidas pelo processo de alívio de carga. De forma a simplificar tanto o entendimento do problema quanto a formulação da metodologia proposta, optou-se pela escolha de um único estágio de corte de carga. A modelagem utilizada aborda o problema de subfrequência devido à perda de unidades geradoras em um sistema de geração.

Primeiramente o sistema opera em regime permanente. Tal condição é verificada quando $\ddot{\delta}=0, \dot{\delta}=0$ e $\delta$ é constante para cada unidade geradora. O ângulo $\delta$ é determinado a partir do fluxo de carga, sendo que os valores de $\ddot{\delta}$ e $\dot{\delta}$ resultam da hipótese de que o sistema encontra-se em equilíbrio (Monticelli, 1983). Considere que no tempo $t=0$ ocorra uma grande perda de geração no SEP, o que ocasiona uma repentina queda de velocidade dos geradores. A fim de restabelecer rapidamente a frequência do sistema, evitando que a mesma alcance valores inaceitáveis do ponto de vista operacional, cargas são automaticamente retiradas do sistema. Portanto, define-se uma frequência crítica de operação chamada de $\omega^{c r}$.

Conforme descrito acima, pode-se classificar o problema em três intervalos de tempo distintos, relacionados também a diferentes topologias. Tais intervalos, juntamente com suas respectivas equações diferenciais serão descritos a seguir. Sendo que $i$ representa o índice de cada gerador do sistema, $\operatorname{com} i=1, \ldots, n$. 
- Sistema pré-perda de geração:

$$
M^{p r g} \cdot \ddot{\delta}_{i}+D^{p r g} \cdot \dot{\delta}_{i}=P_{m i}^{p r g}-P_{e i}^{p r g}=0 \quad\left\{\begin{array}{l}
t \leq 0 \\
\delta(t)=\delta_{0} \\
\dot{\delta}(t)=0
\end{array}\right.
$$

Na Equação (2.42) $P_{m i}^{p r g}$ e $P_{e i}^{p r g}$ são as respectivas potências mecânica e elétrica antes da perda de geração, $M^{\text {prg }}$ é a constante de inércia equivalente e $D^{\text {prg }}$ é a constante de amortecimento do sistema neste período. O ângulo elétrico de equilíbrio $\left(\delta_{0}\right)$ é obtido após a resolução do fluxo de carga.

- Sistema pré-corte de carga ou pós-perda de geração:

$$
M^{p r c} \cdot \ddot{\delta}_{i}+D^{p r c} \cdot \dot{\delta}_{i}=P_{m i}^{p r c}-P_{e i}^{p r c} \quad\left\{\begin{array}{l}
0<t \leq t_{c} \\
\delta(0)=\delta_{0} \\
\dot{\delta}(0)=0
\end{array}\right.
$$

sendo $P_{m i}^{p r c}$ e $P_{e i}^{p r c}$ as respectivas potências mecânica e elétrica antes do corte de carga, $M^{p r c}$ é a constante de inércia equivalente e $D^{\text {prc }}$ é a constante de amortecimento do sistema antes do corte de carga.

- Sistema pós-corte de carga:

$$
M^{p p c} \cdot \ddot{\delta}_{i}+D^{p p c} \cdot \dot{\delta}_{i}=P_{m i}^{p p c}-P_{e i}^{p p c} \quad\left\{\begin{array}{l}
t>t_{c} \\
\delta\left(t_{c}\right)=\delta^{p r c}\left(t_{c}\right) \\
\dot{\delta}(t c)=\dot{\delta}^{p r c}(t c)
\end{array}\right.
$$

Na Equação (2.44) $P_{m i}^{p p c}$ e $P_{e i}^{p p c}$ são as respectivas potências mecânica e elétrica após o corte de carga e $\delta^{p r c}\left(t_{c}\right)$ é o ângulo elétrico no instante do corte de carga na condição pré-corte de carga. A constante de amortecimento do sistema póscorte de carga é $D^{p p c}$ e $M^{p p c}$ é a constante de inércia equivalente deste período possuindo o mesmo valor numérico de $M^{\text {prc }}$.

Antes da perda de geração o sistema encontra-se em equilíbrio. A solução desta equação possui valores constantes no tempo, sendo determinada pelo fluxo de carga. A solução do sistema pré-corte de carga no instante do corte de carga $t_{c}$ fornece as condições iniciais para as equações do pós-corte de carga. 
Portanto, dada uma grande perda de geração, deseja-se determinar o valor da frequência do sistema no instante $t_{c}$, de forma que a frequência crítica pré-determinada não seja atingida. Sendo assim, define-se $\omega_{c}$ como a frequência de corte de carga.

Note que o problema não consiste na determinação da solução de um conjunto de equações diferenciais e sim na solução de três conjuntos de forma sequencial.

\subsubsection{Modelagem do corte de carga multiestágio}

A modelagem para um corte de carga multiestágios é praticamente idêntica a modelagem monoestágio. Embora a modelagem multiestágios seja apresentada, não foram obtidos resultados para esta abordagem. Pode-se classificar o problema de acordo com o número de possibilidades de corte de carga. Portanto, o número de topologias encontradas para o corte de carga multiestágio $\left(N_{t}\right)$, pode ser determinado pela expressão abaixo:

$$
N_{t}=n_{e}+2
$$

onde $n_{e}$ representa o número de estágios de corte de carga a serem utilizados.

Sendo assim, obtém-se as topologias abaixo:

- Sistema pré-perda de geração:

$$
M^{p r g} \cdot \ddot{\delta}+D^{p r g} \cdot \dot{\delta}=P_{m i}^{p r g}-P_{e i}^{p r g}=0 \quad\left\{\begin{array}{l}
t \leq 0 \\
\delta(t)=\delta_{0} \\
\dot{\delta}(t)=0
\end{array}\right.
$$

- Sistema pré-corte de carga ou pós-perda de geração:

$$
M^{p r c} \cdot \ddot{\delta}+D^{p r c} \cdot \dot{\delta}=P_{m i}^{p r c}-P_{e i}^{p r c} \quad\left\{\begin{array}{l}
0<t \leq t_{c 1} \\
\delta(0)=\delta_{0} \\
\dot{\delta}(0)=0
\end{array}\right.
$$


- Sistema pós-corte de carga referente ao primeiro estágio:

$$
M^{(1)} \cdot \ddot{\delta}+D^{(1)} \cdot \dot{\delta}=P_{m i}^{(1)}-P_{e i}^{(1)} \quad\left\{\begin{array}{l}
t_{c_{1}}<t \leq t_{c_{2}} \\
\delta\left(t_{c_{1}}\right)=\delta^{(1)}\left(t_{c_{1}}\right) \\
\dot{\delta}\left(t_{c_{1}}\right)=\dot{\delta}^{(1)}\left(t_{c_{1}}\right)
\end{array}\right.
$$

- Sistema pós-corte de carga referente ao estágio $k$ :

$$
M^{(k)} \cdot \ddot{\delta}+D^{(k)} \cdot \dot{\delta}=P_{m i}^{(k)}-P_{e i}^{(k)} \quad\left\{\begin{array}{l}
t_{c(k)}<t \leq t_{c(k+1)} \\
\delta\left(t_{c k}\right)=\delta^{(k)}\left(t_{c k}\right) \\
\dot{\delta}\left(t_{c k}\right)=\dot{\delta}^{(k)}\left(t_{c k}\right)
\end{array}\right.
$$

\subsubsection{Linearização do modelo para estudo do corte de carga}

O SEP pode ser descrito pelo modelo multimáquina descrito em (2.39). Uma condição de operação do sistema está associada a um ponto de equilíbrio de seu modelo matemático. Considerando que o ponto de operação do sistema não se afasta significativamente de seu ponto original, quando o mesmo é submetido a pequenas perturbações, a dinâmica do sistema pode ser estudada localmente. Como visto em (2.39) o SEP é representado por um conjunto de equações diferenciais não lineares na forma de espaço de estados. Assim:

$$
\dot{x}=f(x), x(0)=x_{e}
$$

onde $x \in R^{n}$, sendo $n$ o número de estados do sistema e $x(0)$ a condição inicial.

Considerando que $x_{e}$ é um ponto de equilíbrio, ou seja, $f\left(x_{e}\right)=0$, define-se $\Delta x=$ $x-x_{e}$. Com a expansão por série de Taylor na vizinhança da condição inicial $x_{e}$, obtém-se a Equação (2.51).

$$
f(x)=f\left(x_{e}\right)+\frac{\partial f}{\partial x} \cdot \Delta x+\ldots
$$

Admitindo-se que a trajetória de $x$ não se afasta significativamente de $x_{e}$, os termos de ordem superior a 1 podem ser desprezados em (2.51) e com o fato de que $f\left(x_{e}\right)=0$, obtém-se:

$$
f(x) \approx A \cdot \Delta x,
$$

sendo $A$ a matriz jacobiana de $f$ calculada em $x_{e}$. 
Além disso, têm-se:

$$
\Delta \dot{x}=\frac{d}{d t} \cdot\left(x-x_{e}\right)=\dot{x}-\dot{x}_{e}=\dot{x} \quad \Rightarrow \dot{x}=\Delta \dot{x}
$$

Portanto, a Equação (2.54) é uma representação linearizada de (2.50) por:

$$
\Delta \dot{x}(t)=A \cdot \Delta x(t)
$$

onde $A \in R^{n \times n}$ é a matriz de estados do sistema linearizado (Kuiava, 2007).

A maioria dos modelos matemáticos utilizados na representação dos SEPs para a construção de planos de corte de carga são determinados a partir de linearizações. Portanto, a linearização vale apenas numa proximidade do ponto de equilíbiro adotado, enquanto que o problema envolvendo o corte de carga só é realizado para grandes perturbações, ou seja, o sistema afasta-se significativamente de seu ponto de equilíbrio.

Com a base matemática adquirida nesta seção é possível realizar uma revisão bibliográfica sobre as diferentes metodologias empregadas nos esquemas de alívio de carga durante condições de emergência. Tendo isto em mente o próximo capítulo apresentará alguns destes métodos e, em seguida, o capítulo 4 apresentará a proposta deste trabalho. 


\section{Capítulo 3}

\section{Revisão Bibliográfica}

Neste capítulo, destacam-se algumas das principais metodologias utilizadas para a construção de planos de corte de carga em SEPs encontradas na literatura.

Esquemas automáticos de alívio de carga são criados para a restauração da frequência do sistema (dentro de níveis aceitáveis do ponto de vista operacional) durante condições de emergência causadas por um desequilíbrio entre carga e geração. Após o blecaute ocorrido na região norte dos Estados Unidos no ano de 1965 o North American Electric Council (NERC) recomendou a implementação de um esquema automático de alívio de carga durante condições de subfrequência, atualmente conhecido como UFLS (do inglês, Under-frequency Load Shedding). Ficou determinado que cada região contida no NERC definiria suas próprias regras sobre o quanto de carga deveria ser retirado, dentro de qual limite o corte seria efetuado e em qual instante de tempo o montante deveria ser desconectado. O objetivo com o qual o esquema UFLS foi criado estava na recomposição da frequência do sistema dentro de cada região (durante uma condição de subfrequência) simultaneamente à recomposição das unidades geradoras (IEEE Power Engineering Society, 2007).

Normalmente as ações de controle aplicadas durante a recomposição do sistema são efetuadas localmente, ou seja, cada área do sistema possui um esquema regional de alívio de carga (ERAC). Na maioria dos casos a implementação do ERAC é realizada utilizando-se relés de subfrequência localizados nos sistemas de distribuição ou subestações de transmissão, pois nestes locais é onde são encontrados a maioria dos disjuntores capazes de interromper o fornecimento de energia para as cargas durante condições de 
emergência (IEEE Power Engineering Society, 2007).

Todos os geradores do sistema possuem uma proteção de subfrequência pois, conforme mencionado no capítulo 1, procura-se evitar os danos causados aos geradores e cargas por condições de subfrequência. Portanto, um estudo criterioso deve ser realizado de modo que o ERAC esteja coordenado com o restante dos esquemas de proteção, evitando assim o blecaute do mesmo através do efeito de desligamento em cascata das unidades geradoras (Bialek, 2007; Andersson et al., 2005).

O método convencional de alívio de carga, que é baseado somente no valor absoluto de frequência, muitas vezes não se torna uma opção atrativa devido ao excessivo montante de carga retirado durante certas condições de emergência. A interrupção de energia para mais consumidores que o necessário é utilizada de forma a garantir que o sistema atinja uma nova condição de equilíbrio estável e sem que algum limite de operação seja ultrapassado.

Em (Anderson e Mirheydar, 1992) foi proposta uma metodologia adaptativa para o ajuste dos relés de proteção baseada na taxa de variação da frequência. Neste trabalho utiliza-se uma representação linearizada para uma ilha do SEP, representação esta que é denominada de SFR (do inglês, System Frequency Response), conforme o modelo apresentado na Figura 3.1, onde todos os parametros estão em p.u. O comportamento do modelo depende de alguns fatores; o ganho $\left(K_{m}\right)$, o fator de amortecimento $(D)$, a constante de inércia da ilha $(H)$, a constante de tempo $\left(T_{R}\right)$, o estatismo do gerador $(R)$ e a fração de realimentação da turbina de alta pressão $\left(F_{H}\right)$. Neste modelo, todos os parâmetros foram estimados do conhecimento de um típico projeto do sistema.

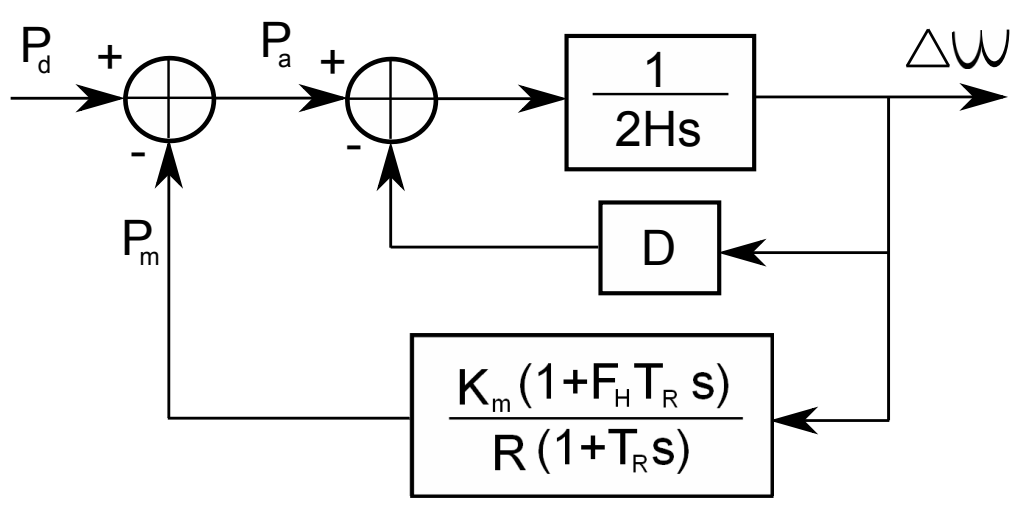

Figura 3.1: Modelo SFR.

Considerando um degrau de potencia $\left(P_{\text {step }}\right)$ na entrada $P_{d}$ obtem-se a solução no 
domínio do tempo para a variação da frequência como:

$$
\Delta \omega(t)=\frac{R P_{\text {step }}}{D R+K_{m}}\left[1+\alpha e^{-\zeta \omega_{n} t} \sin \left(\omega_{r} t+\phi\right)\right] p u
$$

A Equação (3.1) representa o comportamento da frequência do sistema em relação ao ponto de equilíbrio.

O corte de carga é efetuado em estágios onde montantes de carga vão sendo retirados durante certas condições de emergência. Portanto, o trabalho proposto em (Anderson e Mirheydar, 1992) utiliza a taxa de variação da frequência para a determinação de qual será o montante de carga a ser retirado. Sendo assim, a expressão da taxa de variação da frequência pode ser encontrada derivando-se a Equação (3.1). Calculando a derivada no tempo $t=0$ obtém-se:

$$
m_{0}=60 \frac{d \Delta \omega(0)}{d t}=\frac{60 P_{\text {step }}}{2 H} H z / s
$$

Na Equação (3.2) $m_{0}$ é definida como a inclinação inicial em hertz por segundo. Pode ser encontrada uma melhor estratégia para o corte de carga através da observação da taxa de variação da frequência, pois quanto mais acentuada é a inclinação da frequência maior deverá ser a montante retirado, de forma a restabelecer a condição normal do sistema visando maior rapidez com um menor número de consumidores sem energia elétrica.

A grande vantagem encontrada em relação ao UFLS convencional é que os relés, além de identificarem a condição de subfrequência (através da medição do valor absoluto da frequência), também são capazes de identificar mais um indicativo para a escolha do montante de carga que será retirado através do cálculo da taxa de variação da frequência. A partir de então, várias metodologias baseadas no UFLS convencional e na taxa de variação da frequência vem sendo desenvolvidas, sendo que em cada uma das propostas são inseridas novas ferramentas capazes de auxiliar a construção e implementação dos planos emergenciais de corte de carga. No decorrer do texto serão destacados alguns trabalhos desenvolvidos nesta área.

O desenvolvimento no setor de comunicação propiciou um grande avanço para a implementação dos esquemas emergenciais de alívio de carga. O trabalho apresentado 
em (Parniani e Nasri, 2006) integra as duas metodologias citadas acima (valor absoluto e a taxa de variação da frequência) ao sistema SCADA. É definida uma frequência principal do sistema $\left(f_{c}\right)$, definida por:

$$
f_{c}=\frac{\sum_{i=1}^{n} H_{i} f_{i}}{\sum_{i=1}^{n} H_{i}}
$$

Em (3.3) $f_{i}$ representa a frequência do gerador $i$ em hertz e $n$ é o número total de geradores.

O algoritmo proposto em (Parniani e Nasri, 2006) é dividido em duas partes. A primeira delas consiste em identificar a magnitude do distúrbio, basicamente calculandose a taxa de variação da frequência $\frac{d f_{c}}{d t}$, como já visto em (3.3).

A segunda parte preocupa-se em determinar as caracteristicas do distúrbio e os valores dos cortes de carga. Porém, primeiramente serão definidas algumas grandezas importantes para o entendimento do procedimento.

O valor $\Delta P_{c r}$ representa o valor máximo de sobrecarga permitido de modo que a frequência do sistema não ultrapasse um valor mínimo. Outra variável a ser definida é a sobrecarga $\Delta P_{t h r}$. Este valor representa o maior valor de sobrecarga permitido ao gerador que possui a menor constante de inércia, sendo que este distúrbio encontra-se no ponto mais próximo a este menor gerador.

Sendo assim, na segunda parte do algoritmo os distúrbios são identificados em três tomadas de decisão. Na primeira delas se $\Delta P_{L} \leq \Delta P_{t h r}$ não existe a necessidade de corte de carga, onde $\Delta P_{L}$ representa o déficit de potência do sistema. Outra situação é quando $\Delta P_{t h r} \leq \Delta P_{L} \leq \Delta P_{c r}$, e para esta condição o distúrbio é pequeno e um corte de carga local com retardo é suficiente para que o sistema retorne a um novo ponto de equilíbrio. A terceira e última condição encontrada é $\Delta P_{L} \geq \Delta P_{c r}$, e neste caso o plano de corte de carga deve ser executado, sendo que a distribuição do corte de carga é efetuada levando-se em conta que os geradores localizados próximos ao distúrbio sofrem um maior desvio de frequência em relação aos demais. Os resultados obtidos mostraram que um menor montante de carga foi retirado durante algumas condições de subfrequência comparados a outros métodos convencionais. Por outro lado, o sistema 
sofreu um desvio de frequência mais severo que os demais métodos apresentados.

O trabalho apresentado em (Chuvychin et al., 1996) propõe um esquema de corte de carga adaptativo que utiliza-se tanto do valor absoluto da frequência quanto da taxa de variação da mesma, implementado com relés de proteção. Neste trabalho é proposta uma técnica para a coordenação entre o esquema de alívio de carga e a ativação da reserva girante através do controle de velocidade local.

Uma estratégia de controle pode ser utilizada durante certas condições de subfrequência denominada UFGC (do inglês, Under Frequency Governor Control). Se uma condição severa de subfrequência ocorrer, a reserva girante pode ser ativada tão rápida quanto o possível para que um blecaute do sistema possa ser evitado (Chuvychin et al., 1996).

Os relés de proteção monitoram constantemente o valor absoluto da frequência e a taxa de variação da mesma. Estes valores podem ser colocados em um plano de fase $\left(\frac{d f}{d t}\right.$ vs. $\left.f\right)$ onde são definidas algumas regiões limites, conforme mostra a Figura 3.2. Dependendo da posição dos pontos no plano de fase as tomadas de decisão podem ser enunciadas.

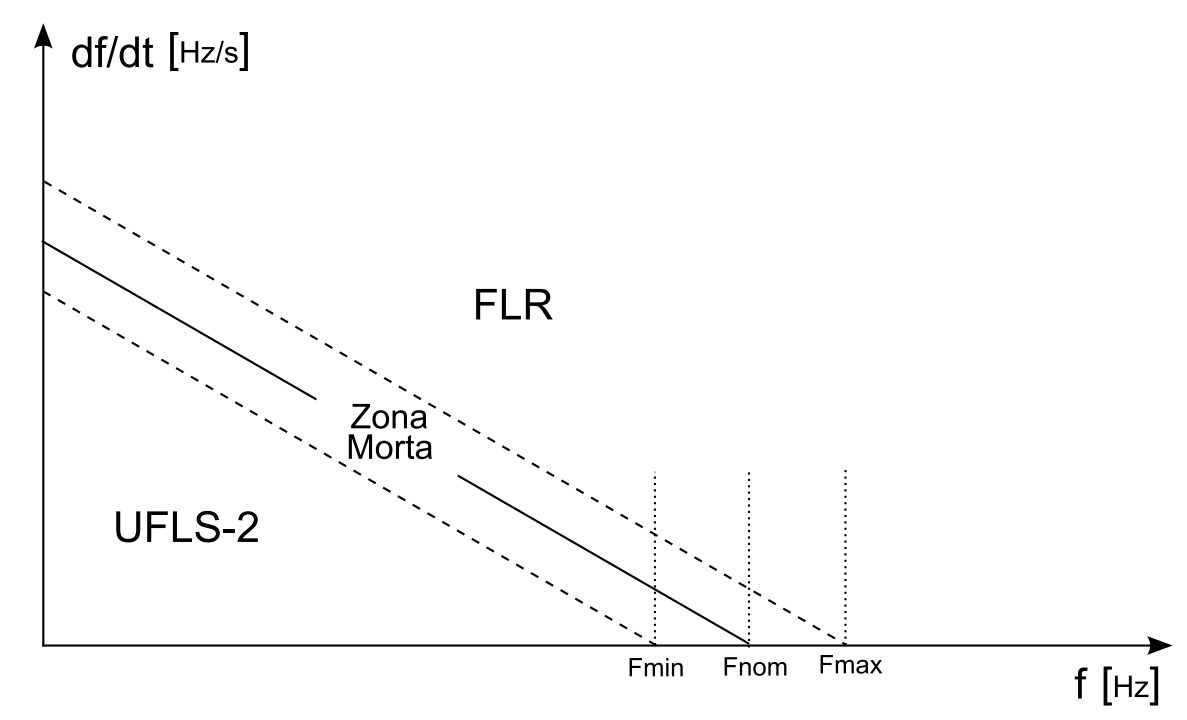

Figura 3.2: Plano de fase.

Quando $d f / d t<0$ uma rápida ação de corte de carga deve ser tomada, afim de prevenir um rápido declínio na velocidade.

Caso $f(t)<F_{\text {min }}$ e $d f / d t \geq 0$, sendo que $d f / d t \leq(d f / d t)_{\text {ref }}$, o corte de carga com atraso (UFLS-2) opera até alguns estágios fazendo com que a frequência retorne a zona 
morta. Esta zona morta é a região onde serão tomadas as ações de controle para que a freqência retorne ao seu valor nominal. Para casos em que a frequência atinja valores acima da nominal, cargas são novamente conectadas ao sistema, finalizando assim o processo de controle para a restauração do sistema (Chuvychin et al., 1996).

A utilização de controladores lógicos programáveis (CLPs) vem se tornando uma importante ferramenta para a implementação de esquemas de alívio de carga a partir dos anos 80. A atuação dos disjuntores durante o corte de carga pode ser programada e implementada utilizando-se CLPs. A vantagem apresentada pela aplicação dos CLPs em relação aos métodos convencionais (compostos por relés) está no acesso sobre o atual estado de operação do sistema. Entretanto, a aquisição de tais informações é restrita somente às partes do sistema que possuem monitoramento, e os cortes são pré-definidos através da construção de tabelas. Muitas vezes, a execução dos planos emergenciais utilizando tabelas não acompanha todas as mudanças de carga, geração e configurações de operação do sistema. Em (Shokooh et al., 2005), entretanto, foi proposto um esquema de corte de carga inteligente, que procura melhorar a implementação dos planos, através da atualização destas tabelas em tempo real de acordo com a mudança na topologia do sistema. Um computador servidor recebe as informações advindas do sistema de monitoramento e, baseado em um procedimento de cálculo, atualiza as tabelas de corte de carga contidas nos equipamentos CLPs.

Com a finalidade de reduzir os montantes de corte de cargas, técnicas de otimização podem ser aplicadas a uma função objetivo, que pode incluir, por exemplo, a dinâmica do sistema, montantes de corte disponíveis, limites operacionais, desvio da frequência nominal entre outros (Halevi e Kottick, 1993). A otimização é construída requerendo o mínimo valor de frequência permitido e a limitação sobre o montante total de corte de carga. O trabalho de corte de carga inteligente apresentado em (Shokooh et al., 2005) também beneficia-se do emprego de tais técnicas de otimização em seu algoritmo de cálculo.

Em (Hsu et al., 2008) é apresentada uma outra estratégia adaptativa para a execução dos esquemas de alívio de carga envolvendo redes neurais artificiais (RNAs) aplicadas em um sistema contendo unidades de cogeração. Este trabalho aborda um problema de corte de alívio de carga local. Em tal trabalho, considera-se que a concessionária de energia interrompa o seu fornecimento devido a alguma contingência e, assim, toda 
a demanda de uma determinada planta deve ser suprida por seu próprio sistema de cogeração. Selecionando a potência total de geração, valor total de demanda e o decaimento da frequência como entradas da RNA, o montante de corte de carga mínimo é determinado para manter a estabilidade do sistema. Porém, existe a necessidade da construção de um algoritmo capaz de efetuar o treinamento da RNA, sendo esta uma tarefa nada trivial, principalmente tratando-se de sistemas de grande porte.

Outro caso de instabilidade em que o corte de carga deve ser empregado está relacionado com o problema de subtensão. O incremento gradativo de carga pode levar o sistema a um problema de instabilidade de tensão ocasionado pela redução gradativa dos módulos das tensões em suas barras. O colapso de tensão pode ocorrer caso não exista um suporte de potência reativa adequado para o sistema (provido pelos capacitores em derivação, por exemplo). Para mais informações a respeito de esquemas de alívio de carga por subtensão, o trabalho apresentado em (Begovic et al., 1995) pode ser consultado, pois este assunto não encontra-se no escopo deste trabalho.

A busca para encontrar um modelo capaz de representar o comportamento dinâmico do SEP é de interesse comum entre todas as metodologias apresentadas no decorrer do texto. Na maioria dos casos, o comportamento da frequência do sistema é descrito através de linearizações e aproximações, realizadas a partir das equações diferenciais que descrevem o comportamento dinâmico do sistema, descritas em (2.39). Tais aproximações, além de simplificarem o modelo, permitem a inclusão de dispositivos de controle no mesmo, como o caso dos reguladores de velocidade.

Na prática, as metodologias mais utilizadas durante a construção dos planos de corte de carga são baseadas em modelos linearizados. Posteriormente, para a validação do plano proposto, simulações não lineares são efetuadas, mas nem sempre os resultados obtidos são realmente efetivos.

Com o intuito de aprimorar os modelos e metodologias usualmente empregados em estudos de corte de carga, este trabalho propõe a utilização de um modelo não linear baseado em funções energia, capaz de representar o comportamento do sistema de forma precisa para que os montantes de carga retirados durante condições de emergência sejam reduzidos. O modelo e o método proposto serão apresentados nos capítulos subsequentes. 



\section{Capítulo 4}

\section{Metodologia Proposta para}

\section{Determinação de Planos de Corte}

\section{de Carga}

Conforme já foi mencionado neste trabalho, as diversas metodologias empregadas para a determinação dos planos de corte de carga utilizam uma modelagem equivalente e linearizada do sistema. Estas simplificações, embora facilitem a implementação dos métodos, podem acarretar em um montante de corte de carga maior que o necessário para que o sistema se recomponha, de forma a garantir a estabilidade do mesmo.

Com o intuito de aprimorar os diversos métodos existentes, a metodologia apresentada neste trabalho utiliza uma representação não linear para o SEP, o que permite um estudo do comportamento dinâmico de suas máquinas de forma precisa. Portanto, os planos de alívio de carga podem ser determinados de forma eficiente, com o objetivo de reduzir o número de consumidores desprovidos de energia durante certas condições de subfrequência.

Entretanto, a escolha de um modelo mais completo para a representação do sistema (incluindo regulação de velocidade, dentre outros) acarreta num grande esforço na análise e determinação dos esquemas de alívio de carga para sistemas de grande porte. Sendo assim, é proposta neste trabalho uma ferramenta baseada nas funções energia do sistema capaz de auxiliar tais estudos, diminuindo assim tanto o esforço computacional quanto o empregado pelo projetista, pois evita-se assim as simulações não lineares 
realizadas para a validação do plano de corte encontrado.

Uma abordagem energética é empregada no problema. Assim, dada uma perda de geração é possível determinar o valor mínimo de frequência atingido pelo sistema sem que haja a necessidade de se conhecer a trajetória do mesmo. Portanto, neste trabalho é proposta uma metodologia baseada em uma função energia para o sistema buscando a determinação de planos de corte de carga.

\subsection{Modelagem da Função Energia para corte de carga mo- noestágio}

Métodos energéticos, os quais empregam o conceito de energia do sistema, são mais adequados para aplicações em tempo real, pois sem que haja a necessidade do conhecimento da solução do sistema pode-se extrair importantes informações e características do mesmo. Tal metodologia vem sendo aplicada em estudos de estabilidade transitória (Athay et al., 1979; Chiang et al., 1995; Silva et al., 2005).

O conjunto de equações diferenciais não lineares que representam os SEPs não possui, em geral, soluções analíticas. Embora estas soluções analíticas não existam, soluções numéricas podem ser determinadas com o emprego de métodos numéricos. Com o intuito de reduzir o esforço computacional envolvido no processo é proposta uma solução energética capaz de determinar o valor mínimo de frequência atingido pelo sistema, sem que haja a necessidade do conhecimento exato da trajetória do sistema durante o período pré-corte de carga.

Seja $\varphi(t)$ a solução de uma equação diferencial do sistema $\dot{x}=f(x)$. Uma função $V(\varphi(t))$, tal que $V: R^{n} \longrightarrow R$, é dita ser uma quantidade conservada pelo campo vetorial se $\dot{V}=0$, ou seja, $V(\varphi(t))$ é constante ao longo de toda solução $\forall t$. Assim, $V$ é conhecida como sendo uma primeira integral deste sistema. Como este sistema admite primeira integral pode-se dizer que ele é um sistema conservativo.

É possível determinar uma função energia para sistemas elétricos, desde que a constante de amortecimento do sistema $(D)$ seja desprezada, pois este termo é responsável pela dissipação de energia do sistema, o que caracterizaria o sistema como não conser- 
vativo (Chiang et al., 1995). Sendo assim, utilizando a Equação (2.39), tem-se:

$$
\begin{gathered}
\dot{\delta}=\omega \\
M \cdot \ddot{\delta}=P_{m}-\left|E^{\prime}\right|^{2} \cdot G_{11}-C_{12} \cdot \operatorname{sen}(\delta)-D_{12} \cdot \cos (\delta)
\end{gathered}
$$

onde $E^{\prime}$ é a f.e.m interna do gerador equivalente. Multiplicando a velocidade angular $(\omega)$ em ambos os lados, obtém-se:

$$
M \cdot \omega \cdot \frac{d \omega}{d t}-P_{m} \cdot \frac{d \delta}{d t}+\left|E^{\prime}\right|^{2} \cdot G_{11} \cdot \frac{d \delta}{d t}+C_{12} \cdot \operatorname{sen}(\delta) \cdot \frac{d \delta}{d t}+D_{12} \cdot \cos (\delta) \cdot \frac{d \delta}{d t}=0
$$

Observe que a Equação (4.3) pode ser definida como a derivada temporal de uma função $V$. Assim:

$$
\dot{V}(\delta, \omega)=M \cdot \omega \cdot \frac{d \omega}{d t}-P_{m} \cdot \frac{d \delta}{d t}+\left|E^{\prime}\right|^{2} \cdot G_{11} \cdot \frac{d \delta}{d t}+C_{12} \cdot \operatorname{sen}(\delta) \cdot \frac{d \delta}{d t}+D_{12} \cdot \cos (\delta) \cdot \frac{d \delta}{d t}
$$

Integrando (4.3), utilizando como referência angular $\delta_{0}$ (ângulo onde $\omega=0$ ), obtêmse:

$$
\frac{M \cdot \omega^{2}}{2}-P_{m} \int_{\delta_{0}}^{\delta} d \delta+\left|E^{\prime}\right|^{2} \cdot G_{11} \int_{\delta_{0}}^{\delta} d \delta+C_{12} \int_{\delta_{0}}^{\delta} \operatorname{sen}(\delta) \cdot d \delta+D_{12} \int_{\delta_{0}}^{\delta} \cos (\delta) \cdot d \delta=0
$$

Portanto:

$$
\begin{aligned}
V(\delta, \omega)= & \frac{M \cdot \omega^{2}}{2}+\left(\left|E^{\prime 2}\right| \cdot G_{11}-P_{m}\right)\left(\delta-\delta_{0}\right)+C_{12}\left(\cos \left(\delta_{0}\right)-\cos (\delta)\right)+ \\
& +D_{12}\left(\operatorname{sen}(\delta)-\operatorname{sen}\left(\delta_{0}\right)\right)
\end{aligned}
$$

Divide-se a expressão anterior em duas parcelas:

$$
V(\delta, \omega)=V_{k}(\omega)+V_{p}(\delta, \omega)
$$


Assim,

$$
\left\{\begin{aligned}
V_{k}= & \frac{M \cdot \omega^{2}}{2} \\
V_{p}= & \left(\left|E^{\prime 2}\right| \cdot G_{11}-P_{m}\right)\left(\delta-\delta_{0}\right)+C_{12}\left(\cos \left(\delta_{0}\right)-\cos (\delta)\right)+ \\
& +D_{12}\left(\operatorname{sen}(\delta)-\operatorname{sen}\left(\delta_{0}\right)\right)
\end{aligned}\right.
$$

Portanto $V(\delta, \omega)$ é dita como uma primeira integral do sistema, onde $V_{k}(\omega)$ é a parcela relativa a energia cinética e $V_{p}(\delta, \omega)$ é a parcela relativa a energia potencial. A Equação (4.8) também pode ser definida como uma função energia para um sistema conservativo.

Para as três topologias relativas ao problema de corte de carga, tomando o mesmo ângulo de referência $\delta_{0}$, definem-se as funções energia a seguir:

- Sistema pré-perda de geração:

$$
\left\{\begin{aligned}
V_{k}^{p r g} & =\frac{M^{p r g} \cdot \omega^{2}}{2} \\
V_{p}= & \left(\left|E^{\prime 2}\right| \cdot G_{11}^{p r g}-P_{m}\right)\left(\delta-\delta_{0}\right)+C_{12}^{p r g}\left(\cos \left(\delta_{0}\right)-\cos (\delta)\right)+ \\
& +D_{12}^{p r g}\left(\operatorname{sen}(\delta)-\operatorname{sen}\left(\delta_{0}\right)\right)
\end{aligned}\right.
$$

- Sistema pré-corte de carga ou pós-perda de geração:

$$
\left\{\begin{aligned}
V_{k}^{p r c} & =\frac{M^{p r c} \cdot \omega^{2}}{2} \\
V_{p}= & \left(\left|E^{\prime 2}\right| \cdot G_{11}^{p r c}-P_{m}\right)\left(\delta-\delta_{0}\right)+C_{12}^{p r c}\left(\cos \left(\delta_{0}\right)-\cos (\delta)\right)+ \\
& +D_{12}^{p r c}\left(\operatorname{sen}(\delta)-\operatorname{sen}\left(\delta_{0}\right)\right)
\end{aligned}\right.
$$

- Sistema pós-corte de carga:

$$
\left\{\begin{aligned}
V_{k}^{p p c} & =\frac{M^{p p c} \cdot \omega^{2}}{2} \\
V_{p}= & \left(\left|E^{\prime 2}\right| \cdot G_{11}^{p p c}-P_{m}\right)\left(\delta-\delta_{0}\right)+C_{12}^{p p c}\left(\cos \left(\delta_{0}\right)-\cos (\delta)\right)+ \\
& +D_{12}^{p p c}\left(\operatorname{sen}(\delta)-\operatorname{sen}\left(\delta_{0}\right)\right)
\end{aligned}\right.
$$

\subsection{Critério das Áreas}

Para o problema de estabilidade transitória foi desenvolvida uma metodologia, baseada no conceito de energia do sistema, denominada de critério das áreas iguais. A 
criação deste método possibilitou que ações de correção pudessem ser tomadas em tempo real evitando que o sistema se torne instável mesmo em condições não corriqueiras e não testadas na fase de projeto do sistema de proteção. Assim, com a utilização das curvas de potência do sistema encontra-se o ângulo crítico de abertura através de um cálculo de áreas (Bretas e Alberto, 2000).

O cálculo das áreas na curva de potência corresponde à energia potencial do sistema. Portanto, algumas informações podem ser retiradas destes gráficos e aplicadas no problema de corte de carga. A seguir serão desenvolvidas duas expressões para a determinação do valor mínimo de frequência atingido pelo sistema para duas situações distintas.

Inicialmente considere que o sistema encontre-se em equilíbrio e esteja operando no ponto 1 sobre a curva $P_{e}^{p r g}$, indicado no gráfico da Figura 4.1. A energia cinética neste ponto é nula, pois o sistema opera na velocidade síncrona. Dada a perda de geração o sistema migra instantaneamente para o ponto 2 , localizado sob a curva $P_{e}^{p r c}$. A partir do ponto 2 podem ser verificadas duas condições.

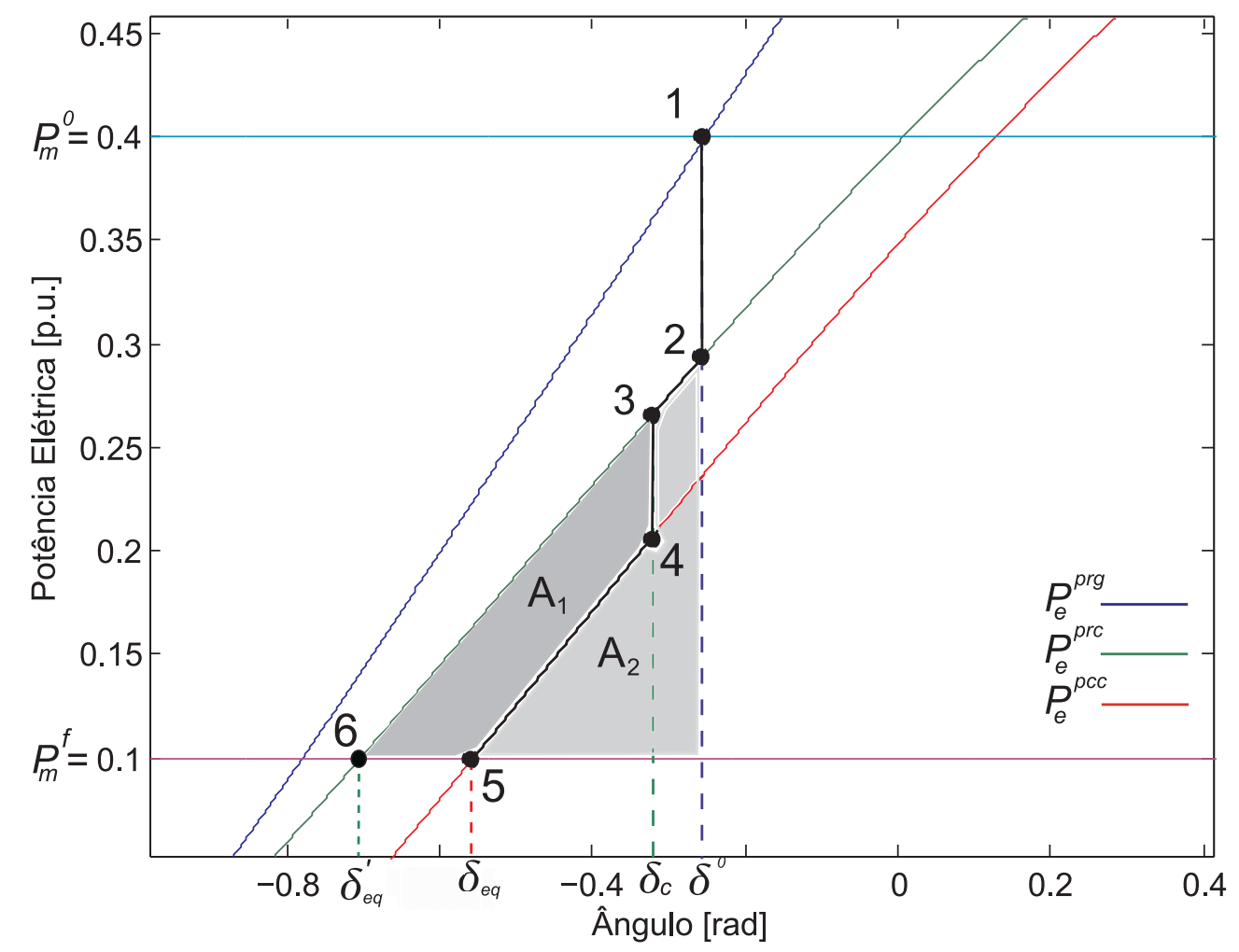

Figura 4.1: Critério das áreas iguais adaptado ao corte de carga. 
Na primeira delas considera-se que o sistema não possui um plano de corte de carga. Sendo assim, o sistema migrará do ponto 2 para o ponto 6 onde será estabelecido o novo ponto de equilíbrio após alguns instantes de oscilação. Nesta condição a área $A_{3}=A_{1}+A_{2}$ representa a energia potencial que será convertida em energia cinética caso nenhum corte de carga seja efetuado.

Já na segunda opção considera-se que o sistema possui um plano de corte de carga constituído por apenas um estágio de corte. No instante em que o corte de carga é efetuado o sistema migra do ponto 3 para o ponto 4 sob a curva $P_{e}^{p c c}$. Posteriormente, o sistema atinge o equilíbrio representado pelo ponto 5 , após alguns instantes de oscilação. A área $A_{2}$ representa a energia potencial que será convertida em cinética para o caso em que o corte de carga for necessário.

Isolando-se a velocidade na expressão da energia cinética em (4.8), obtém-se a Equação (4.12).

$$
\omega=\omega_{0}-\left|\sqrt{\frac{2 \cdot V_{k}}{M}}\right|
$$

Caso o sistema não possua corte de carga, têm-se:

$$
V_{k}=A_{3}
$$

A substituição de (4.13) em (4.12) resulta na Equação (4.14).

$$
\omega_{s c}^{\min }=\omega_{0}-\left|\sqrt{\frac{2 \cdot A_{3}}{M^{p r c}}}\right|,
$$

onde $\omega_{s c}^{\text {min }}$ representa a frequência mínima atingida pelo sistema quando o mesmo não possui esquema de alívio de carga.

Caso o sistema possua corte de carga, têm-se:

$$
V_{k}=A_{2}
$$

Substituindo (4.15) em (4.12) obtém-se a Equação (4.16).

$$
\omega_{c c}^{\min }=\omega_{0}-\left|\sqrt{\frac{2 \cdot A_{2}}{M^{p r c}}}\right|
$$


onde $\omega_{c c}^{\text {min }}$ representa a frequência mínima atingida pelo sistema quando o mesmo possui um plano de corte de carga com um estágio.

Portanto, através da Figura (4.1) fica evidente de que quanto maior se torna a área $A_{2}$, ou seja, quanto maior for o tempo em que o corte de carga for acionado, menor será a frequência atingida pelo sistema.

Através de $\omega_{s c}^{\text {min }}$ verifica-se se existe ou não a necessidade de corte de carga para uma determinada contingência. Outra contribuição é verificada através de $\omega_{c c}^{\text {min }}$ que serve como um indicativo informando se o corte proposto é suficiente.

O critério de áreas desenvolvido para o estudo de casos de corte de carga informa os mínimos valores de frequência atingidos pelo sistema com ou sem corte de carga. Entretanto, o instante de tempo ou frequência de corte de carga não podem ser extraídos diretamente por esta metodologia.

O gráfico de potência apresentado pela Figura (4.1) mostra o típico comportamento de um SEP durante uma medida de alívio de carga. O sistema modelado será mostrado e explicado com maiores detalhes numa seção posterior a esta.

\subsection{Proposta do Trabalho}

A seguir será apresentada a metodologia proposta neste trabalho, que basicamente consiste na determinação da frequência de corte de carga. De forma a facilitar o entendimento do método, o plano será constituído por apenas um estágio de corte durante o processo de alívio de carga.

\subsubsection{Corte de carga monoestágio}

Primeiramente analisam-se as possibilidades tanto sobre as perspectivas de perda de geração quanto dos montantes de carga que estarão disponíveis para a construção dos planos emergenciais. O conjunto de equações diferenciais no período pré-corte de carga deve ser resolvido numericamente como se o sistema não dispusesse de qualquer plano de corte. Com a utilização das funções energia (já obtidas para o sistema) não será necessária a resolução do conjunto de equações diferenciais relativas ao período pós-corte de carga. Isto traz uma grande economia no tempo de processamento e na mão de obra 
empregada pelo projetista. Sendo assim, somente faz-se necessário a construção das funções energia referentes a cada possibilidade de corte, informações essas necessárias para que o plano de corte seja determinado.

Através do valor de frequência crítica estipulado para o sistema $\left(\omega^{c r}\right)$, juntamente com a Equação (4.10), determina-se a energia cinética crítica.

$$
V_{k}^{c r}=\frac{\left(\omega_{0}-\omega^{c r}\right)^{2} \cdot M^{p r c}}{2}
$$

Portanto, $V_{k}^{c r}$ é o máximo valor de energia cinética aceitável pelo sistema, de modo que a frequência crítica pré-estipulada não seja ultrapassada.

A Figura 4.2 apresenta o comportamento típico para as funções energia de um SEP com $D=0$, no caso onde ocorre uma perda de geração seguida pela retirada de uma parcela de carga no instante $t_{c}$. Este gráfico foi obtido após várias simulações utilizando-se o sistema equivalente em estudo, este sistema é apresentado no capítulo seguinte. As curvas em azul e marrom representam as energias totais do sistema nos períodos pré-corte de carga e pós-corte de carga, respectivamente. Em verde e vermelho estão as curvas de energia potencial nos períodos pré-corte de carga e pós-corte de carga, respectivamente.

Para um sistema conservativo, sabe-se que o ponto onde o sistema atinge o menor valor de energia potencial é exatamente onde obtém-se o maior valor de energia cinética. Portanto, tendo encontrado o menor valor de energia potencial para o sistema é possível determinar qual o máximo valor de energia cinética atingido pelo mesmo. A Figura 4.2, apresenta uma forma de se obter tal valor de energia. Desta forma, a seguinte equação pode ser extraída:

$$
V_{k}^{\max }+V_{p}^{\min }=V_{t o t}
$$

Sendo assim, dado um valor máximo de energia cinética permitido pelo sistema, juntamente ao valor mínimo de energia potencial $\left(V_{p}^{\text {min }}\right)$ atingido pelo mesmo após o corte de carga (obtido através da simulação), determina-se um valor crítico de energia total denominado $V_{t o t}^{c r}$. Assim, obtém-se a relação abaixo:

$$
V_{t o t}^{c r}=V_{k}^{c r}+V_{p}^{\text {min }}
$$




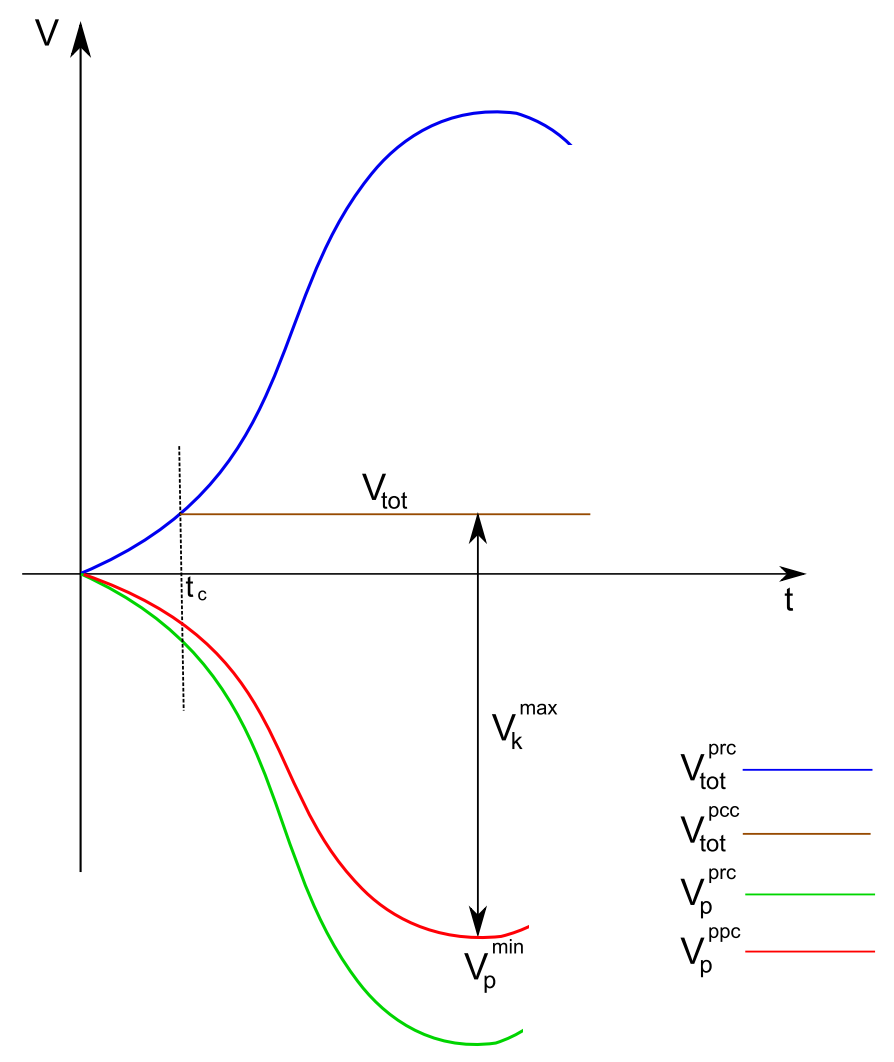

Figura 4.2: Funções energia.

A Equação (4.19) fornece o máximo valor de energia que pode ser atingido pelo sistema após a perda de geração, ou seja, antes que o sistema atinga tal valor de energia o corte de carga deve ser efetuado. Assim, define-se $V_{\text {tot }}^{c}$ como a energia total de corte, conforme a expressão abaixo:

$$
V_{t o t}^{c}<V_{t o t}^{c r}=V_{k}^{c r}+V_{p}^{\text {min }}
$$

Utilizando o instante de tempo onde $V_{\text {tot }}^{c}$ ocorre, é possível obter o valor de energia cinética de corte denominado $V_{k}^{\max }$, e consequentemente, o valor de frequência de corte de carga pode ser determinado através da equação abaixo:

$$
\omega_{c}=\omega_{0}-\left|\sqrt{\frac{2 \cdot V_{k}^{\max }}{M^{p r c}}}\right|
$$

Os planos de corte de carga são constituídos pelos montantes de carga que serão retirados durante a condição de subfrequência e pelos respectivos valores de frequência $\omega^{c}$ correspondentes a cada um destes montantes. O método proposto neste trabalho é 
capaz de determinar $\omega^{c}$ de forma que a frequência crítica $\left(\omega^{c r}\right)$ não seja atingida. Sendo assim, um corte mais conservador pode ser encontrado. Para isto, basta que o corte de carga seja efetuado com um valor de frequência superior ao encontrado por (4.21) ou através da escolha de um montante de carga superior ao considerado durante a fase de projeto.

Apesar de não encontrar-se no escopo deste trabalho o corte de carga multiestágio é utilizado com o intuito de reduzir ainda mais o número de consumidores desprovidos de energia elétrica durante condições de subfrequência. Conforme visto através das metodologia apresentadas na revisão bibliográfica deste trabalho, os montantes de carga vão sendo retirados na medida em que a frequência do sistema descresce e, posteriormente, o mesmo retorna a uma nova condição de equilíbrio. 


\section{Capítulo 5}

\section{Resultados}

A seguir será apresentado o sistema elétrico de potência utilizado nos testes da metodologia proposta. Para um melhor entendimento do problema serão estudados os comportamentos da frequência e da potência elétrica dado um plano de corte qualquer contendo um único estágio.

Logo a seguir, dado um montante de carga, a metodologia proposta determinará a frequência de corte de carga para um plano de alívio de carga monoestágio. Será também realizada uma comparação entre as representações linearizada e não linear do SEP utilizado.

\subsection{Descrição do sistema em estudo}

Considere o SEP representado pela Figura 5.1. Este contém um conjunto de quatro geradores idênticos conectados em paralelo, com suas reatâncias transitórias de eixo direto representadas por $x_{d}^{\prime}$. A rede elétrica é constituída por duas reatâncias $x_{t}$ e $x_{l}$, sendo que $S_{l f}$ e $S_{l c}$ são as potências consumidas por duas cargas conectadas ao mesmo barramento. O montante de carga representado por $S_{l c}$ será desconectada do sistema durante o processo de alívio de carga. O restante do sistema é grande o suficiente para que seja considerado como um barramento infinito. O barramento infinito equivale a uma máquina de inércia infinita, dotada de uma capacidade de geração ilimitada, sendo capaz de fornecer ou absorver potência elétrica a uma velocidade constante. Desta forma, define-se a referência angular para o sistema através da tensão no barramento 
infinito.

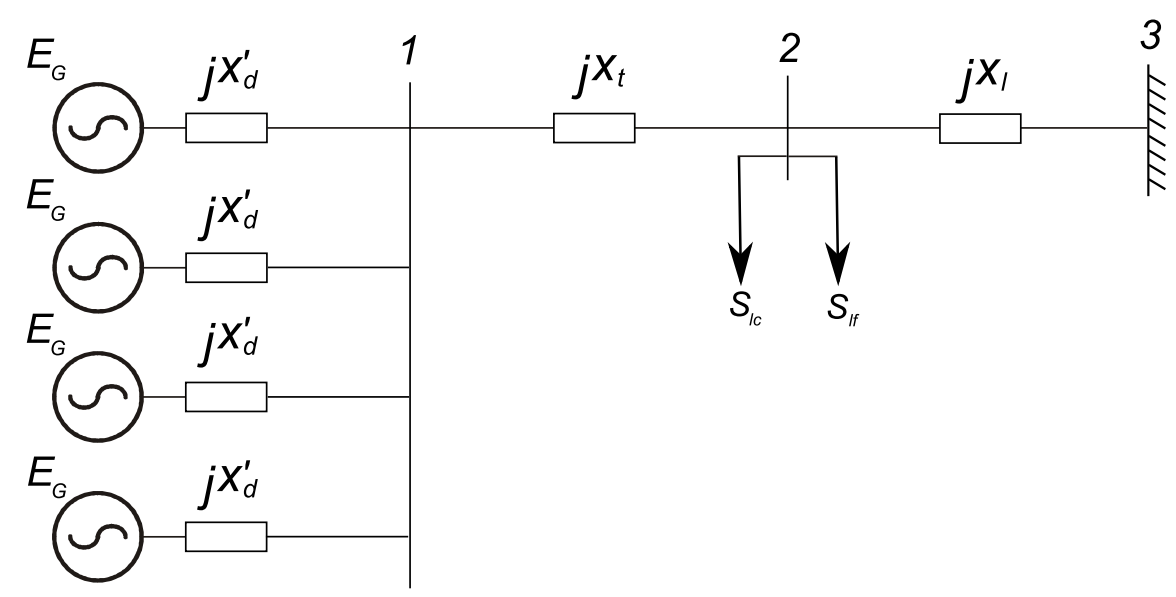

Figura 5.1: SEP simplificado.

O sistema da Figura 5.1 pode ser representado de forma equivalente pelo sistema da Figura 5.2, onde $x_{e q}$ representa a reatância transitória de eixo direto equivalente do conjunto de geradores do novo sistema, obtida através da combinação em paralelo entre as reatâncias $x_{d}^{\prime}$. O gerador equivalente possui uma constante $M_{e q}$ resultante da soma de todas as constantes $M$ individuais de cada unidade.

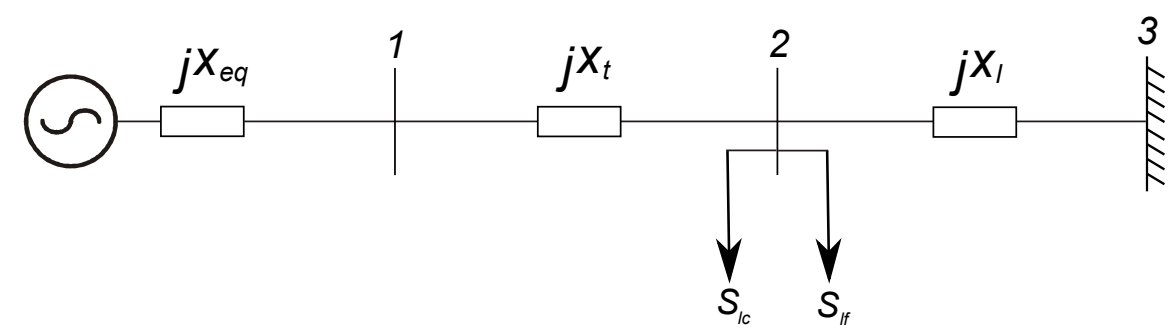

Figura 5.2: SEP simplificado equivalente.

O problema em estudo consiste na perda de três das quatro unidades geradoras que compõem o sistema. Um único estágio de corte de carga é definido para que o valor da frequência crítica estipulado em $58 \mathrm{~Hz}$ não seja atingido. Assim, para uma frequência de corte de carga ajustada em $59 \mathrm{~Hz}$, o montante de carga representado pela admitância $y_{l c}$ será desconectado, valor este encontrado através da Equação 2.21.

O programa computacional ANAREDE foi utilizado para a determinação do ponto de equilíbrio do sistema pré-perda de geração. O método para a resolução do fluxo de carga empregado foi o de Newton-Raphson, com tolerância de convergência do erro para a potência ativa de $1 M W$ e tolerância de convergência do erro para potência reativa de 
$1 M V A r$.

A Tabela 5.1 mostra os dados do sistema equivalente em p.u. juntamente com as tensões nas barras advindas do fluxo de carga do mesmo. A base de potência utilizada foi de $100 M V A$.

Tabela 5.1: Dados SEP equivalente.

\begin{tabular}{|c|c|c|}
\hline$V_{1}=0,753 \angle-18,7^{\circ}$ & $V_{2}=0,769 \angle-30,5^{\circ}$ & $V_{3}=1 \angle 0^{\circ}$ \\
\hline$x_{e q}=j 0,1$ & $x_{t}=j 0,3$ & $x_{l}=j 0,8$ \\
\hline \multicolumn{2}{|c|}{$S_{l f}+S_{l c}=0,89+j 0,01$} & $P_{m}=0,4$ \\
\hline \multicolumn{2}{|c|}{$M_{e q}=0,001 \quad D=0,0003$} \\
\hline
\end{tabular}

A matriz $Y_{x d}$ que é composta somente pelas admitâncias dos geradores contém a admitância relativa à reatância $x_{l}$. Caso esta medida não fosse tomada, ocorreria uma inconsistência no modelo proposto, pois a matriz $Y_{x d}$ somente seria constituída pela admitância transitória equivalente do conjunto de geradores. Portanto, não seria possível reduzir o sistema a todos os nós que injetam corrente no mesmo, lembrando que o barramento infinito injeta corrente no sistema da mesma forma que o conjunto de geradores assim o faz. A forma encontrada para que tal problema fosse solucionado, foi através da inserção da admitância relativa a $x_{l}$ na matriz de admitância transitória do sistema. Desta forma, o barramento adjunto ao barramento infinito foi preservado durante o processo de redução (nó 2), de maneira a representar a injeção de corrente relativa ao barramento infinito.

$$
Y_{x d}=\left[\begin{array}{cc}
\frac{1}{j x_{d}^{\prime}} & 0 \\
0 & \frac{1}{j x_{l}}
\end{array}\right]
$$

Define-se uma nova matriz denominada $Y_{b u s L}$ no período pré-perda de geração, para que a força eletromotriz do gerador equivalente seja calculada posteriormente a partir dos dados fornecidos pela Tabela 5.1. Portanto:

$$
Y_{\text {bus } L}=Y_{\text {bus }}^{\prime}+Y_{l}^{\prime}=\left[\begin{array}{ccc}
\frac{1}{j x_{t}} & \frac{-1}{j x_{t}} & 0 \\
\frac{-1}{j x_{t}} & \left(\frac{1}{j x_{t}}+\frac{1}{j x_{l}}\right) & \frac{-1}{j x_{l}} \\
0 & \frac{-1}{j x_{l}} & \frac{1}{j x_{l}}
\end{array}\right]+\left[\begin{array}{ccc}
0 & 0 & 0 \\
0 & \left(y_{l c}+y_{l f}\right) & 0 \\
0 & 0 & 0
\end{array}\right]
$$




$$
Y_{\text {busL }}=\left[\begin{array}{ccc}
j 3,333 & j 3,333 & 0 \\
j 3,333 & 1,505-j 4,600 & j 1,250 \\
0 & j 1,250 & -j 1,250
\end{array}\right]
$$

A corrente do gerador equivalente pode ser determinada utilizando-se a expressão abaixo:

$$
I_{i}=\sum_{j=1}^{n} Y_{i j} \cdot E_{j}
$$

Em (5.4) $Y_{i j}$ 's são os elementos da matriz $Y_{b u s L}$ e $E_{j}$ é a tensão na barra que injeta a corrente $I_{i}$ no sistema. Portanto, a corrente do gerador equivalente fica:

$$
\begin{gathered}
I_{G}=Y_{11} \cdot V_{1}+Y_{12} \cdot V_{2}+Y_{13} \cdot V_{3} \\
I_{G}=\frac{1}{j x_{t}} \cdot V_{1}-\frac{1}{j x_{t}} \cdot V_{2}+0 \cdot V_{3}=0,496+j 0,169
\end{gathered}
$$

Sendo assim, o fasor tensão na barra interna do gerador será:

$$
E^{\prime}=V_{1}+I_{G} \cdot j x_{d}^{\prime}=0,755 \angle-14,72^{\circ}
$$

Determinado o ângulo da tensão interna do gerador equivalente, obtém-se todas as condições iniciais necessárias para que o sistema pré-perda de geração seja construído.

Finalmente, a matriz completa do sistema pode ser expressa por:

$$
\begin{gathered}
\widetilde{Y}_{B U S}=\left[\begin{array}{cccc}
\frac{1}{j x_{d}^{\prime}} & 0 & \frac{-1}{j x_{d}^{\prime}} & 0 \\
0 & \frac{1}{j x_{l}} & 0 & \frac{-1}{j x_{l}} \\
\frac{-1}{j x_{d}^{\prime}} & 0 & \left(\frac{1}{j x_{t}}+\frac{1}{j x_{d}^{\prime}}\right) & \frac{-1}{j x_{t}} \\
0 & \frac{-1}{j x_{l}} & \frac{-1}{j x_{t}} & \left(\frac{1}{j x_{t}}+y_{l c}+y_{l f}+\frac{1}{j x_{l}}\right)
\end{array}\right] \\
\widetilde{Y}_{B U S}=\left[\begin{array}{cccc}
-j 10 & 0 & j 10 & 0 \\
0 & -j 1,25 & 0 & j 1,25 \\
j 10 & 0 & -j 13,33 & j 3,33 \\
0 & j 1,25 & j 3,33 & 1,51-j 4,6
\end{array}\right]
\end{gathered}
$$

Aplicando o processo de redução de rede, apresentado no capítulo de modelagem, 
para que o sistema represente somente as barras de injeção de corrente, obtém-se:

$$
Y_{R E D}=G+j B
$$

São definidas as matrizes reduzidas para o sistema estudado sob as três diferentes topologias envolvidas no processo de alívio de carga. Primeiramente tem-se a matriz reduzida no período pré-perda de geração dada pela Equação (5.11). A configuração do sistema neste período é mostrada na Figura 5.3.

$$
Y_{R E D}^{p r g}=\left[\begin{array}{ll}
0,571-j 1,069 & 0,286+j 0,715 \\
0,286+j 0,715 & 0,143-j 0,892
\end{array}\right]
$$

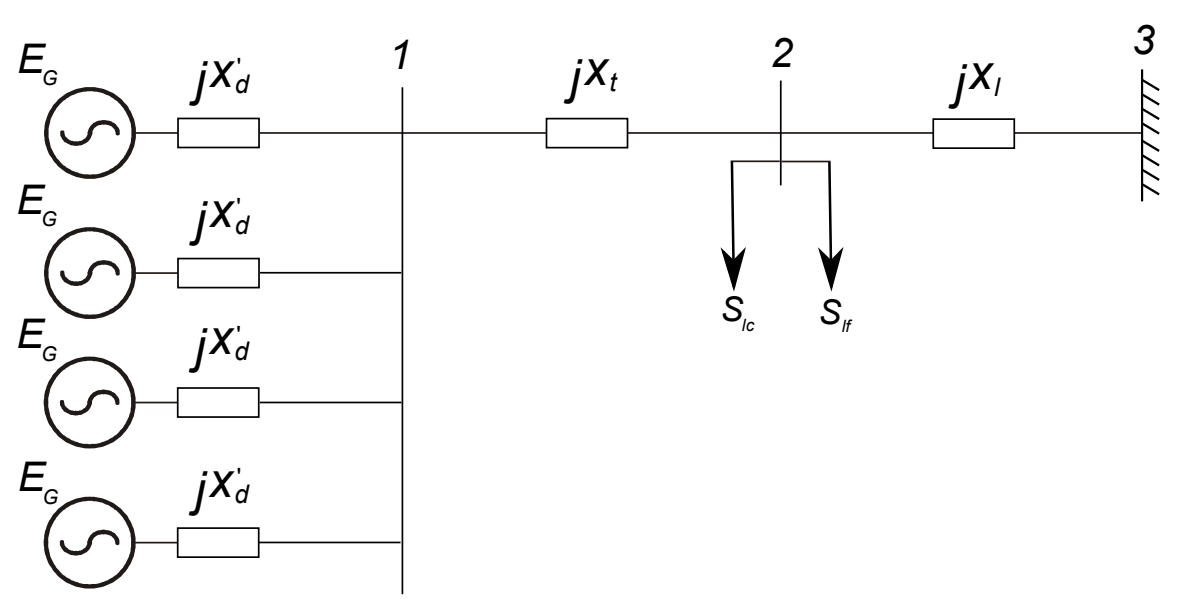

Figura 5.3: SEP no período pré-perda de geração.

Devido à perda de geração, a admitância equivalente do conjunto tem seu valor reduzido. Assim, o período denominado de pré-corte de carga é representado pela matriz reduzida $Y_{R E D}^{p r c}$ e a configuração do sistema neste instante é vista pela Figura 5.4.

$$
Y_{R E D}^{p r c}=\left[\begin{array}{ll}
0,322-j 0,851 & 0,282+j 0,505 \\
0,282+j 0,505 & 0,247-j 0,808
\end{array}\right]
$$

Após o corte de carga a admitância $y_{l c}$ é retirada do sistema, o que resulta na matriz reduzida pós-corte de carga. Assim, neste período obtém-se a matriz dada pela 


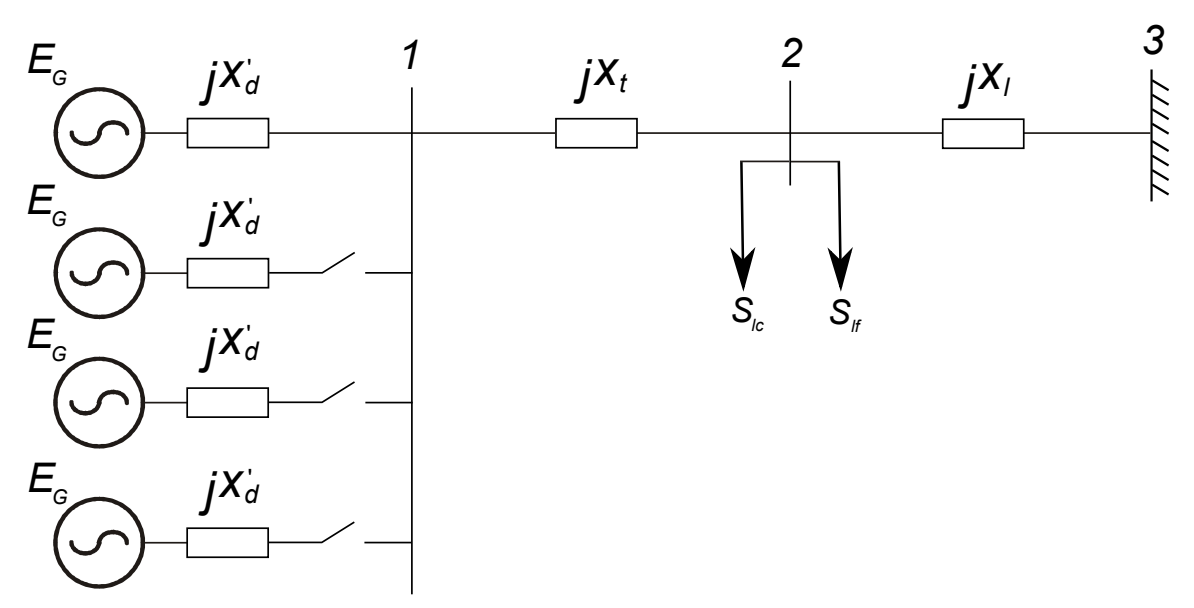

Figura 5.4: SEP no período pré-corte de carga.

Equação 5.13.

$$
Y_{R E D}^{p p c}=\left[\begin{array}{ll}
0,282-j 0,797 & 0,247+j 0,553 \\
0,247+j 0,553 & 0,216-j 0,766
\end{array}\right]
$$

A configuração do sistema no período pós-corte de carga é mostrada na Figura 5.5.

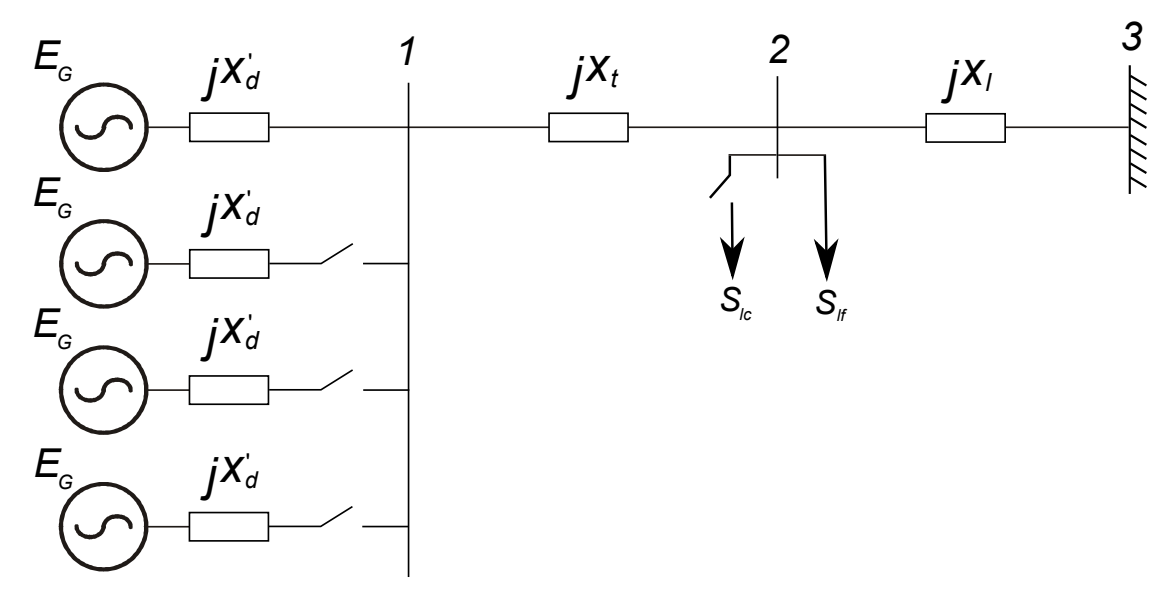

Figura 5.5: SEP no período pós-corte de carga.

Por simplicidade considerou-se também que a constante de amortecimento equivalente do sistema reduzido não se altera durante todas as etapas.

Portanto, utilizando-se a Equação (2.39) e definindo que o montante de corte de carga será retirado quando a frequência do sistema atingir $59 \mathrm{~Hz}$, os conjuntos de equações diferenciais que descrevem o comportamento do sistema para o problema de corte de carga proposto são: 
- Sistema pré-perda de geração:

$$
\begin{aligned}
& \left\{\begin{array}{l}
\dot{\omega}=-0.3 \cdot \omega+74,227-540,057 \cdot \operatorname{sen}(\delta)-215,770 \cdot \cos (\delta) \\
\dot{\delta}=\omega
\end{array}\right. \\
& \left\{\begin{array}{l}
t \leq 0 \\
\delta(t)=-0,257 \mathrm{rad} \\
\dot{\delta}(t)=0
\end{array}\right.
\end{aligned}
$$

- Sistema pré-corte de carga ou pós-perda de geração:

$$
\begin{aligned}
& \left\{\begin{array}{l}
\dot{\omega}=-1.2 \cdot \omega-334,622-1525,030 \cdot \operatorname{sen}(\delta)-851,49 \cdot \cos (\delta) \\
\dot{\delta}=\omega
\end{array}\right. \\
& \left\{\begin{array}{l}
0<t \leq 9,018 \mathrm{~ms} \\
\delta(0)=-0,257 \mathrm{rad} \\
\dot{\delta}(0)=0
\end{array}\right.
\end{aligned}
$$

- Sistema pós-corte de carga:

$$
\begin{aligned}
& \left\{\begin{array}{l}
\dot{\omega}=-1.2 \cdot \omega-244,030-1669,111 \cdot \operatorname{sen}(\delta)-746,486 \cdot \cos (\delta) \\
\dot{\delta}=\omega
\end{array}\right. \\
& \left\{\begin{array}{l}
t>9,018 \mathrm{~ms} \\
\delta\left(t_{c}\right)=\delta\left(t_{c}\right)^{\mathrm{prc}}=-0,287 \mathrm{rad} \\
\dot{\delta}\left(t_{c}\right)=-6,437 \mathrm{rad} / \mathrm{s}
\end{array}\right.
\end{aligned}
$$

onde $M^{p p c}=M^{p r c}=2,5 \times 10^{-4} p \cdot u$.

As soluções das equações diferenciais foram obtidas através da função ode45 do programa computacional MATLAB na versão R2008a, assim, os valores de tc e $\delta(0)$ puderam ser determinados. As análises referentes ao comportamento das potências e da frequência durante o processo de alívio de carga serão realizadas a seguir. 


\subsubsection{Comportamento da frequência}

O efeito que o corte de carga produz sobre o comportamento da frequência do sistema após a perda de grande parte da geração, para o sistema em estudo, pode ser visto através da Figura 5.6.

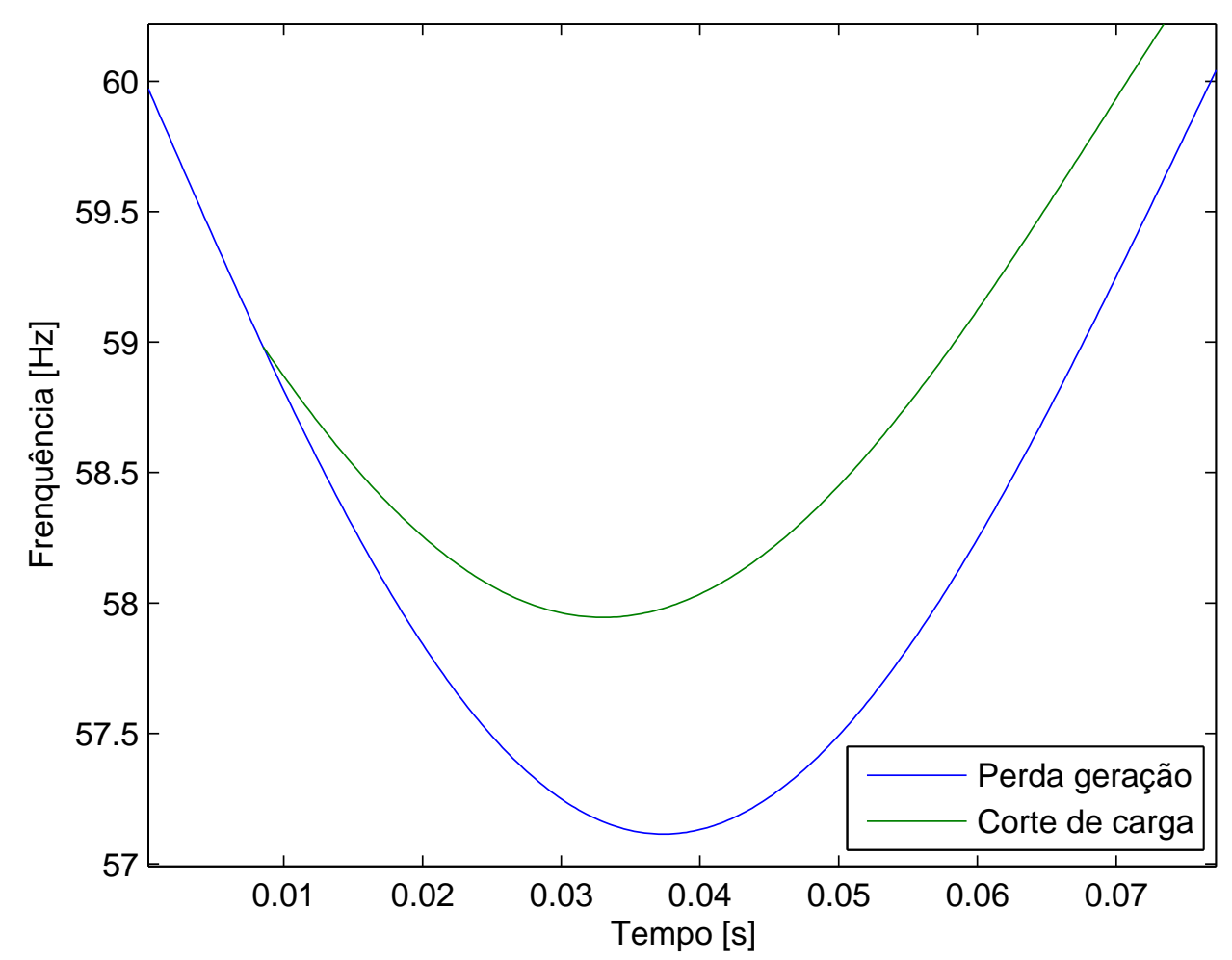

Figura 5.6: Variação da frequência durante o corte de carga.

Caso nenhuma medida corretiva fosse tomada a curva em azul representaria a frequência no barramento de geração. Note que a frequência atingiria um valor abaixo da frequência mínima permitida, estipulada em $58 \mathrm{~Hz}$, podendo ocasionar o desligamento do conjunto de geradores pela atuação dos relés de proteção, através da função de subfrequência.

Afim de evitar a completa perda do sistema de geração, quando o sistema atinge a frequência de $59 \mathrm{~Hz}, 20 \%$ da carga é desconectada. Como pode ser visto pelo gráfico, a curva verde mostra o comportamento da frequência para o sistema quando o mesmo é constituído por apenas um estágio de corte de carga. Portanto, fica clara a melhoria propiciada pelo esquema de alívio de carga adotado, pois o valor mínimo atingido pela 
frequência foi reduzido.

\subsubsection{Comportamento da potência elétrica}

Para uma melhor compreensão do comportamento do sistema no processo do corte de carga, observe o gráfico da Figura 5.7, onde estão representadas as curvas de potência elétrica e mecânica em função do ângulo do gerador equivalente para as três condições: 1) Sistema pré-perda de geração; 2) Sistema pós-perda degeração; 3) Sistema pós-corte de carga.

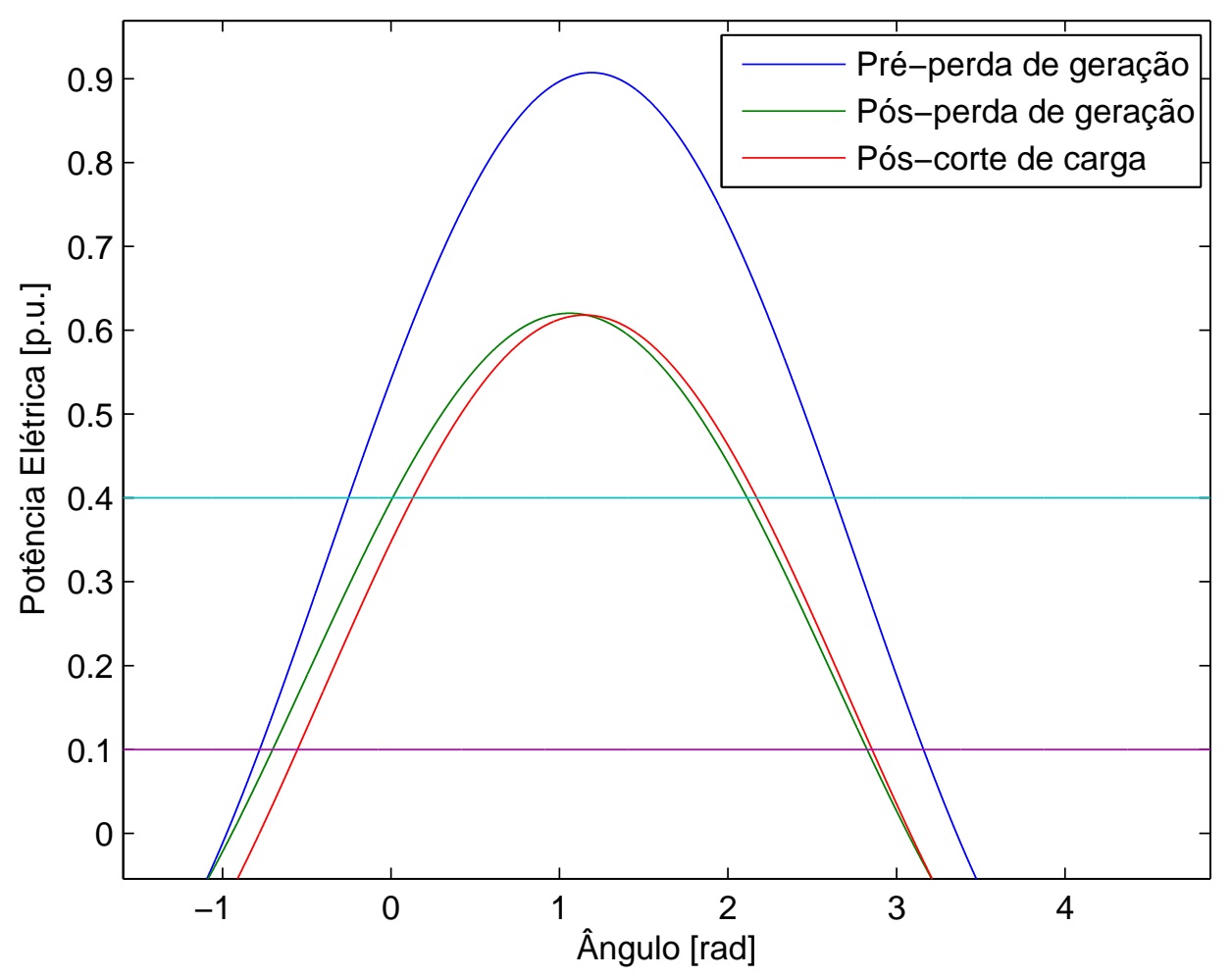

Figura 5.7: Curva $P \times \delta$ SEP simplificado equivalente.

O gráfico da Figura 5.7 é apresentado novamente ampliando-se a região de operação durante o processo de corte de carga. Assim, obtém-se o gráfico da Figura 5.8.

Primeiramente o sistema encontra-se em equilíbrio e está operando no ponto 1 indicado no gráfico, onde $\delta_{0}$ é o ângulo de equilíbrio da equação pré-perda de geração e $P_{m}^{0}$ representa a potência mecânica equivalente do conjunto de geradores neste mesmo instante de tempo. Antes da perda de geração é sabido que a potência elétrica é igual 


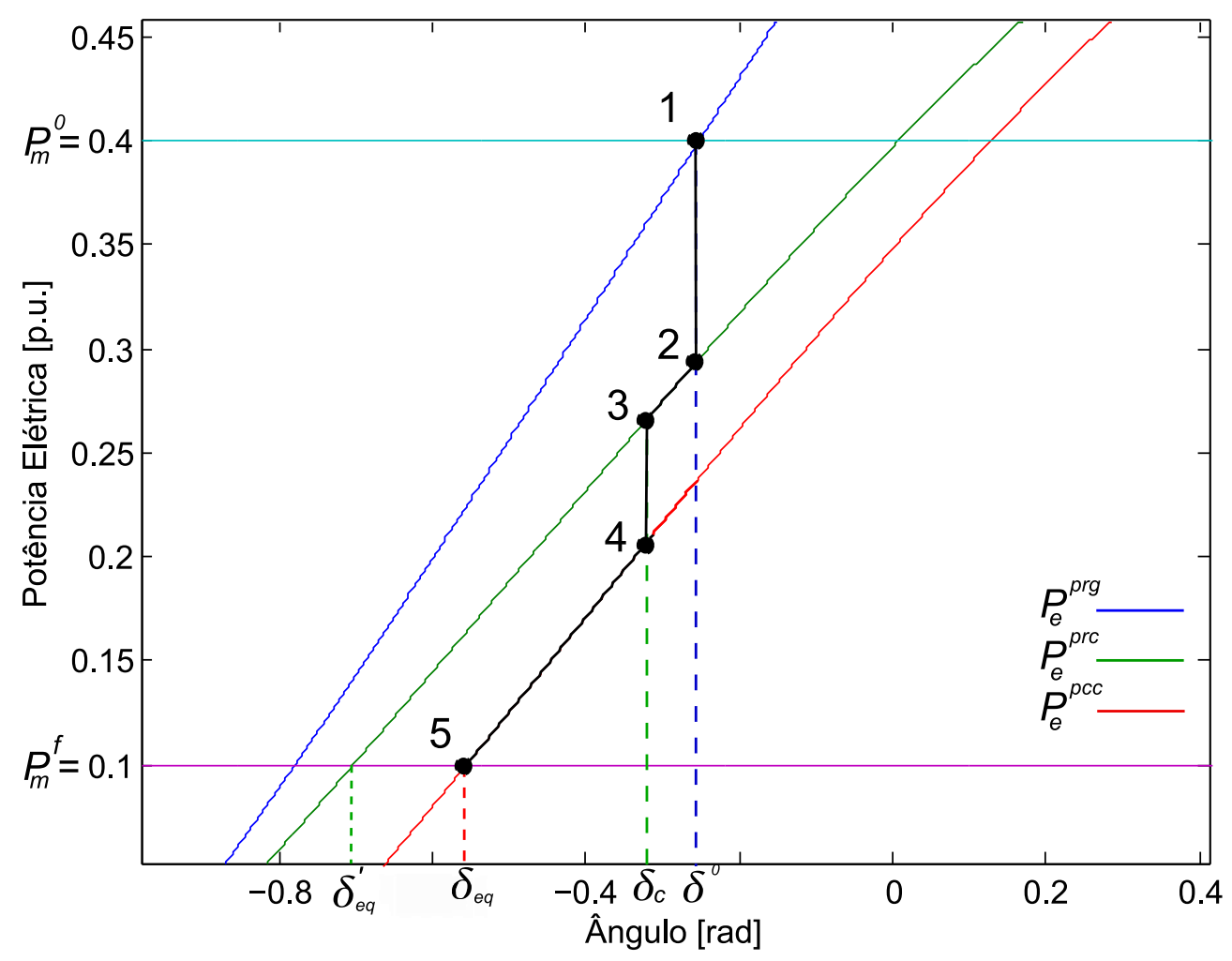

Figura 5.8: Curva $P x \delta$ SEP simplificado equivalente durante o corte de carga.

a potência mecânica (condição que caracteriza o equilíbrio). Assim, $P_{m}^{0}$ e $\delta_{0}$ podem ser determinados através do fluxo de carga. Portanto, a equação diferencial durante o período pré-perda de geração não precisa ser resolvida numericamente.

Considere a perda de três das quatro unidades geradoras que compõem o sistema em estudo. Instantaneamente a potência mecânica equivalente passa a valer $P_{m}^{f}$. Já o valor da reatância transitória de eixo direto equivalente passa a ter um valor superior ao encontrado anteriormente no período pré-perda de geração, pois após a perda das unidades geradoras apenas uma reatância permaneceu conectada ao sistema, sendo que anteriormente quatro reatâncias encontravam-se conectadas em paralelo. Sendo assim, a capacidade de transmissão de potência do sistema diminui.

Como não se pode alterar o ângulo de maneira descontínua, a potência elétrica diminui instantaneamente, migrando da curva $P_{e}^{p r g}$ no ponto 1 para a curva $P_{e}^{p r c}$ no ponto 2. No ponto 2, a potência elétrica é maior que a potência mecânica, o que desacelera a máquina equivalente. Note que se nenhuma medida fosse tomada o sistema oscilaria em torno do ponto de equilíbrio $\delta_{e q}^{\prime}$. Porém, o sistema ultrapassaria o valor de mínima frequência permitida, conforma mostrado na Figura 5.8. 
Para que o sistema no período pré-corte de carga não atinja a frequência crítica previamente estipulada, o ponto 3 é a condição do sistema onde o corte de carga é efetuado, com ângulo $\delta_{c}$ no tempo de abertura $t_{c}$. Com a retirada de carga, o sistema passa do ponto 3 para o ponto 4 na curva $P_{e}^{p p c}$.

No ponto 4, a potência elétrica ainda é maior que a potência mecânica e o conjunto de máquinas desacelera até que o sistema oscile em torno do novo ponto de equilíbrio onde a potência elétrica se iguala a potência mecânica. Assim, o novo ângulo de equilíbrio atingido é denotado por $\delta_{e q}$. O caminho em preto que percorre as curvas de potência mostra o comportamento do sistema durante todo o processo de alívio de carga de forma que a frequência crítica não seja atingida.

\subsection{Corte de carga monoestágio}

Para que a metodologia proposta possa ser validada como uma ferramenta útil no projeto de planos de corte de carga, alguns testes serão aplicados ao sistema em estudo representado pela Figura ??, cuja os dados se encontram na Tabela 5.1. Pretende-se mostrar o comportamento das funções energia sob diferentes planos de corte. A perda de geração consiste na perda de três das quatro unidades geradoras que compõem o sistema. Sendo assim, as únicas expressões a serem construídas serão relativas às funções energia do período pós-corte de carga. A partir da resolução do conjunto dee quações diferenciais relativo ao período pré-corte, serão construídas as curvas das equações de energia para o sistema.

Posteriormente serão definidos os conjuntos de equações diferencias relativos ao período pós-corte de carga para uma verificação do comportamento da frequência do sistema durante o processo de alívio de carga, validando assim a metodologia proposta. Nesta verificação será utilizada uma constante $D=0,0002 p$.u.. O valor de $D$ pode parecer pequeno. Entretanto, quando este valor é comparado com a constante de inércia equivalente do conjunto de geradores do sistema, que corresponde a $M_{e q}=0,001$, conclui-se que $D$ obtém um valor de grandeza equivalente à $M$.

Define-se a frequência mínima permitida pelo sistema como sendo $58,5 \mathrm{~Hz}$, também chamada de frequência crítica. Desta maneira, obtém-se o valor de energia cinética 
crítica com a utilização da Equação (4.17):

$$
V_{k}^{c r}=\frac{(376,991-367,566)^{2} \cdot 2,5 \times 10^{-4}}{2}=11,1033 \times 10^{-3} \text { p.u. }
$$

A solução numérica do conjunto de equações diferencias do período pós-perda de geração será utilizada para a determinação das expressões de energia do sistema, de onde serão extraídos os valores das energias, tempo de corte de carga e finalmente a frequência de corte de carga.

A seguir serão analisadas três situações envolvidas durante o processo de alívio de carga. Elas estão relacionadas ao tamanho do corte de carga, ao atraso no instante em que o corte de carga deve ser efetuado e um caso onde o corte de carga foi realizado com sucesso.

\subsubsection{Tamanho do Corte Insuficiente}

Uma situação que se deseja evitar é o dimensionamento de um corte de carga utilizando-se um montante menor que o necessário para que o sistema não ultrapasse o limite de frequência definido por $\omega^{c r}$. Portanto, a seguir será mostrado o comportamento da frequência do sistema caso esta situação seja encontrada.

O montante de corte escolhido para este caso foi de $5 \%$ da carga total. Portanto, as expressões das energias do sistema relativas a este montante de corte podem ser vistas a seguir:

- Sistema pré-corte de carga ou pós-perda de geração:

$$
\left\{\begin{aligned}
V_{k}^{p r c} & =1,25 \times 10^{-4} \cdot \omega^{2} \\
V_{p}= & 0,084(\delta+0,257)+0,3813(\cos (-0,257)-\cos (\delta))+ \\
& +0,2129(\operatorname{sen}(\delta)-\operatorname{sen}(-0,257))
\end{aligned}\right.
$$

- Sistema pós-corte de carga:

$$
\left\{\begin{aligned}
V_{k}^{p p c} & =1,25 \times 10^{-4} \cdot \omega^{2} \\
V_{p}= & 0,079(\delta+0,257)+0,390(\cos (-0,257)-\cos (\delta))+ \\
& +0,207(\operatorname{sen}(\delta)-\operatorname{sen}(-0,257))
\end{aligned}\right.
$$


As equações acima resultaram nos gráficos representados pela Figura 5.9 e pela Figura 5.10.

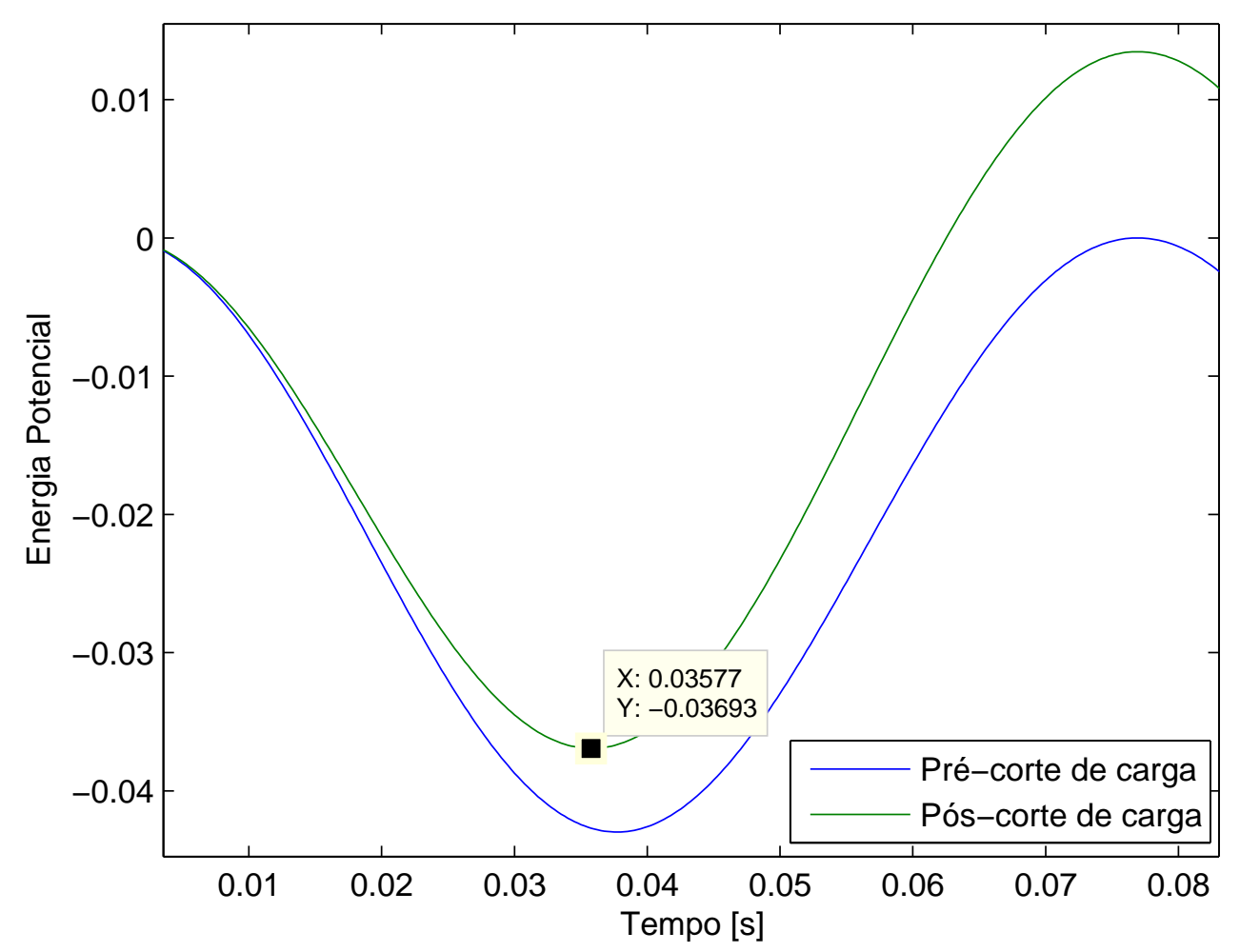

Figura 5.9: Energia potencial para o corte de carga insuficiente.

Através do gráfico de energia potencial, curva verde da Figura 5.9, obtém-se o valor mínimo de energia potencial para o sistema, -0,03693p.u.. Com a utilização da Equação (4.20) determina-se a energia total de corte, assim:

$$
V_{\text {tot }}^{c}<V_{\text {tot }}^{c r}=11,1033 \times 10^{-3}+(-0,03693)=-25,827 \times 10^{-3} p . u .
$$

Observa-se uma inconsistência no valor encontrado em (5.20), pois através do gráfico da Figura 5.10 verifica-se que a energia total do sistema no período pós-corte de carga (curva em verde) não admite valores menores que zero. Portanto, este fato indica que o corte de carga proposto é insuficiente, indicando a necessidade de um montante maior de corte, de forma que a frequência crítica pré-estipulada não seja ultrapassada. 


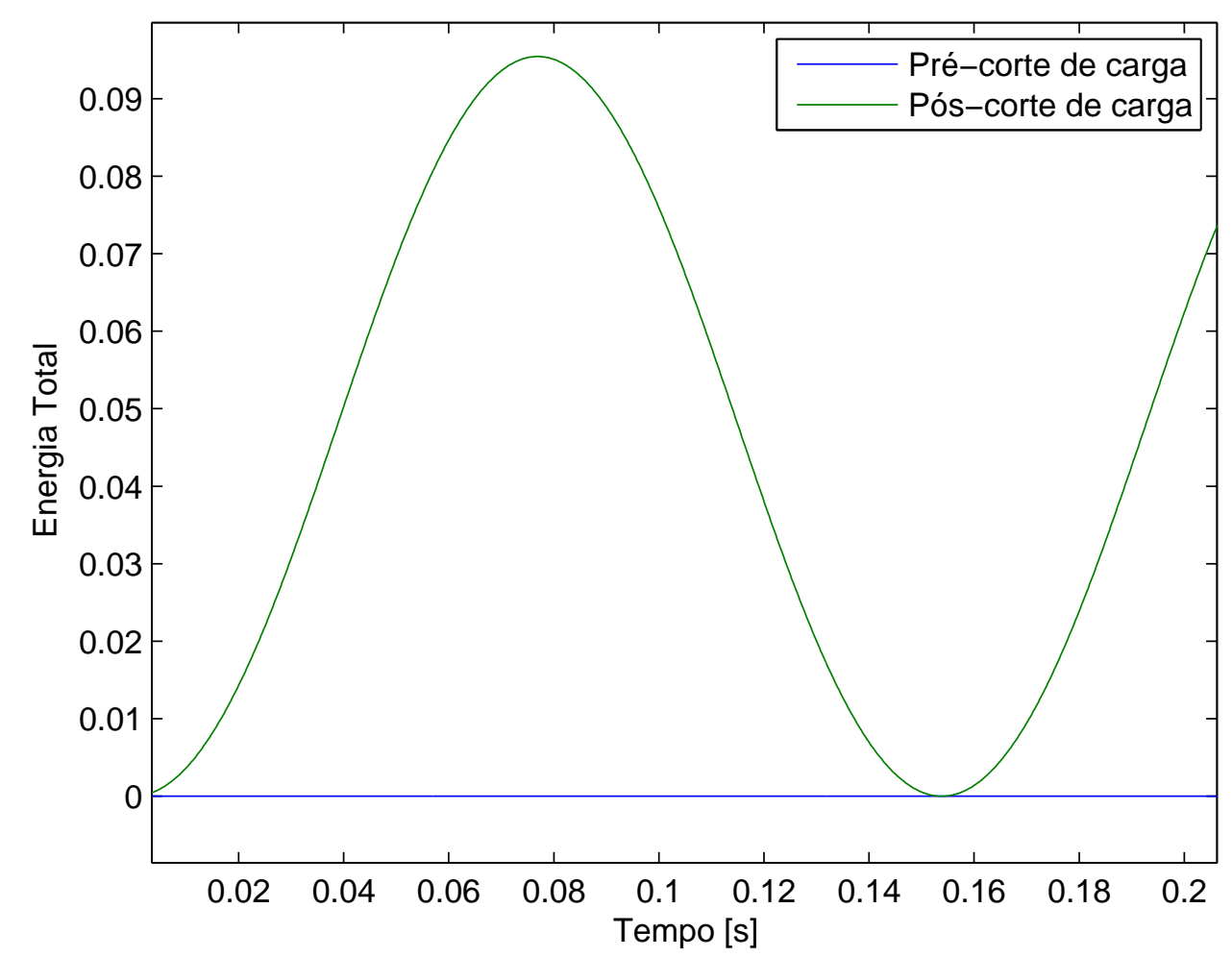

Figura 5.10: Energia total para o corte de carga insuficiente.

A seguir serão apresentados os conjuntos de equações diferencias relativos ao montante de corte deste tópico:

- Sistema pré-corte de carga ou pós-perda de geração:

$$
\begin{aligned}
& \left\{\begin{array}{l}
\dot{\omega}=-0,8 \cdot \omega-334,622-1525,030 \cdot \operatorname{sen}(\delta)-851,49 \cdot \cos (\delta) \\
\dot{\delta}=\omega
\end{array}\right. \\
& \left\{\begin{array}{l}
t \geq 0 \\
\delta(t)=-0,257 \mathrm{rad} \\
\dot{\delta}(t)=0
\end{array}\right.
\end{aligned}
$$

- Sistema pós-corte de carga:

$$
\left\{\begin{array}{l}
\dot{\omega}=-0,8 \cdot \omega-314,796-1561,480 \cdot \operatorname{sen}(\delta)-828,509 \cdot \cos (\delta) \\
\dot{\delta}=\omega
\end{array}\right.
$$




$$
\left\{\begin{array}{l}
t \geq 0 \\
\delta(t)=-0,257 \mathrm{rad} \\
\dot{\delta}(t)=0
\end{array}\right.
$$

O comportamento da frequência do sistema é mostrado através da Figura 5.11.

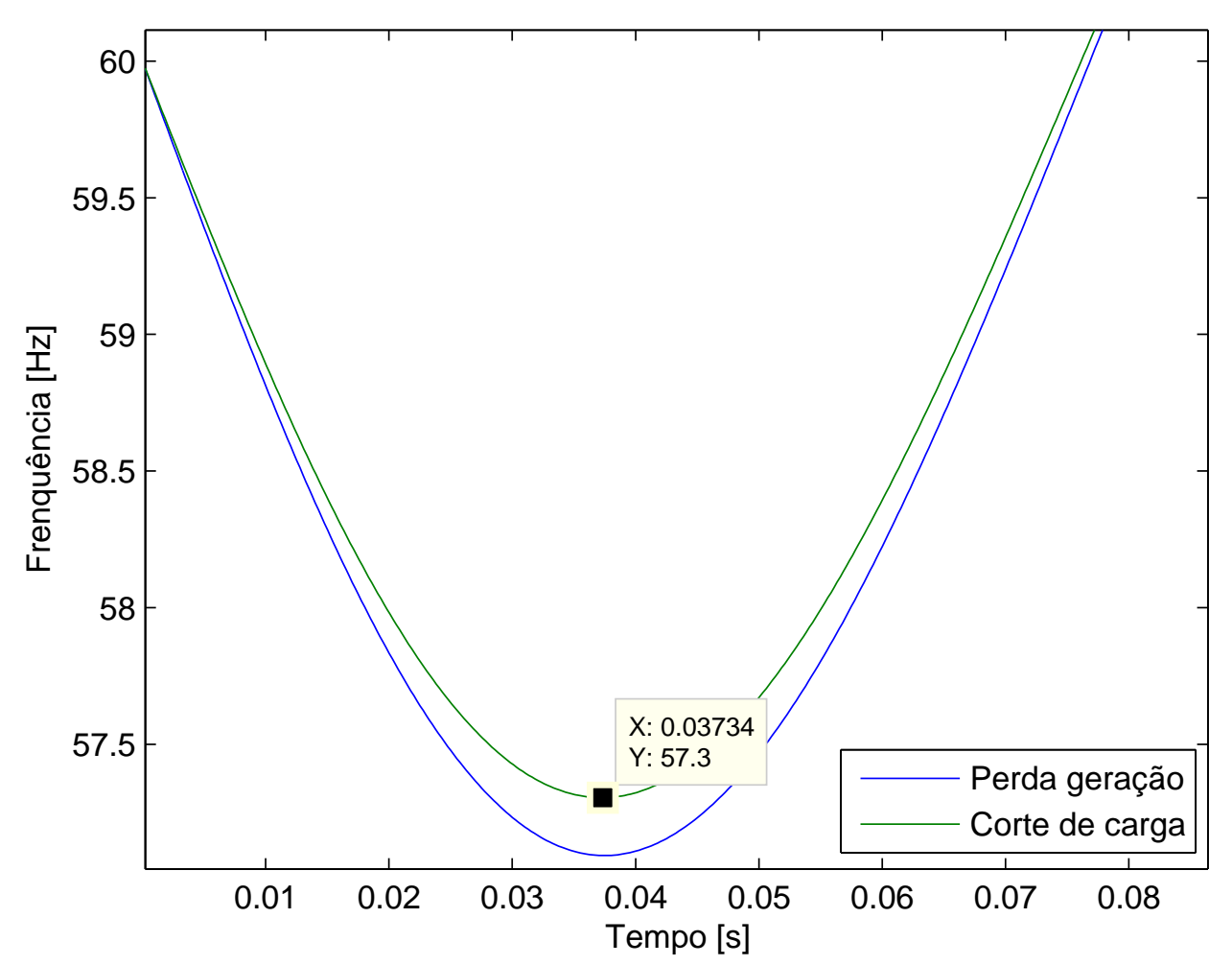

Figura 5.11: Comportamento da frequência para o corte de carga insuficiente.

Conforme visto pela Figura 5.11 mesmo com uma frequência de corte ajustada em 59,99Hz (quase imediatamente após a perda de geração), a frequência do sistema ultrapassou a frequência crítica estipulada, pois a frequência mínima atingida foi de $57,30 \mathrm{~Hz}$.

\subsubsection{Tempo de corte atrasado}

Nesta seção será mostrado o comportamento da frequência do sistema caso o corte de carga seja efetuado numa frequência posterior à calculada através da metodologia proposta. Na prática esta situação pode ocorrer caso não seja levado em consideração o tempo de atuação dos dispositivos envolvidos no processo de alívio de carga. 
O montante de corte escolhido para este caso foi de $31 \%$ da carga total. Portanto, as expressões das energias do sistema relativas a este montante de corte podem ser vistas a seguir:

- Sistema pré-corte de carga ou pós-perda de geração:

$$
\left\{\begin{aligned}
V_{k}^{p r c} & =1,25 \times 10^{-4} \cdot \omega^{2} \\
V_{p}= & 0,084(\delta+0,257)+0,3813(\cos (-0,257)-\cos (\delta))+ \\
& +0,2129(\operatorname{sen}(\delta)-\operatorname{sen}(-0,257))
\end{aligned}\right.
$$

- Sistema pós-corte de carga:

$$
\left\{\begin{aligned}
V_{k}^{p p c} & =1,25 \times 10^{-4} \cdot \omega^{2} \\
V_{p}= & 0,045(\delta+0,257)+0,436(\cos (-0,257)-\cos (\delta))+ \\
& +0,168(\operatorname{sen}(\delta)-\operatorname{sen}(-0,257))
\end{aligned}\right.
$$

As equações acima resultaram nos gráficos representados pela Figura 5.12 e pela Figura 5.13.

Através do gráfico de energia potencial, curva verde da Figura 5.12, obtém-se o valor mínimo de energia potencial para o sistema, $-0,01014 p$.u. . Com a utilização da Equação (4.20) determina-se a energia total de corte, assim:

$$
V_{\text {tot }}^{c}<V_{\text {tot }}^{c r}=11,1033 \times 10^{-3}+(-0,01014)=9,633 \times 10^{-4} \text { p.u. }
$$

O valor para a energia total de corte encontrado na simulação, inferior à $V_{t o t}^{c r}$, foi de $9,248 \times 10^{-4}$ p.u.. Observando o gráfico da Figura 5.13, encontra-se um valor de tempo de corte de carga igual a $50,18 \times 10^{-3} s$ juntamente com o valor de energia total de corte mencionado anteriormente.

Foi encontrado um valor de $1,844 \times 10^{-3} p$.u. para a energia cinética de corte no instante de tempo $t_{c}$, através do gráfico de energia cinética visto pela Figura 5.14. Note que as curvas em verde e azul estão sobrepostas, pois as expressões de energia cinética são idênticas nos períodos pré-corte de carga e pós-corte de carga. 


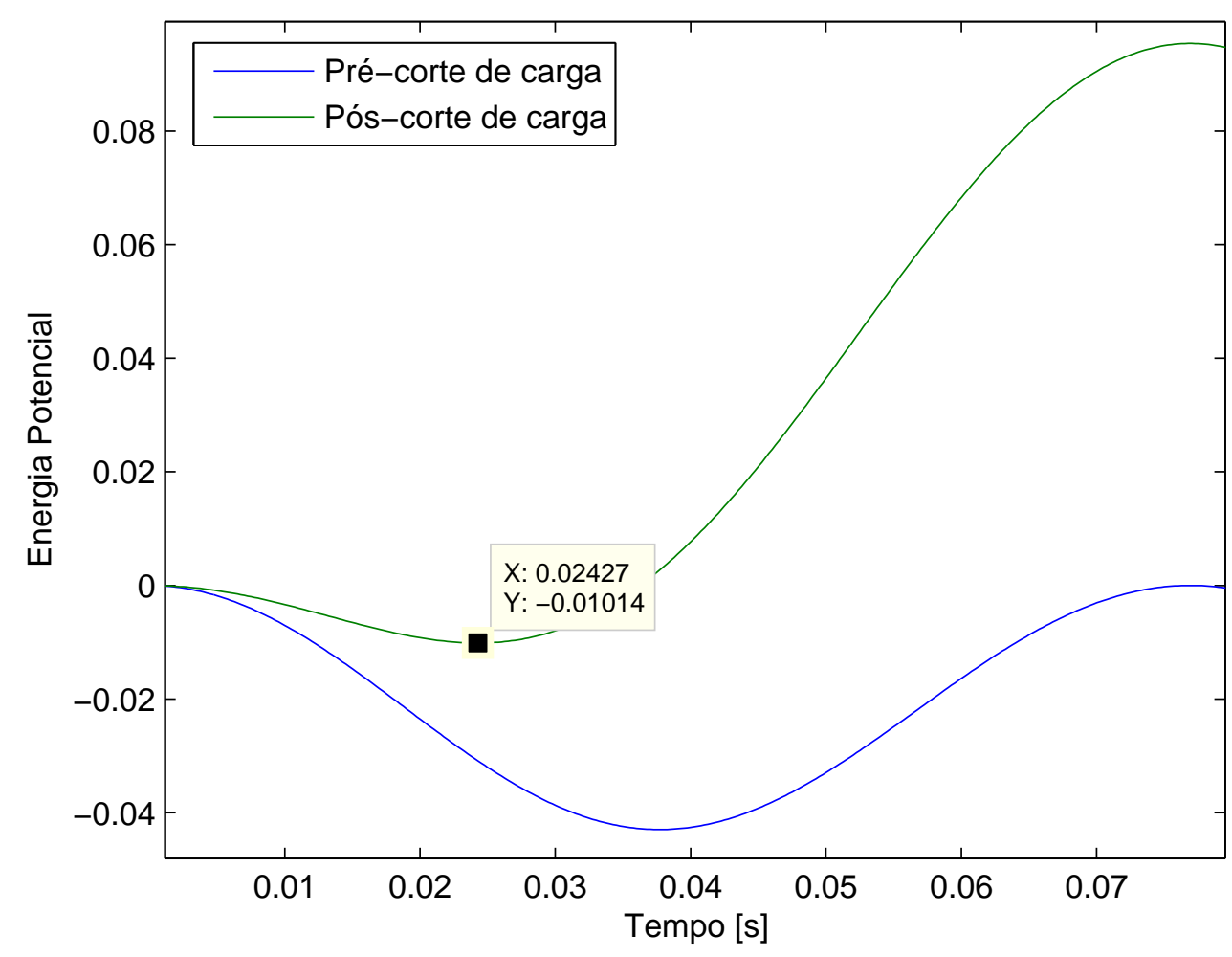

Figura 5.12: Energia potencial para o corte de carga atrasado.

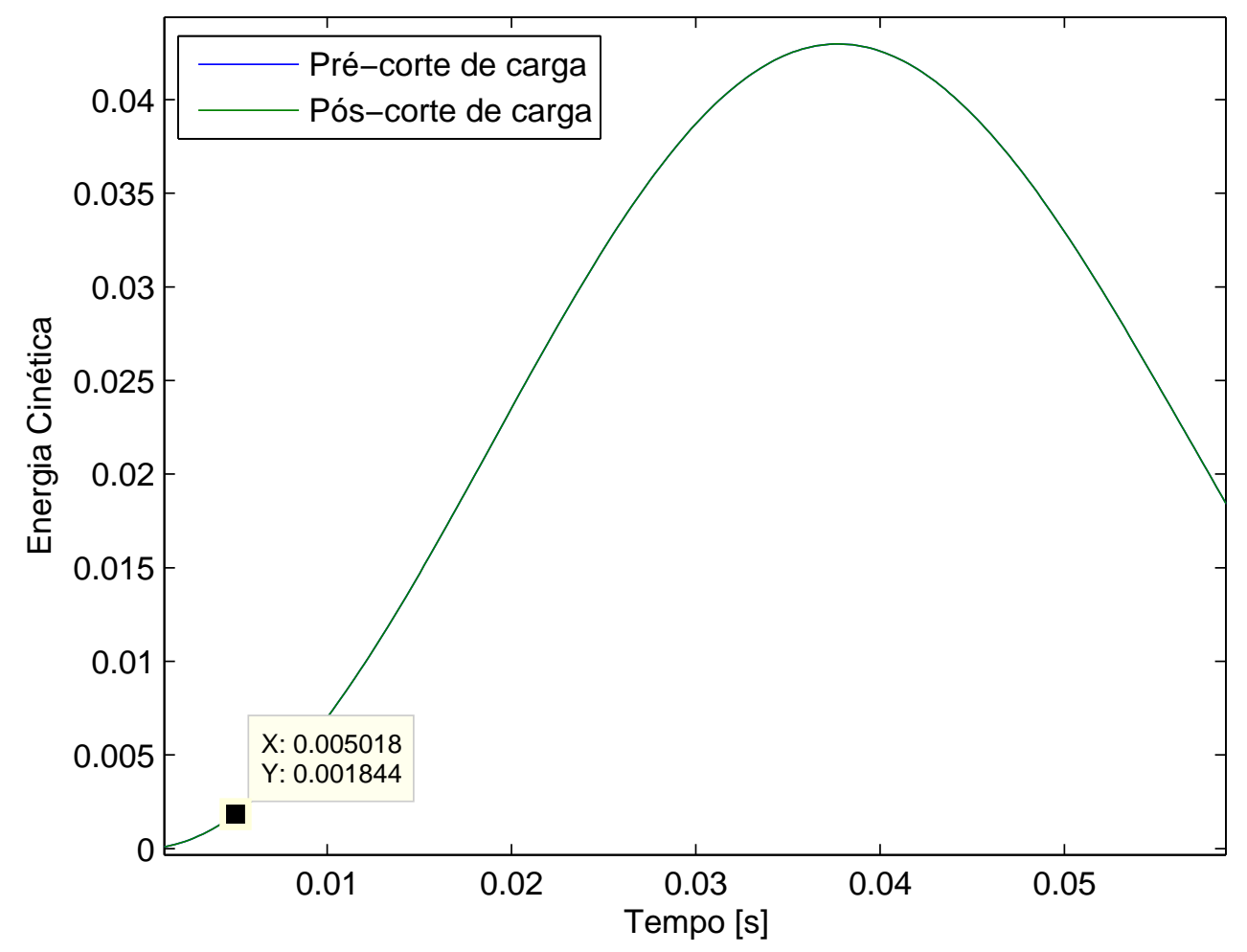

Figura 5.14: Energia cinética para o corte de carga atrasado. 


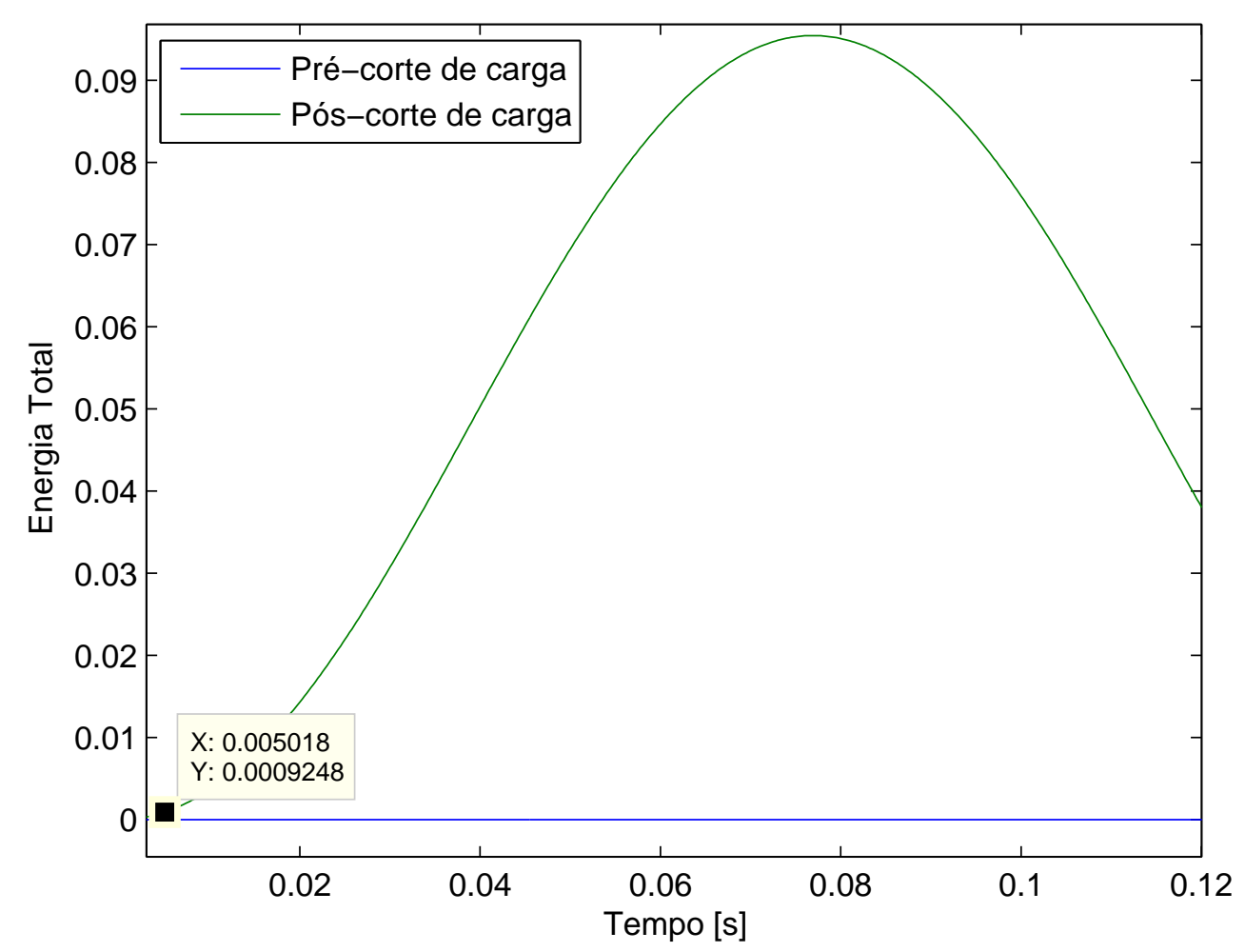

Figura 5.13: Energia total para o corte de carga atrasado.

Portanto, utilizando-se a Equação (4.21), o valor para a frequência de corte é obtido, conforme abaixo:

$$
\omega_{c}=376,991-\left|\sqrt{\frac{2 \cdot 1,844 \times 10^{-3}}{2,5 \times 10^{-4}}}\right|=373,150 \mathrm{rad} / \mathrm{s}
$$

Transformando a unidade de $\omega_{c}$, obtém-se:

$$
f_{c}=373,150 \times 2 \pi=59,3887 \mathrm{~Hz}
$$

A seguir estão os conjuntos de equações diferencias relativos ao montante de corte deste tópico:

- Sistema pré-corte de carga ou pós-perda de geração:

$$
\left\{\begin{array}{l}
\dot{\omega}=-0.8 \cdot \omega-334,622-1525,030 \cdot \operatorname{sen}(\delta)-851,49 \cdot \cos (\delta) \\
\dot{\delta}=\omega
\end{array}\right.
$$




$$
\left\{\begin{array}{l}
t \geq 0 \\
\delta(t)=-0,257 \mathrm{rad} \\
\dot{\delta}(t)=0
\end{array}\right.
$$

- Sistema pós-corte de carga:

$$
\begin{aligned}
& \left\{\begin{array}{l}
\dot{\omega}=-0,8 \cdot \omega-180,943-1744,428 \cdot \operatorname{sen}(\delta)-673,362 \cdot \cos (\delta) \\
\dot{\delta}=\omega
\end{array}\right. \\
& \left\{\begin{array}{l}
t \geq 0 \\
\delta(t)=-0,257 \mathrm{rad} \\
\dot{\delta}(t)=0
\end{array}\right.
\end{aligned}
$$

Considera-se o caso em que o corte é efetuado quando a frequência do sistema atinge o valor de $58,8 \mathrm{~Hz}$. Observe que o corte de carga é efetuado para uma frequência inferior à calculada, o que caracteriza um atraso no instante de corte previamente determinado em (5.27).

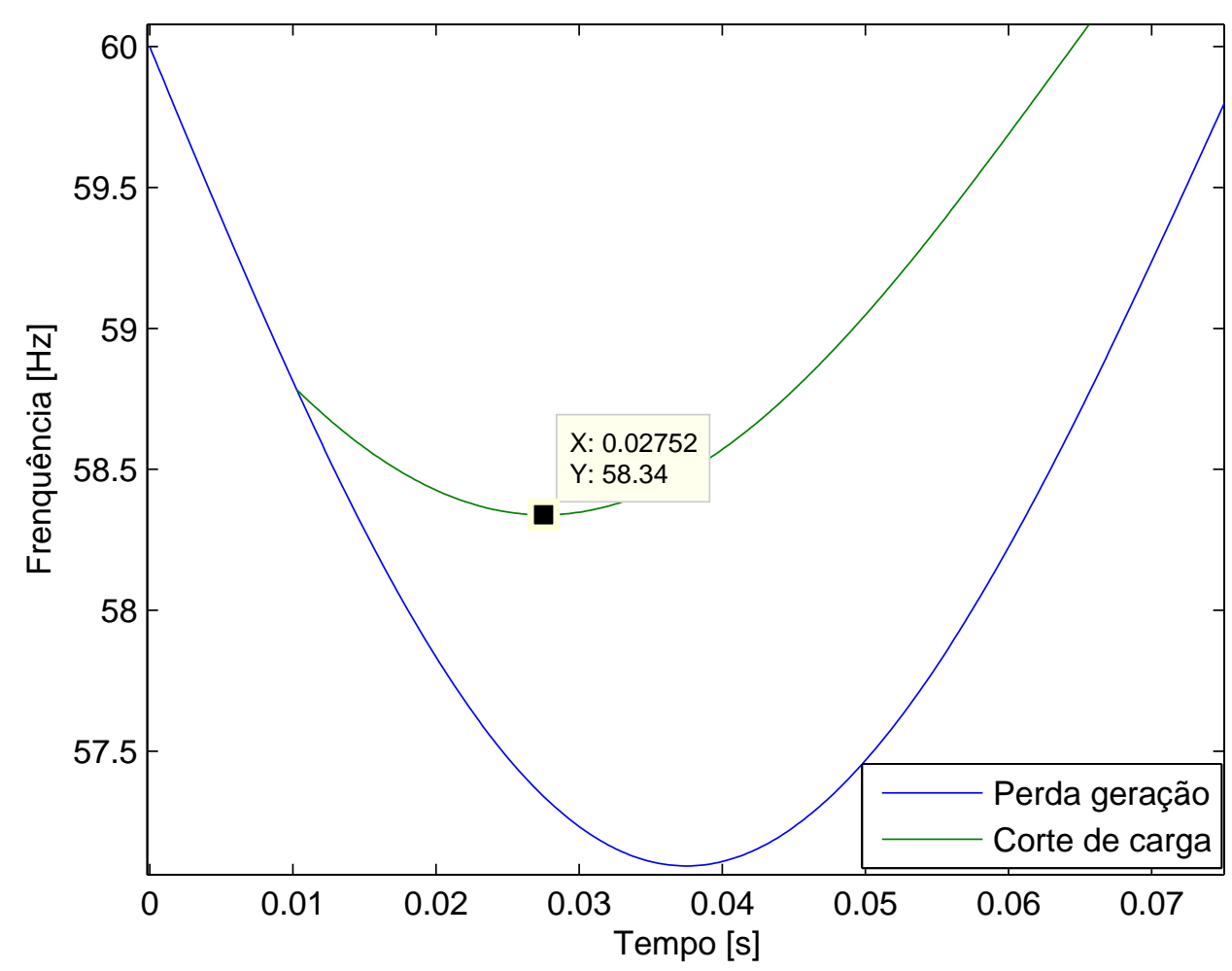

Figura 5.15: Comportamento da frequência para o corte de carga atrasado. 
O comportamento da frequência do sistema é mostrado através da Figura 5.15. Conforme o esperado, o sistema atingiu uma frequência inferior a frequência crítica, estipulada em $58,5 \mathrm{~Hz}$, pois o valor mínimo de frequência encontrado na curva em verde da Figura 5.15 foi de 58, $34 \mathrm{~Hz}$.

\subsubsection{Tempo de corte exato}

Para uma situação em que o corte de carga seja realizado corretamente considere que o corte de carga apresentado na seção anterior seja efetuado na frequência calculada em (5.27), ou seja, $w_{c}=59,389 H z$. Assim, obtém-se o gráfico da Figura 5.16.

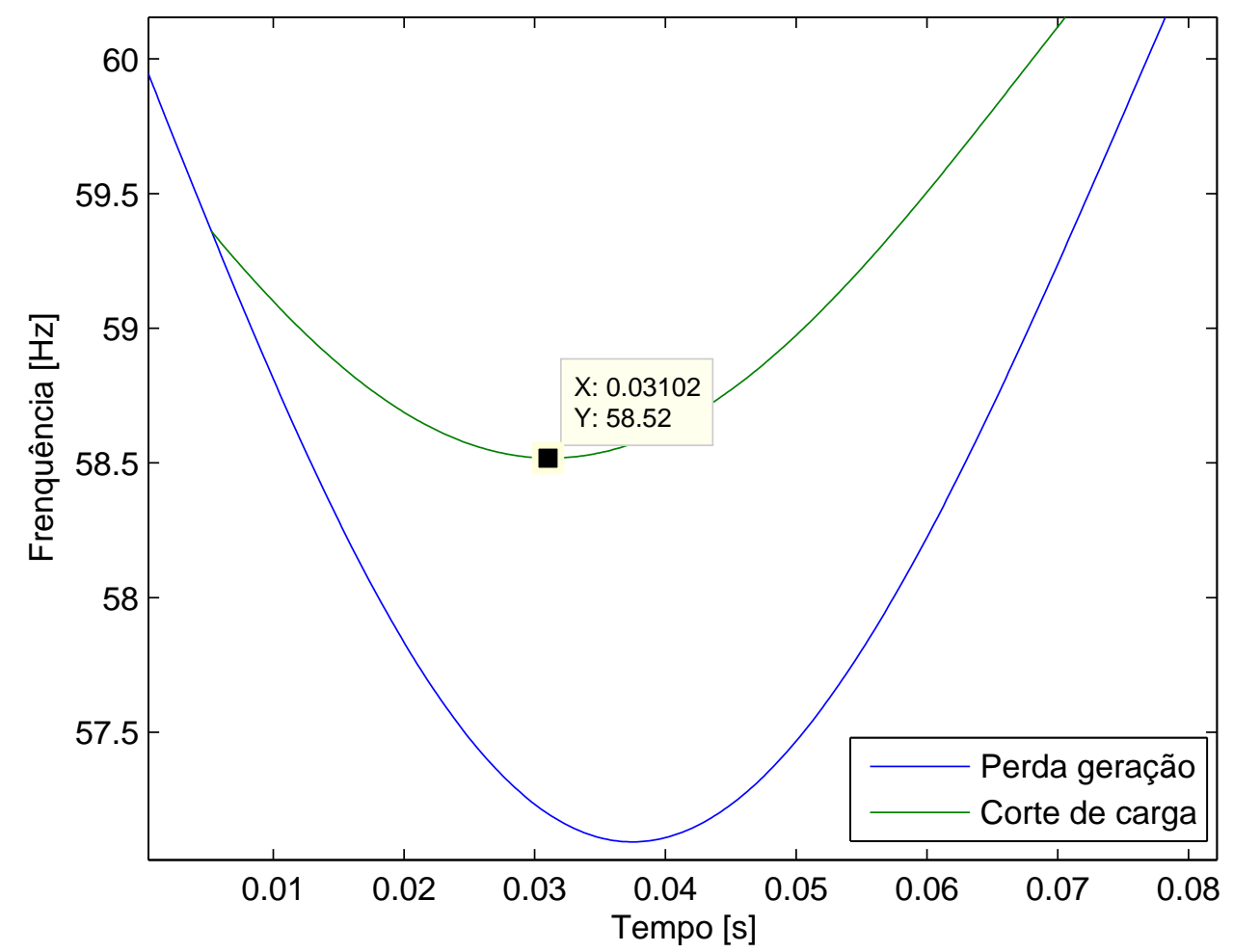

Figura 5.16: Comportamento da frequência para o corte de carga no instante exato.

O mínimo valor de frequência encontrado foi de $58,518 \mathrm{~Hz}$. Assim, o valor crítico de frequência não foi atingido, indicando que a estimativa encontrada para $w_{c}$ resultou em um corte eficiente para o montante selecionado.

Caso seja necessário optar por um corte de carga mais conservador, basta eliminar um montante maior ou mesmo efetuar o corte de carga em uma frequência superior à 
encontrada pela Equação 5.26, pois a metodologia proposta resulta num corte de carga em que a frequência atingida pelo sistema seja bem próxima de $\omega^{c r}$.

A Tabela 5.2.3 apresenta os diferentes resultados obtidos nesta seção. Observou-se o comportamento das funções energia para montantes de corte que foram suficientes e insuficientes. Conclui-se então que, para os casos onde a energia total crítica for negativa, um montante de carga maior deve ser escolhido para o corte. A metodologia mostrou-se adequada pois, como visto através da Figura 5.16, o corte foi realizado com sucesso.

Tabela 5.2: Resultado para os ajustes propostos.

\begin{tabular}{|c|c|c|}
\hline Corte [\%] & $w_{c}[\mathrm{~Hz}]$ & $w^{\text {min }}[\mathrm{Hz}]$ \\
\hline \hline 5 & 59,99 & 57,30 \\
\hline 31 & 58,80 & 58,34 \\
\hline 31 & 59,39 & 58,52 \\
\hline
\end{tabular}

\subsection{Modelo linearizado}

A maioria das metodologias empregadas atualmente utiliza-se de uma modelagem linearizada do sistema. Portanto, será realizado um comparativo entre o modelo não linear e o modelo linearizado, mostrando a diferença encontrada na frequência do sistema em ambos os casos para uma perda de 3 das 4 unidades geradoras que constituem o mesmo.

Considere o sistema da Figura 5.3. Este sistema é representado pelas Equações 5.14, 5.28 e 5.29, as quais caracterizam um típico processo de alívio de carga. Este sistema será linearizado em torno de um ponto de operação para que posteriormente seja simulado uma perda no sistema de geração.

Primeiramente tem-se o sistema pré-corte de carga ou pós-perda de geração, para a perda de 3 das 4 unidades geradoras. Dessa forma:

$$
\left\{\begin{array}{l}
\dot{\delta}=\omega \\
\dot{\omega}=-12 \cdot \omega-334,622-1525,030 \cdot \operatorname{sen} \delta-851,49 \cdot \cos (\delta)
\end{array}\right.
$$


Igualando as derivadas de velocidade angular e de ângulo a zero em (5.30) obtém-se a Equação 5.31.

$$
\left\{\begin{array}{l}
\dot{\delta}=\omega=0 \\
\dot{\omega}=-1,2 \cdot \omega-334,622-1525,030 \cdot \operatorname{sen} \delta-851,49 \cdot \cos (\delta)=0
\end{array}\right.
$$

O ponto de equilíbrio do sistema pós-perda de geração é encontrado através da resolução da Equação 5.31. Sendo assim, o ponto de equilíbrio deste sistema é:

$$
\left\{\begin{array}{l}
\delta_{e}^{p p c}=-0,7020 \\
\omega_{e}^{p p c}=0
\end{array}\right.
$$

Linearizando o sistema pós-perda de geração de carga em torno do ponto de equilíbrio encontrado acima, obtém-se a expressão abaixo:

$$
\left[\begin{array}{c}
\Delta \dot{\delta}^{p p c} \\
\Delta \dot{\omega}^{p p c}
\end{array}\right]=\left[\begin{array}{cc}
0 & 1 \\
-1525,03 \cdot \cos \left(\delta_{e}^{p p c}\right)+851,49 \cdot \sin \left(\delta_{e}^{p p c}\right) & -1,2
\end{array}\right] \cdot\left[\begin{array}{c}
\Delta \delta \\
\Delta \omega
\end{array}\right]
$$

Substituindo o valor numérico de $\delta_{e}^{p p c}$ em (5.33), obtém-se:

$$
\left\{\begin{array}{l}
\Delta \dot{\delta}=\Delta \omega \\
\Delta \dot{\omega}=-1714,3 \cdot \Delta \delta \cdot \Delta \omega-1,2 \cdot \Delta \omega
\end{array}\right.
$$

Portanto, a Equação 5.34 representa o sistema pós-perda de geração linearizado em torno do ponto de operação $\delta_{e}^{p p c}$ e $\omega_{e}^{p p c}$. Assim, as variáveis $\delta$ e $\omega$ são agora representadas pelas variações em relação aos seus pontos de equilíbrio, resultando nas variáveis $\Delta \delta$ e $\Delta \omega$.

Outro fator importante a ser determinado é a condição inicial do sistema. Para isto, considere o sistema pré-perda de geração abaixo:

$$
\left\{\begin{array}{l}
\dot{\omega}=-0.3 \cdot \omega+74,227-540,057 \cdot \operatorname{sen}(\delta)-215,770 \cdot \cos (\delta) \\
\dot{\delta}=\omega
\end{array}\right.
$$


O ponto de equilíbrio do sistema acima pode ser encontrado com a utilização de algum método numérico. Sendo assim, tem-se:

$$
\Delta \delta_{e}(0)=0,445
$$

Desta forma, a condição inicial do sistema pós-perda de geração linearizado é:

$$
\left\{\begin{array}{l}
\delta(0)=0,445 \\
\omega(0)=0
\end{array}\right.
$$

A Figura 5.17 apresenta o comportamento da frequência do sistema não linear no período pré-perda de geração juntamente com a frequência dada pelo modelo linearizado em torno do ponto de equilíbrio determinado em (5.32).

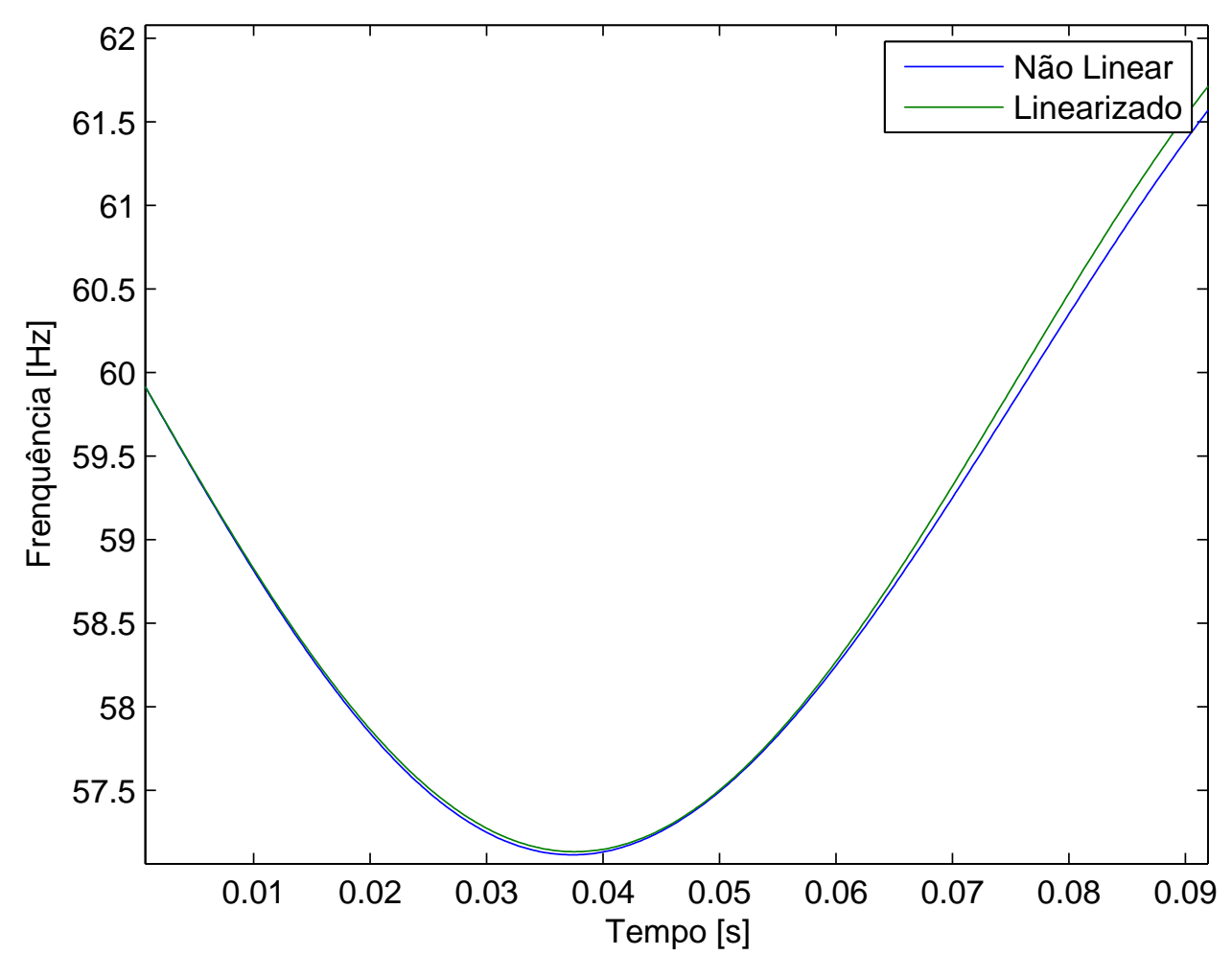

Figura 5.17: Comparação do comportamento da frequência entre o sistema linearizado e o não linear.

Observe que os comportamentos da frequência em ambos os sistemas são muito próximos. Dentre as razões pelas quais uma diferença razoável no comportamento da frequência não foi encontrada,pode-se citar o fato de que o sistema utilizado é extre- 
mamente simples, já que foram desprezados alguns componentes e limites operacionais deste sistema. Desta forma, não foi possível verificar uma melhora significativa na precisão dos resultados através do uso do modelo não linear. Por outro lado, este sistema simplificado foi adequado para um estudo de seu comportamento dinâmico quando o mesmo é submetido a condições de subfrequência. O sistema também foi adequado para que fosse elaborada a metodologia proposta deste trabalho, servindo para a validação da mesma.

Outro aspecto importante a ser resaltado é em relação ao barramento infinito utilizado na modelagem do sistema utilizado. Todo o déficit de potência causado pela perda de geração é quase que instantaneamente suprido pelo barramento infinito. Assim, pode-se perceber os curtos períodos de tempo em que o sistema sofre a oscilação de frequência, sendo que na prática (para sistemas de médio e grande porte) a primeira oscilação pode chegar até a ordem de segundos.

Na sequência deste trabalho, pretende-se utilizar modelos mais realistas do SEP, de forma que a diferença entre os modelos linearizado e não linear possa ser percebida mais claramente, conforme será mencionado no capítulo posterior. 


\section{Capítulo 6}

\section{Conclusões e Perspectivas Futuras}

Neste trabalho, foi proposta uma metodologia para determinação de planos de corte de carga, tendo como resultado final o valor de frequência no instante em que o corte deve ser efetuado.

A metodologia baseia-se em conceitos energéticos. Assim, sem que haja necessidade de se conhecer a trajetória da frequência, durante condições de subfrequência, o valor mínimo atingido por ela pode ser determinado o que se traduz em grande redução do esforço computacional. A vantagem apresentada pelo método proposto em relação aos métodos convencionalmente utilizados consiste na representação não linear utilizada para o SEP pois, sabendo com precisão os limites de frequência atingidos pelo sistema durante condições de emergência, pode-se projetar um plano de corte visando uma maior eficiência e rapidez, reduzindo assim o número de consumidores desprovidos de energia elétrica durante o processo de alívio de carga.

Um modelo simples de SEP foi utilizado com o intuito de validar a metodologia proposta. Com este foi verificado que o plano de corte proposto não permitiu que o sistema atingisse o mínimo valor de frequência permitido após uma grande perda no sistema de geração. De fato, o método não só determina a frequência de corte como informa se o montante de carga selecionado é ou não suficiente para que o sistema não atinja a frequência crítica.

Foram encontradas algumas dificuldades na elaboração do sistema teste para a realização do estudo. A simplicidade do mesmo não permitiu que fosse demonstrada uma diferença expressiva entre o modelo linear e não linear, já que além das simplificações 
adotadas o barramento infinito supre quase que instataneamente quaisquer possíveis desbalanços de potência. Entretanto, o modelo foi capaz de demonstrar o comportamento do sistema sob uma condição de subfrequência, possibilitando a elaboração da metodologia proposta e comprovando o seu potencial, pois a frequência de corte de carga pode ser determinada com precisão.

Para a sequência deste trabalho, poderá ser desenvolvido um algoritmo para determinação de planos de corte de carga multiestágios, que levem em consideração a temporização dos relés de subfrequência.

Antes disso, porém, deverá ser desenvolvido um modelo mais realista para o sistema teste, de forma a explicar mais claramente as diferenças de precisão entre as modelagens linearizada e não linear e, por consequência, evidenciando melhor as vantagens da metodologia proposta. 


\section{Referências Bibliográficas}

Anderson, P. M., Fouad, A. A. and Happ, H. H. (1979). Power system control and stability, Systems, Man and Cybernetics, IEEE Transactions on 9(2): 103-103.

Anderson, P. M. and Mirheydar, M. (1992). An adaptive method for setting underfrequency load shedding relays, IEEE J PWRS 7(2): 647-655.

Andersson, G., Donalek, P., Farmer, R., Hatziargyriou, N., Kamwa, I., Kundur, P., Martins, N., Paserba, J., Pourbeik, P., Sanchez-Gasca, J., Schulz, R., Stankovic, A., Taylor, C. and Vittal, V. (2005). Causes of the 2003 major grid blackouts in north america and europe, and recommended means to improve system dynamic performance, IEEE J PWRS 20(4): 1922-1928.

Athay, T., Podmore, R. and Virmani, S. (1979). A practical method for the direct analysis of transient stability, IEEE J PWRAS (2): 573-584.

Begovic, M., Fulton, D., Gonzalez, M. R., Goossens, J., Guro, E. A., Haas, R. W., Henville, C. F., Manchur, G., Michel, G. L., Pastore, R. C., Postforoosh, J., Schmitt, G. L., Williams, J. B., Zimmerman, K. and Burzese, A. A. (1995). Summary of "system protection and voltage stability", IEEE J PWRD 10(2): 631-638.

Berdy, J., Brown, P. G. and Goff, L. E. (1974). Protection of steam turbine -generators during abnormal frequency conditions, Georgia Tech Protective Relaying Conference p. 7.

Bialek, J. (2007). Why has it happened again? comparison between the ucte blackout in 2006 and the blackouts of 2003, Power Tech, 2007 IEEE Lausanne pp. 51-56.

Bretas, N. G. and Alberto, L. F. C. (2000). Estabilidade transitória em sistemas eletroenergéticos, Publicação EESC/USP, São Carlos, SP. 
Chiang, H.-D., Chu, C.-C. and Cauley, G. (1995). Direct stability analysis of electric power systems using energy functions: theory, applications, and perspective, IEEE J PROC 83(11): 1497-1529.

Chuvychin, V., Gurov, N. and Rubcov, S. (2005). Adaptive underfrequency load shedding and underfrequency load restoration system, Proc. IEEE Russia Power Tech, pp. 1-6.

Chuvychin, V. N., Gurov, N. S., Venkata, S. S. and Brown, R. E. (1996). An adaptive approach to load shedding and spinning reserve control during underfrequency conditions, IEEE J PWRS 11(4): 1805-1810.

Fitzgerald, A. E., Kingsley, C. J. and Umans, S. D. (2006). Máquinas elétricas - com introdução à eletrônica de potência, Bookman.

Gomes, P. and Sardinha, S. L. A. (2001). Impacto dos novos agentes do dimensionamento dos esquemas de alívio de carga, $16^{\circ}$ Seminário Nacional de Produção e Transmissão de Energia Elétrica pp. 1-7.

Halevi, Y. and Kottick, D. (1993). Optimization of load shedding system, IEEE Transaction on Energy Conversion 8(2): 207-213.

Hsu, C.-T., Chuang, H.-J. and Chen, C.-S. (2008). Artificial neural network based adaptive load shedding for an industrial cogeneration facility, Proc. IEEE Industry Applications Society Annual Meeting IAS '08, pp. 1-8.

IEEE Power Engineering Society (2007). Ieee guide for the application of protective relays used for abnormal frequency load shedding and restoration, IEEE Std C37.117-2007 pp. c1-43.

IEEE Task Force (1999). Damping representation for power system stability studies, IEEE J PWRS 14(1): 151-157.

Kimbark, E. W. (1995). Power system stability [books and reports], IEEE M PER 15(3): 40.

Kuiava, R. (2007). Controle robusto de dispositivos facts para o amortecimento de oscilações em sistemas elétricos de potência, Dissertação de Mestrado, Escola de Engenharia de São Carlos, Universidade de São Paulo. 
Kundur, P. (1994). Power system stability and control, McGraw-Hill, New York.

Monticelli, A. J. (1983). Fluxo de carga em redes de energia elétrica, Edgard Blücher, São Paulo.

Parniani, M. and Nasri, A. (2006). Scada based under frequency load shedding integrated with rate of frequency decline, Proc. IEEE Power Engineering Society General Meeting, p. 6pp.

Ramos, R. A., Alberto, L. F. C. and Bretas, N. G. (2000). Modelagem de máquinas síncronas aplicada ao estudo de estabilidade de sistemas elétricos de potência, Publicação EESC/USP, São Carlos, SP.

Sauer, P. W. and Pai, M. A. (1998). Power system dynamics and stability, New Jersey, NJ: Prentice-Hall.

Shokooh, F., Dai, J., Shokooh, S., Taster, J., Castro, H., Khandelwal, T. and Donner, G. (2005). An intelligent load shedding (ils) system application in a large industrial facility, IAS 2005 1: 417-425 Vol. 1.

Silva, F. H. J. R., Alberto, L. F. C., London, J. B. A., J. and Bretas, N. G. (2005). Smooth perturbation on a classical energy function for lossy power system stability analysis, IEEE J CASI RP 52(1): 222-229. 